University of San Diego

Digital USD

2016-1

\title{
Clones in the MBA Classroom: Understanding the Relationship Between Culture and MBA Students' Attitudes Toward Socially Responsible Business Leadership: A Mixed Methods Cross- National Study
}

Juan F. Roche

University of San Diego

Follow this and additional works at: https://digital.sandiego.edu/dissertations

Part of the Business Commons, and the Social and Cultural Anthropology Commons

\section{Digital USD Citation}

Roche, Juan F., "Clones in the MBA Classroom: Understanding the Relationship Between Culture and MBA Students' Attitudes Toward Socially Responsible Business Leadership: A Mixed Methods Cross-National Study" (2016). Dissertations. 23.

https://digital.sandiego.edu/dissertations/23

This Dissertation: Open Access is brought to you for free and open access by the Theses and Dissertations at Digital USD. It has been accepted for inclusion in Dissertations by an authorized administrator of Digital USD. For more information, please contact digital@sandiego.edu. 
CLONES IN THE MBA CLASSROOM: UNDERSTANDING THE RELATIONSHIP BETWEEN CULTURE AND MBA STUDENTS' ATTITUDES TOWARD SOCIALLY RESPONSIBLE BUSINESS LEADERSHIP: A MIXED METHODS CROSSNATIONAL STUDY

by

\author{
Juan F. Roche \\ A dissertation submitted in partial fulfillment \\ of the requirement for the degree of \\ Doctor of Philosophy
}

January 2016

Dissertation Committee

Afsaneh Nahavandi, Ph.D., Chair

Noriyuki Inoue, Ph.D., Member

Lea Hubbard Ph.D., Member

University of San Diego 
(C) Copyright by Juan F. Roche All Rights Reserved 2016 



\begin{abstract}
Recurrent corporate scandals have underscored the need for business leaders, the majority of whom were trained in business schools, to address tradeoffs between the interests of investors and those who serve the common good as an expression of socially responsible business leadership (SRBL). This study offers an integrated corporate social responsibility model (ICSRM), which displays the factors that scholarly research suggests promote and hinder corporate social responsibility (CSR) practice. However, because the CSR concept originated in the United States and the American business school model is replicated across the globe, most theories that support this conceptual framework were developed through that lens. This study addresses this weakness by exploring the impact of other cultural contexts on CSR thought and practice.

Specifically, the purpose of this exploratory mixed methods cross-national study is to examine the impact of culture on the motives and views of Master of Business Administration (MBA) students from three distinctive cultural clusters regarding the factors that support CSR. The findings, gleaned from 290 surveys and three focus groups, indicate that these MBA students have almost identical motives toward CSR, which are expressed in their eagerness to manage the tension between profitability and the common good. Additionally, the students demonstrate very similar views regarding the factors that drive CSR's implementation. In short, the study suggests that cultural dimensions do not seem to have a meaningful influence on students' personal attitudes regarding these factors, providing a basis for scholars to better understand and further explore the possible relationship between cultural factors and SRBL.
\end{abstract}




\section{DEDICATION}

To Olga . . . because over 40 years ago a tiny spring burst forth, creating a stream of life filled with precious moments.

And to all MBA students worldwide, who, as future business leaders, face the challenging task of holding the tension between profit making and social responsibility. 


\section{ACKNOWLEDGEMENTS}

The most critical element in completing a PhD program is not the passion and drive that it demands but the support system that provides that little nudge of encouragement, guidance, coaching, insights, and direction to successfully arrive at the finish line. Identifying all the individuals who have sustained and encouraged me in this journey is almost impossible, but I am keenly aware of them all, even if I do not acknowledge them explicitly here: Gracias a todos!

The guidance, feedback, and constant support of my dissertation committee members were fundamental in steering this project from concept to completion. My chair, Dr. Afsanheh Nahavandi, was a true mentor whose insightful questions and big picture perspectives helped me to continually improve all the parts of this study. For her enthusiasm and generosity, I will be forever grateful and count her as a lifelong friend.

Committee members, Dr. Lea Hubbard and Dr. Noriyuki Inoue, through their diverging yet complementary skillsets and perspectives, provided the nuanced methodological depth to navigate both the statistical and qualitative analyses that gave life and meaning to the results of the study. Their contribution to my learning and to this dissertation has been invaluable. Thank you both for sharing your wisdom and time.

To all the professors and staff at the USD School of Leadership and Educational Sciences whose prodigious minds were a well from which I drew to augment my own knowledge and understanding, thank you all. Dr. Robert Donmoyer, with whom I had the privilege of taking four classes, taught me how to construct a solid argument. Dr. Terri Monroe proved that a moment of reflection could be more effective than hours of action. Dr. George Reed's insights regarding systems thinking attested to the 
complexities of leadership. Dr. Fred Galloway's relentless quest for different approaches toward problem solving expanded my frame of reference. Dr. David Herrera instilled in me the understanding that ethics is the true heart of leadership. Dr. Zachary Green guided me in exploring my true self, and Dr. Lee Williams drove home the significance of asking the right question in any research endeavor.

I am also grateful to all my colleagues in this journey. I learned as much from them as I did from my professors. A special thanks to Dr. Tricia Rhodes for her patience in guiding me through the complexities of a language that is not my own.

Without the invaluable backing and constant encouragement of my family, this journey would have been impossible. No hay palabras para describir lo importante que son cada uno de ustedes para mi! 


\section{TABLE OF CONTENTS}

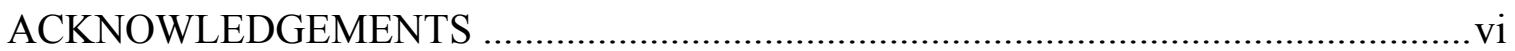

LIST OF TABLES ........................................................................................

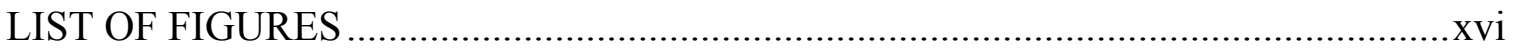

CHAPTER ONE: BACKGROUND AND INTRODUCTION …................................. 1

Statement of the Problem ........................................................................................ 3

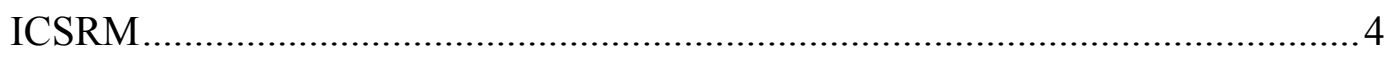

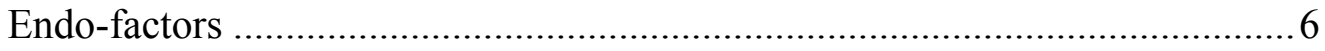

Meso-factors ................................................................................... 7

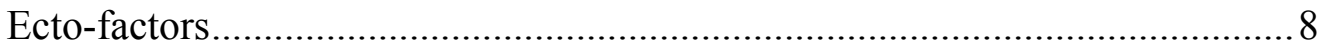

Project GLOBE as a basis to understand cultural influence............................... 8

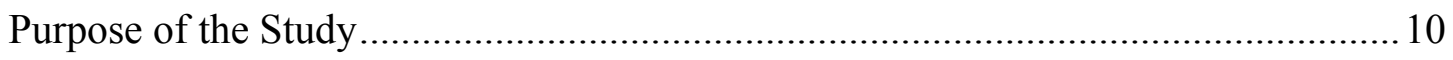

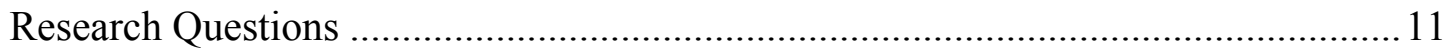

CHAPTER TWO: LITERATURE REVIEW ........................................................... 13

The CSR Concept and History in a Nutshell .................................................... 15

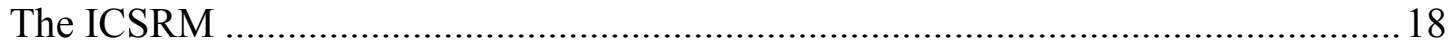

Endo-factor in the evolution of CSR as a definitional construct........................ 19

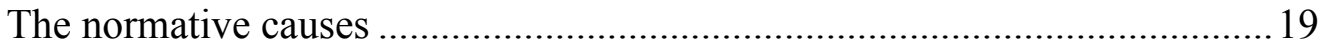

The utilitarian theories ........................................................................ 21

Meso-factors that mediate corporate behavior ............................................2 24

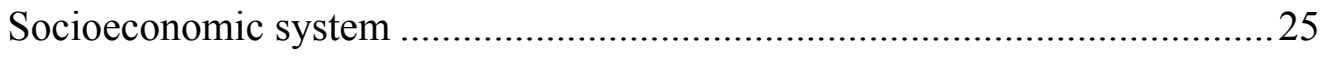

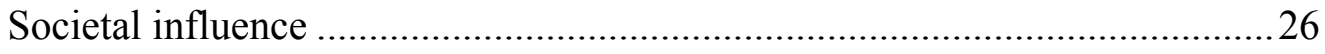

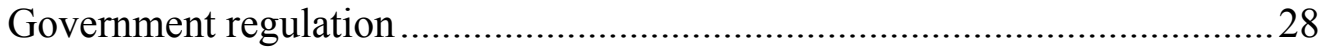


Ecto-factors: The gap in the CSR literature ..................................................... 31

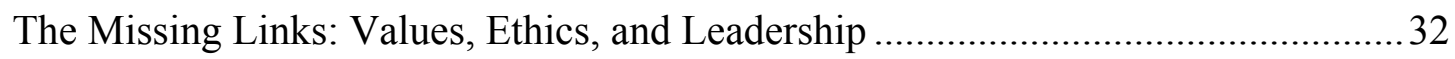

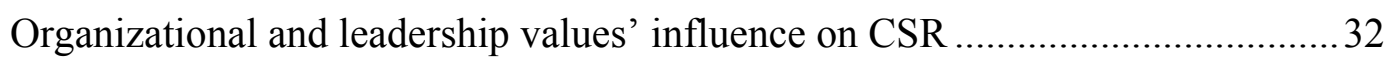

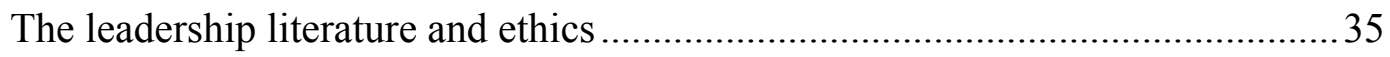

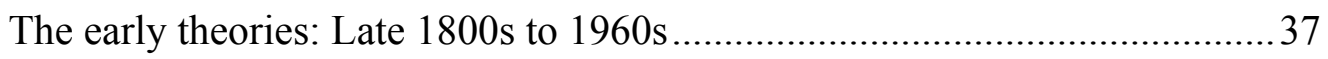

The modern era theories: 1960s to the end of the century............................39

The postmodern theories: 2000 to the present...........................................42

Concept and Dimensions of National Cultures ................................................... 43

History of cultural dimensions .............................................................. 44

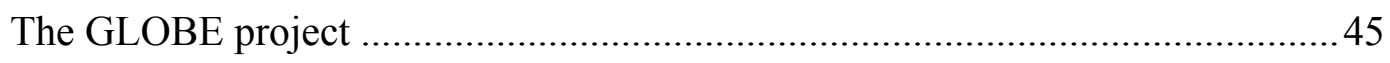

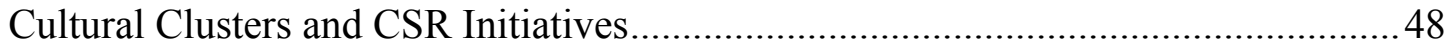

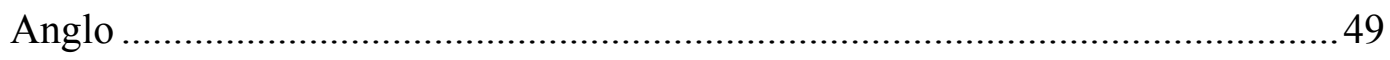

Nordic Europe ...................................................................................... 50

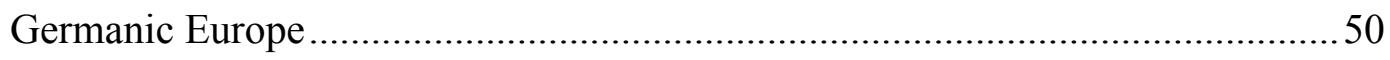

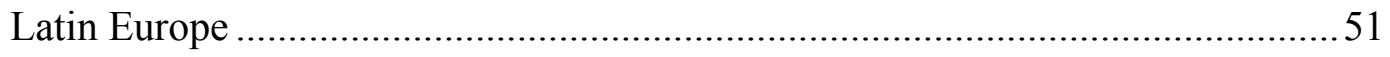

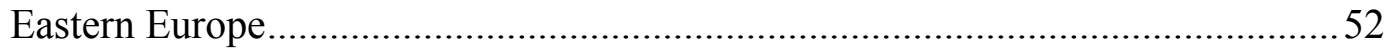

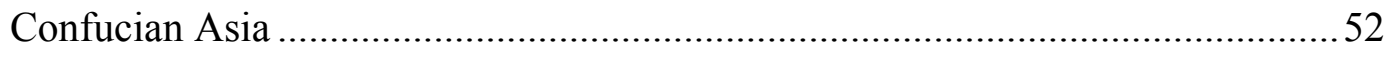

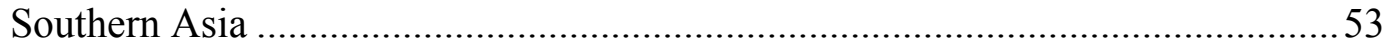

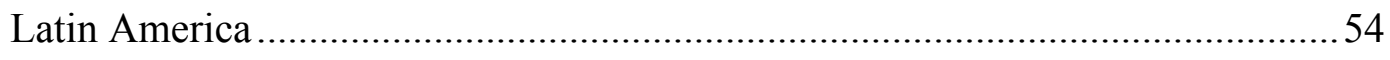

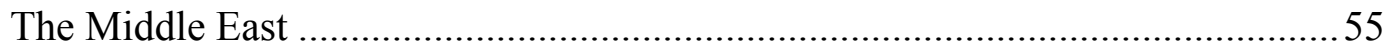

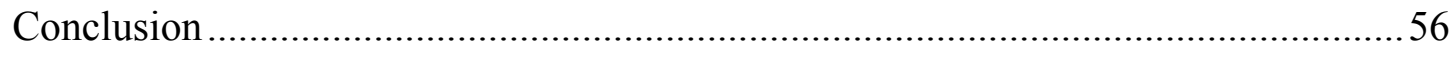

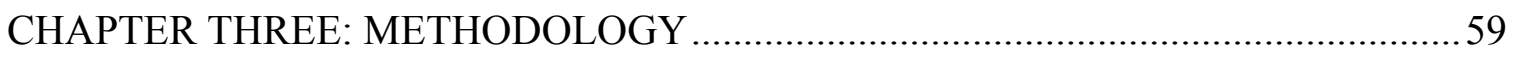

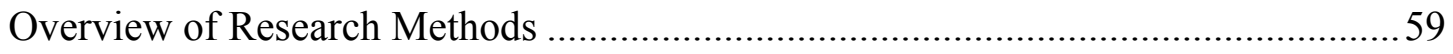


Site and Sample Selection

Site selection

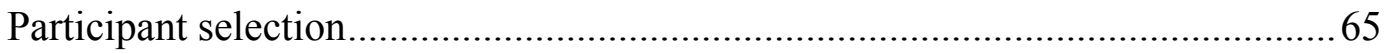

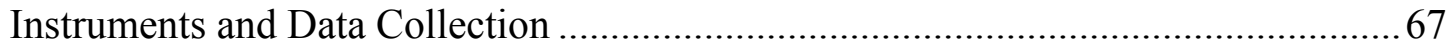

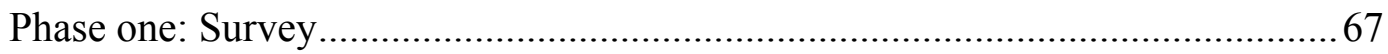

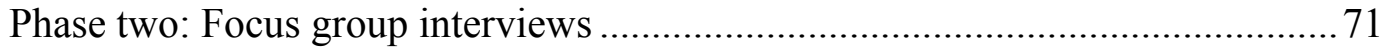

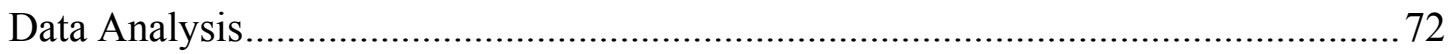

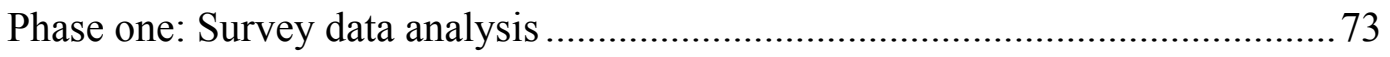

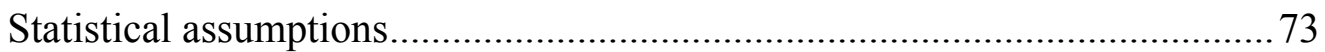

Differences in students' motives and views ............................................. 74

Relatedness between the ICSRM factors .................................................... 75

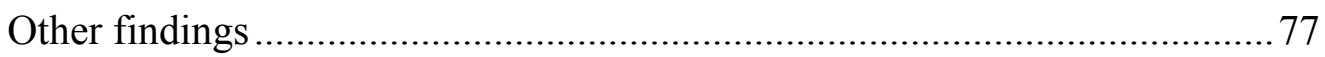

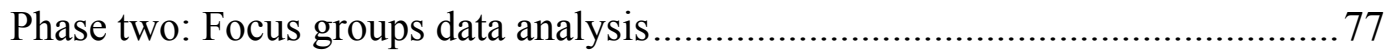

Phase three: Corollaries ........................................................................... 80

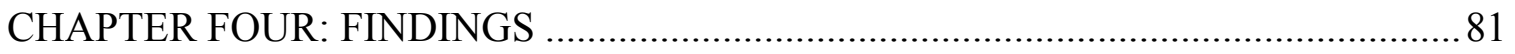

Overview of Purpose and Research Questions................................................... 81

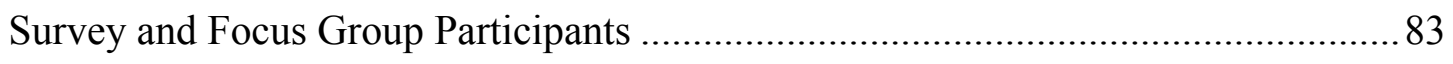

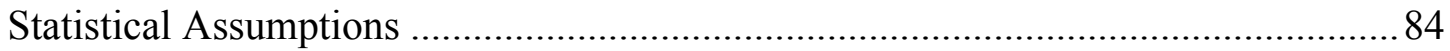

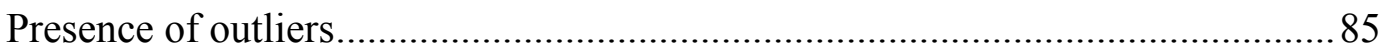

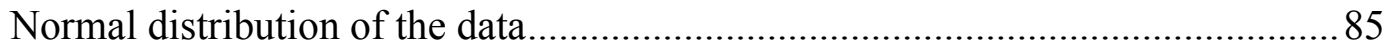

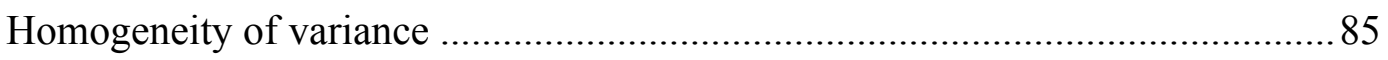

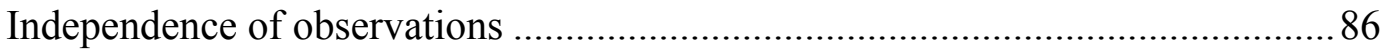

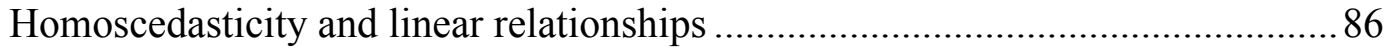




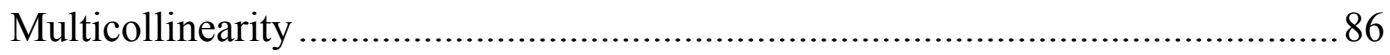

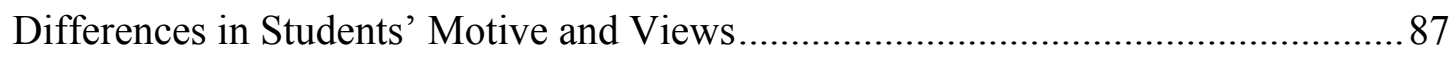

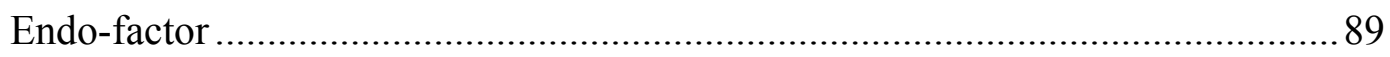

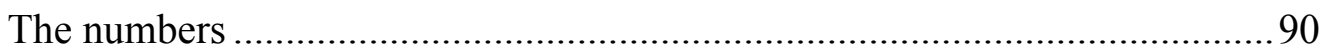

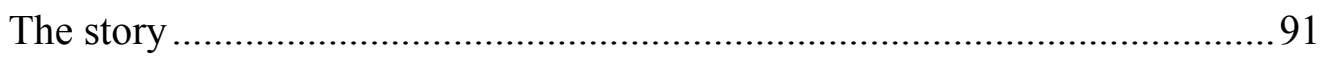

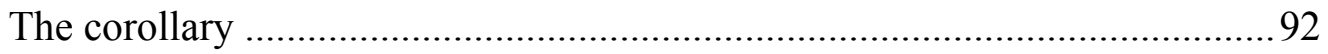

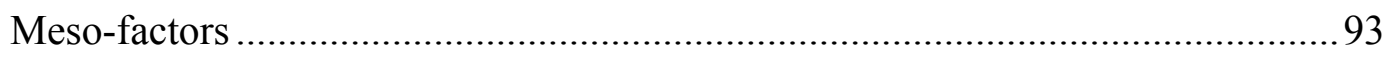

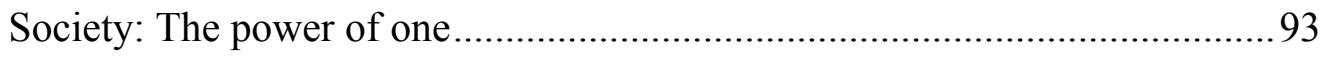

Economy: Free market as possible, government as necessary .........................96

Regulation: A response to past abuses and corruption ...................................100

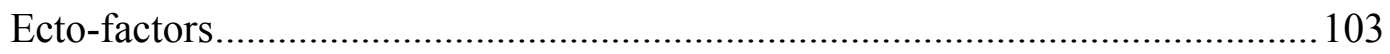

Performance: From analog to digital improvement........................................ 103

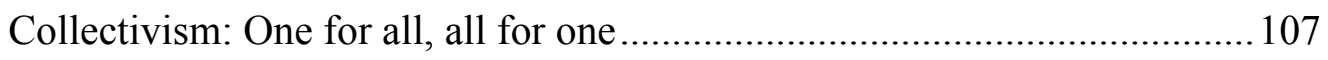

Uncertainty: Planned entrepreneurship ..................................................... 110

Power distance: From centralized control to flat hierarchies ..........................113

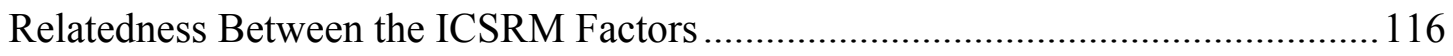

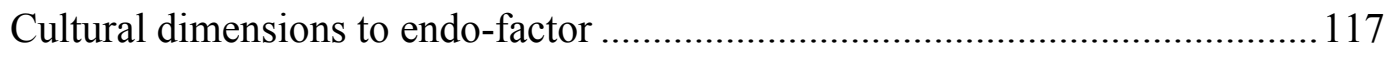

Cultural dimension to meso-factors..................................................................119

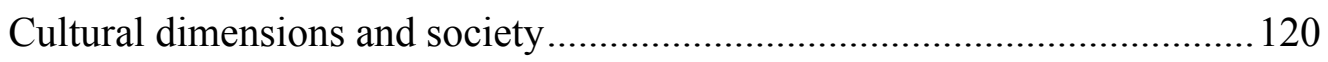

Cultural dimensions and economic model ................................................ 122

Cultural dimensions and government regulation........................................... 124

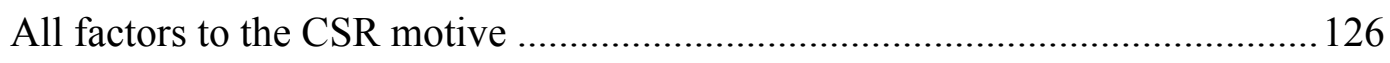

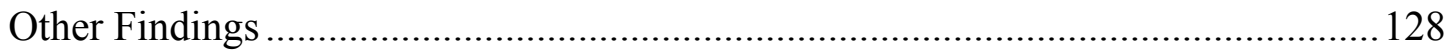


Specialization

Work experience.

Gender

Conclusion: Clones in the MBA Classroom

CHAPTER FIVE: DISCUSSION AND IMPLICATIONS

Summary of Findings: Clones in the MBA Classroom

Research Questions One and Two: Differences in Students' Motives and Views....136

Students' motives regarding the endo-factor CSR

The millennial generation

The culture of the business schools

Internet and globalization

Students' views regarding the meso-factors.

The role of society 144

Socioeconomic model

Government regulation

Students' views regarding the ecto-factors

Performance orientation

Collectivism 150

Uncertainty avoidance

Power distance

Research Questions Three and Four: Relatedness Between the ICSRM Factors......155

Cultural dimensions to endo-factor 156

Cultural dimension to meso-factors. 
Cultural dimensions and society.

Cultural dimensions and economic model ............................................ 157

Cultural dimensions and government regulation...................................... 158

All factors to the CSR motive ................................................................. 159

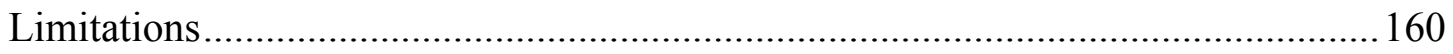

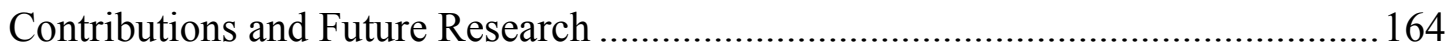

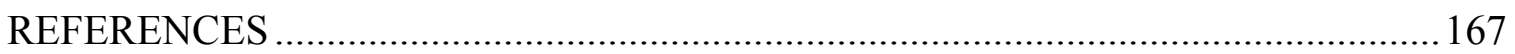

\section{APPENDICES}

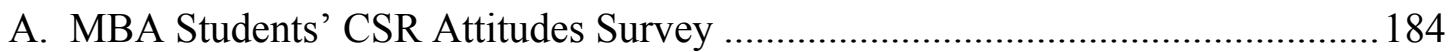

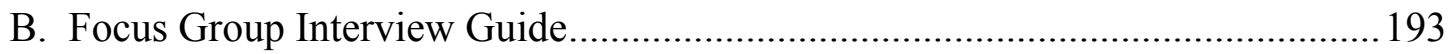

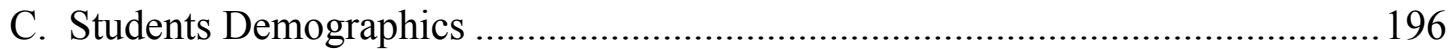




\section{LIST OF TABLES}

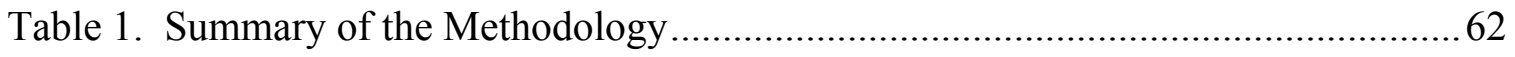

Table 2. Number of Responses by School and Cultural Cluster .................................. 65

Table 3. Sample of Survey Items for Each of the Factors Under Study ........................ 71

Table 4. Number of Responses by School and Cultural Cluster ................................... 84

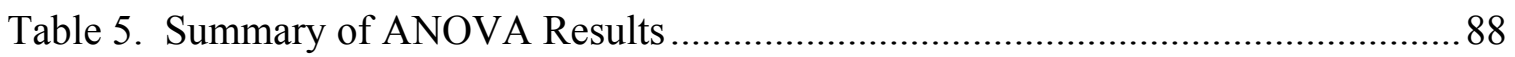

Table 6. ANOVA Results for Motive Regarding CSR ..............................................91

Table 7. ANOVA Results for Views Regarding Society ......................................... 94

Table 8. ANOVA Results for Views Regarding the Economic Model..........................98

Table 9. ANOVA Results for Views Regarding Government Regulation..................... 101

Table 10. ANOVA Result for Views Regarding Performance Orientation ................... 105

Table 11. ANOVA Results for Views Regarding Collectivism Versus Individualism .108

Table 12. ANOVA Results for Views Regarding Uncertainty Avoidance .................... 111

Table 13. Power Distance ANOVA Results........................................................... 114

Table 14. Regression Model of Cultural Dimensions to CSR Attitudes ....................... 118

Table 15. Regression Model of Cultural Dimensions to Civil Society Attitudes .......... 121

Table 16. Regression Model of Cultural Dimensions to Economic System ................. 123

Table 17. Regression Model of Cultural Dimensions to Government Regulation......... 125

Table 18. Hierarchical Regression Model of Meso- and Ecto-Factors to CSR.............. 127

Table 19. ANOVA Results Regarding CSR Motive by Specialization ........................ 129

Table 20. Cultural Cluster and Performance Orientation .......................................... 149

Table 21. Cultural Cluster and Collectivism .......................................................... 151

Table 22. Cultural Cluster and Uncertainty Avoidance .......................................... 152 
Table 23. Cultural Cluster and Power Distance

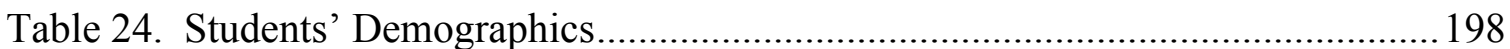




\section{LIST OF FIGURES}

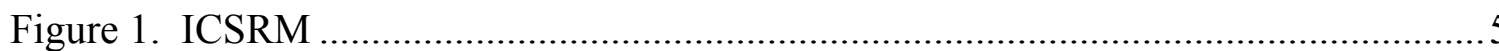

Figure 2. Major cultural clusters in the world. Data from GLOBE project

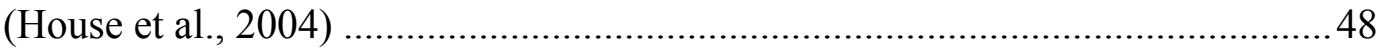

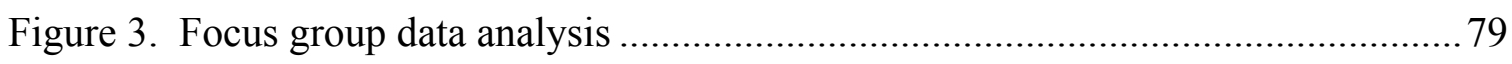

Figure 4. Means results for motive regarding CSR. Scale from 1 to 7 . One represents a normative motive regarding CSR, whereas 7 represents a more utilitarian one 90

Figure 5. Mean results for views regarding role of society. Scale from 1 to 7 . The higher the score, the more the students' belief in the importance of civil organizations as business regulators

Figure 6. Mean results regarding the economic model. Scale from 1 to 7 . The higher the score, the more the students' belief in the importance of free markets for economic and CSR development

Figure 7. Mean results for views regarding regulation. Scale from 1 to 7 . The lower the score, the more the students' belief in the importance of government regulation for CSR development

Figure 8. Mean results for views regarding performance. Scale from 1 to 7 . The higher the score, the more the student values competiveness over harmony and societal relationships 104

Figure 9. Mean results for views regarding collectivism. Scale from 1 to 7 . The higher the score, the more the student values collectivism over individualism .. 107 
Figure 10. Mean results for views regarding uncertainty. Scale from 1 to 7. The higher the score, the more the student displays an uncertainty avoidance preference

Figure 11. Mean results for views regarding power distance. Scale from 1 to 7.

The higher the score, the more the student displays a power distance attitude

Figure 12. Mean results for motive regarding CSR. Scale from 1 to 7 . One represents a normative motive regarding CSR, whereas 7 represents a more utilitarian one.

Figure 13. Mean scores for motive regarding CSR. Scale from 1 to 7 . One represents a normative motive regarding CSR, whereas 7 represents a more utilitarian one

Figure 14. Mean scores regarding CSR and gender. Scale from 1 to 7 . One represents a normative motive regarding CSR, whereas 7 represents a more utilitarian one. 130

Figure 15. Mean scores for all ICSRM factors. For detailed results, see Table 5 


\section{CHAPTER ONE}

\section{BACKGROUND AND INTRODUCTION}

In 1926, at the opening ceremony for Stanford University's new business school, Wallace B. Donham, Dean of the Harvard Business School and keynote speaker, said the following:

The development, strengthening and multiplication of socially minded businessmen is the central problem of business. Moreover, it is one of the great problems of civilization. Our objective, therefore, should be the multiplication of men [sic] who will handle their current business problems in socially constructive ways. (Khurana, 2010, p. 27)

This statement echoes the ethos of industrialist Joseph Wharton-a devout

Quaker with a robust sense of social responsibility—who contributed substantially to the founding of the first collegiate business school in the world at the University of Pennsylvania in 1881. Social responsibility was also the guiding principle of the other 15 business schools that were in existence in the United States by the beginning of the 20th century (Khurana, 2010). Yet, despite this commitment to promoting socially responsible business practices that guided business education in the United States in the early years of Master of Business Administration (MBA) programs and continues to be cited as a primary goal today, reports of executive misconduct and corporate corruption implicating business leaders, many with renowned business education pedigrees, fill the news constantly. This has created a public outcry for the sort of responsible business leadership that those who founded business schools in the 19th century normatively endorsed (Swanson \& Fisher, 2008).

Given that most professional managers and business leaders responsible for running modern organizations have been trained in business schools, it is not surprising 
that many people look to today's business schools to remedy the situation. Indeed, according to the Graduate Management Council, in 2012, there were more than 5,000 MBA programs worldwide, from which 250,000 future business leaders graduated. Clearly, business education has come a long way from the initial 62 graduates of the Wharton business school 130 years ago. Furthermore, American MBA programs are now being replicated across the world. ${ }^{1}$ Many international programs, in fact, are now ranked higher and have more applicants than MBA programs in the United States (Datar, Garvin, \& Cullen, 2010).

Because of the obvious positive consequences of ethical and moral behavior for society, a number of scholars and practitioners have contended not only that business leaders should behave ethically but also that businesses and business education ought to play an important role in social betterment initiatives. In short, business and business education could very well be the engines of innovation and entrepreneurship needed to solve pressing social issues (Aqueveque \& Encina, 2010; Austin, 2000; Barnea \& Rubin, 2010; Márquez, Reficco, \& Berger, 2010; Morsing \& Sauquet, 2011).

With the above objective in mind, other scholars have joined a growing call to revisit business school curricula with an eye toward transforming the values and beliefs that characterize the current social apathy of many business schools. In addition, there is a push to address what they believe is an excessive emphasis on short-term profitability versus the kinds of wealth creation that will ultimately benefit all members of society (Amann, 2011; Datar et al., 2010; Khurana, 2010; Morsing \& Sauquet, 2011; Swanson \& Fisher, 2008).

\footnotetext{
${ }^{1}$ Replication is virtually guaranteed by the use of the same accreditation agencies internationally that are used in the United States.
} 
The apparent contradiction between the social problem-solving and improvement goals that guided the original business schools and the current myopic focus on profits as the ultimate bottom line creates an interesting paradox. While business today may seem to lack a soul, people expect and even demand that it address social issues, largely because of its reputation and ingenuity in decision making and problem solving (Austin, 2000; Márquez et al., 2010).

In response to this demand, over the last 40 years, the concept of corporate social responsibility (CSR) - a notion that emphasizes socially conscious business leadershiphas gained increased attention from both business scholars and corporate executives. Furthermore, the CSR concept has been endorsed, not only in the United States where this movement originated, but also across the world, as globalization has accelerated. Thus, interest in CSR has become a prominent part of any international discussion regarding business ethical dilemmas and conduct. Given the often unique and distinctive cultural and ethical perspectives throughout the world, these discussions have made the relationship between business and society considerably more complex and multifaceted (Alas, 2006; Asslander, 2014; das Neves, 2013; Sanchez-Runde, Nardon, \& Steers, 2013; Waldman \& Konrad, 2006).

\section{Statement of the Problem}

Despite both extensive scholarly research and an abundance of other literature regarding the factors that hinder or promote CSR, there has been little inquiry into how national cultural values relate to the understanding and practice of CSR as an expression of socially responsible business leadership (SRBL). Even less is known about the relationship between cultural factors on the one hand and business schools' stances and 
curricula regarding CSR on the other. We also know virtually nothing about the relationship between the cultural environment in which business students grew up and their motivations toward and attitudes regarding factors that influence SRBL.

Recently, however, some scholars have begun to underscore the potential importance of the cultural context in thinking about and practicing CSR. For example, Velasquez (2014) warned that since values are the standards that people, individually and collectively, use to make judgments as to what is right and what is wrong, CSR thinking could vary across countries that have different societal belief structures. He added that what might be normal and lawful in one country might be illegal in another and what is considered customary business practice in one society might be considered unethical in another.

To date, however, those who have begun to suggest that there is a connection between culture and perspectives regarding CSR have not explored this empirically. An adequate foundation for such an exploration would require a fuller grasp of the literature as it relates to the CSR construct. To that end, I have sought to summarize and integrate nearly 50 years of relevant research into what I call an integrated corporate social responsibility model (ICSRM). This model is briefly discussed in the section that follows.

ICSRM. The ICSRM is displayed graphically in Figure 1. Since CSR is part of the managerial tasks of business leaders, the model assumes that CSR practice is an expression of SRBL. Therefore, in the discussion below, I will use the two terms interchangeably. 


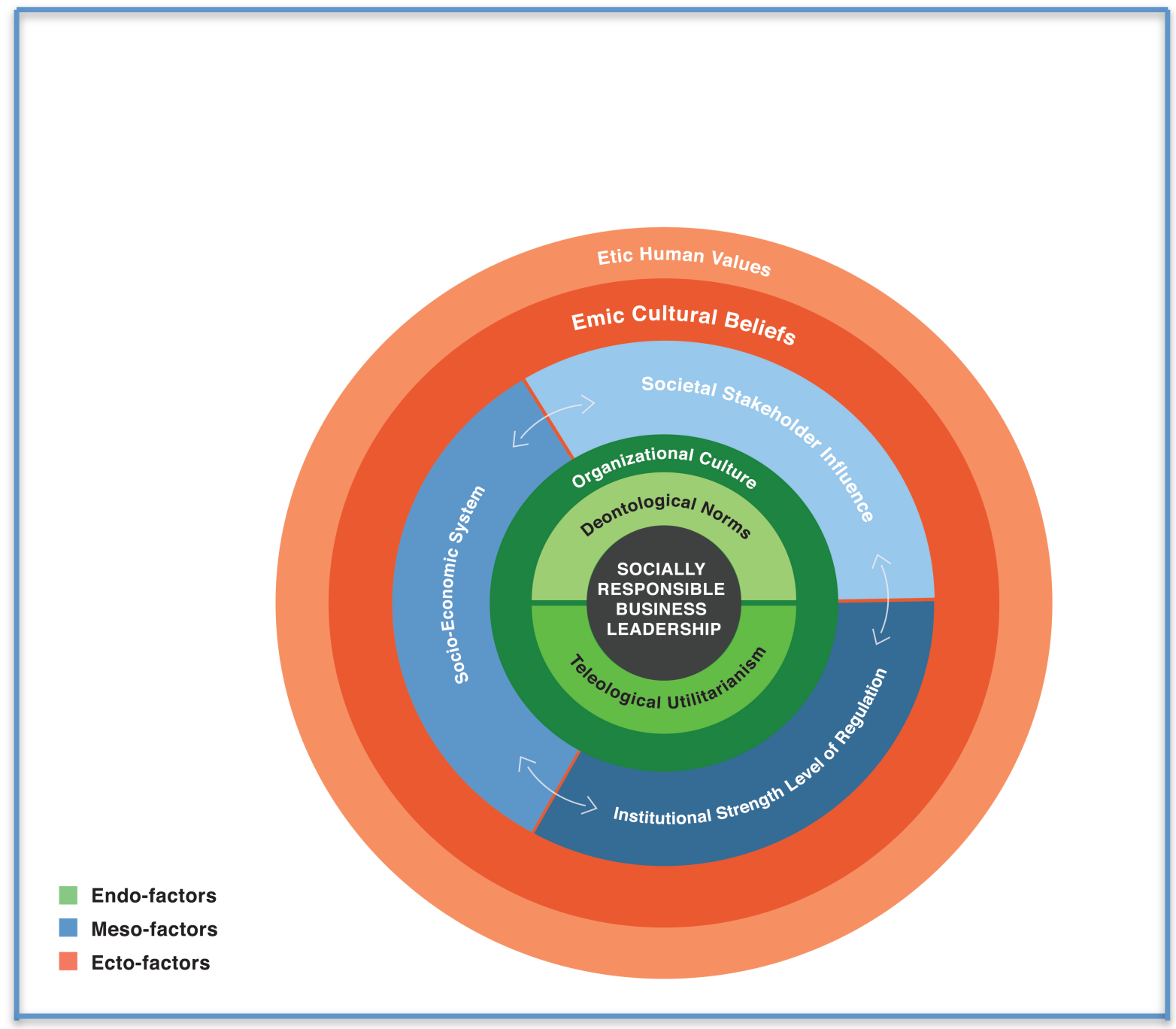

Figure 1. ICSRM.

As the graphic display of the model suggests, there are different levels and multiple factors that influence SRBL practice. Each level is comprised of variables that scholars have identified as having an influence on whether CSR practices are implemented. These variables fit into the following levels: ${ }^{2}$

- Endo-factors (represented in the inner-green circles): Variables related to the internal working of the organization.

\footnotetext{
${ }^{2}$ Endo, meso, and ecto are prefixes of Greek origin meaning within, middle, and outer,
} respectively. 
- Meso-factors (represented in the middle-blue circles): Variables related to the external environment in which the organization operates.

- Ecto-factors (represented in the external-orange circles): Variables related to cultural values of those within the organization.

A detailed discussion of each of these types of factors can be found in the next chapter. A brief overview of each will be presented here.

Endo-factors. Endo-factors are elements within an organization that influence individual, as well as group, attitudes regarding the practice of CSR and SRBL. The literature, in fact, suggests that organizations' approaches to, as well as their members' motives, views, and practices regarding CSR, can be influenced by both deontological norms (Bowen, 1953; Carroll, Lipartito, Post, Werhane, \& Goodpaster, 2012) and a teleological calculus of utility (Drucker, 1998; Porter, 1987; Prahalad, 2010). The term deontological norms refers to moral and ethical codes embraced by an organization and/or those individuals who work within it. The term teleological calculus of utility references perceptions about the economic return of socially responsible investments.

An example of an action influenced by a deontological norm is the decision of a business leader to donate money to educational programs in the community where the business operates simply because the business leader feels it is the right thing to do. An example of an action inspired by a teleological calculus of utility is a business leader's decision to make such a contribution because he or she believes it might, in the long run, lead to better educated and, therefore, wealthier future consumers of the company products. 
Meso-factors. Both normative values and a teleological calculus of utility can be influenced by such things as the socioeconomic system in which the firm operates (Fukukawa, 2010; Matten \& Moon, 2008; Richter, 2010), the institutional strength and level of government regulation (Kostova, Roth, \& Dacin, 2008; Schwartz \& Carroll, 2003), and the societal pressure and stakeholders' influence on the organization (Donaldson \& Dunfee, 1999; Mitchell, Agle, \& Wood, 1997; Morsing \& Langer, 2007). The model characterizes these sorts of variables as meso-factors.

A specific example of a meso-factor related to the socioeconomic system can be seen in highly socialistic economies where the government is the primary provider of social betterment initiatives. Because of the government's role, businesses are more restricted regarding CSR, in that they lack the economic freedom or the market economy or even the perceived need to address social challenges that might otherwise motivate them to be proactive in efforts to improve society.

Environmental laws are examples of factors that can be characterized in terms of level of regulation and the country's institutional strength. If there is little environmental regulation or there are weak institutions to enforce whatever regulations exist, businesses might not even be aware of the environmental consequences of their actions, and, even if they are, they are likely to forgo costly investments in environmental protection infrastructure. Finally, an example of a factor that can be characterized as societal pressure is lobbying by either citizen groups or organized interest groups to reformulate a company's processed food product to omit trans fats. 
Ecto-factors. The model characterizes two levels of cultural tenets that influence the perception and practice of CSR, which I will call emic and etic values. ${ }^{3}$ The former are variables such as cultural beliefs and interpretations that are shared by most people in the nation in which a firm or organization operates, while the latter are values shared cross culturally (Lawrence \& Beamish, 2013; Michalos \& Poff, 2013). Both kinds of values have the potential to influence the perception and practice of CSR and SRBL. However, since the etic values tend to be consistent across most societies, only the emic ones were part of this study.

While endo-factors and meso-factors have been extensively researched, there has been little inquiry regarding how variables in the level labeled ecto-factors relate to those at the other two levels and, ultimately, the attitudes of business leaders toward socially responsible leadership, in general, and CSR, in particular. One of the reasons for this lack of research is that CSR has been, until recently, a Western phenomenon. As businesses globalize, however, the cultural context in which they operate becomes more important. The construct of culture and, consequently, the notion of cultural context are complex and often contested. For this reason, what follows is a description of those cultural aspects, based on the Global Leadership and Organizational Behavior Effectiveness (GLOBE) project, which underlie this issue and are thus relevant to this study.

Project GLOBE as a basis to understand cultural influence. Culture can be defined and understood in a myriad of ways. Anthropologist Clifford Geertz (1973), for

\footnotetext{
${ }^{3}$ The terms emic and etic have been borrowed from anthropology. Their meaning has been altered a bit in the process of transferring them from discussions of ethnographic research to discussions of the model.
} 
example, defined culture as "a system of inherited conceptions expressed in symbolic forms by means of which men communicate, perpetuate, and develop their knowledge about and attitudes toward life" (p. 12). From a managerial perspective, Nahavandi (2012) proposed a more colloquial, but practical, way of understanding the concept of culture, describing it as "the set of norms, customs, values, and assumptions that guide the behavior of a particular group of people" (p. 30). In either case, the common theme in the concept of culture is shared meaning as the primary aspect that drives communal life among members of a collective.

These shared meanings, related to motives, values, beliefs, and identities, are what create cultural dimensions that can be clustered as salient characteristics of a group. Several scholars and researchers have attempted to define these parameters and have provided unique contributions to the field. For example, the project GLOBE (House, Javidan, Hanges, \& Dorfman, 2002) one of the most comprehensive analyses of national cultures, provides 10 cultural clusters based on nine core cultural dimensions. Project GLOBE was primarily based on Hofstede, Hofstede, and Minkov's (2010) initial four taxonomies: small versus large power distance, collectivism versus individualism, femininity versus masculinity, and weak versus strong uncertainty avoidance. Project GLOBE expanded these dimensions to include assertiveness, future orientation, performance orientation, humane orientation, and institutional collectivism. While it makes sense that these types of cultural dimensions influence the perceptions and practices of CSR in different ways depending upon the country, there is a dearth of research regarding this potential relationship. 
To be sure, the very idea of a national culture and national cultural dimensions are contested constructs because both concepts refer to an aggregate of the values and beliefs of multiple subgroups within a national context. However, as a starting point, understanding the influence, if any, that cultural dimensions such as those identified in project GLOBE have on the variables that support and hinder CSR practices would contribute to the body of knowledge regarding SRBL and its peculiarities in different parts of the world.

\section{Purpose of the Study}

The purpose of this exploratory study was to take a first step in generating comprehensive empirical data regarding the relationship between various cultural values and the factors that influence CSR perceptions and practices. Specifically, it studied the motives and views of MBA students from different countries, each with distinctive cultural dimensions (as articulated in Project GLOBE) regarding the different factors that appear to affect the promotion of CSR and SRBL, as depicted in the ICSRM presented in Figure 1.

This two-phase explanatory sequential mixed methods project generated quantitative survey results from samples of students in three business schools located in different parts of the world that have distinctive cultural dimensions. In order to further understand the survey results, the study followed up with three focus group interviews of selected students from each school.

Hopefully, this admittedly modest first effort to study the as yet unexplored relationship between culture and CSR perspectives and practices opened a new avenue of 
inquiry. Ideally, much more research will follow, especially as the business world, including business schools, globalize even further.

\section{Research Questions}

The following overarching research questions served as a guide for the study:

1. How do business students from three different cultural clusters differ, if at all, in their motives toward and views regarding the factors that support CSR, according to the ICSRM?

a. In what ways, if any, do students' motives toward CSR, as defined by the endo-factor (normative and utilitarian), differ?

b. In what ways, if any, do students' views regarding the meso-factors (societal, economic, and regulatory) differ?

c. To what degree, if at all, do students' cultural dimensions, referred to as ecto-factors (collectivism, power distance, performance orientation, and uncertainty avoidance), differ?

2. How do individuals from each of the three cultural clusters make meaning of the factors that support CSR, according to the ICSRM?

3. To what degree, if at all, do cultural dimensions relate to business students' motives toward and views regarding the factors that support CSR, according to the ICSRM?

a. To what degree, if at all, do cultural dimensions relate to business students' motives toward CSR, as defined by the endo-factor (normative and utilitarian)? 
b. To what degree, if at all, do cultural dimensions relate to business students' views regarding the meso-factors (societal, economic, and political)?

4. How do individuals from each of the three cultural clusters make meaning of the relationship between the cultural dimensions and the factors that support CSR, according to the ICSRM?

In summary, the overall purpose of this study was twofold. First, it was to compare the motives toward and views regarding the factors that support CSR of three groups of MBA students belonging to distinctive cultural clusters. Second, it was to determine to what degree cultural dimensions relate to those factors. The next chapter further explores the literature that guided this study. 


\section{CHAPTER TWO}

\section{LITERATURE REVIEW}

Using the term apocalypse to describe the economic efficiency and profitability model into which future business leaders are socialized, management scholars Akrivou and Bradbury-Huang (2015) posit the following provocative query:

In addition to generating great wealth and technical advances for some, [the model] has also threatened well being at the individual, natural system and community levels. We therefore ask how our education of future managers and leaders is contributing to unsustainable communities. (p. 222)

The apprehension expressed in this quote is not new. Many other business scholars have expressed similar concerns and are calling for a profound revision of the paradigm of efficiency and profitability that has been the main focus of business education, deemphasizing the community and societal perspectives (Crossan, Seijts, Gandzs, \& Mazutis, 2013; Datar et al., 2010; Giacalone \& Thompson, 2006; Khurana, 2010; Mintzberg, 2004; Morsing \& Sauquet, 2011; R. A. Peterson \& Ferrell, 2005;

Quinn, 1988; Swanson \& Fisher, 2008). Although these scholars address this issue from several perspectives and propose a variety of solutions, they all agree that an increased emphasis on CSR is needed to assure that future business leaders conceptualize their raison d'etre beyond the profit and efficiency parameters toward a more holistic view of serving society.

Progressive and world renowned educator Paulo Freire (2000) postulates that the problems in education are more political and ideological than they are pedagogical or technical. Therefore, a social-oriented perspective in business education is not going to be solved just by teaching ethics or CSR in the classroom. What seems to be needed is a deeper, more paradigmatic shift such as the one that Thomas Kuhn (1970) describes in 
his book The Structure of Scientific Revolutions, which involves replacing the fundamentals of the field with other tenets that provide a completely new worldview. Not all would necessarily agree. Some might contend that what is really needed is a return to the fundamental philosophical, social, and political tenets of the enlightenment, which contributed to ushering in the Industrial Revolution that began in England in the 18th century (Ashton, 1948).

For example, Adam Smith (1776/1976), who is considered the father of free market economics and the individualistic and self-interested concepts that were brilliantly drafted in his famous opus, The Wealth of Nations, was, paradoxically, a staunch believer in CSR. Smith argued that businesses' ethical conduct was imperative for the capitalist system to benefit society as a whole because of the excessive power that the burgeoning trading companies might accumulate. In fact, in Smith's (1759/1976) lesser known but equally important book, The Theory of Moral Sentiments, he argued that without the strong ethical and moral conduct of what he called the prudent businessman, the then emerging trading companies might create risks and costs that would be borne by the society at large, as we have unfortunately seen with the financial crisis and corporate scandals of 2010. Carroll (2000), one of the leading scholars in the CSR field, points out that "for Smith, the true wealth of nations could only be realized if its citizens cultivated their moral sentiment as a foundation for their commercial enterprises" (p. 91).

Whether a Kuhn-like paradigm shift is needed or simply a return to fundamentals once touted as central to a free market economy, one thing seems clear: for business leaders to adopt a more socially responsible view depends in part on their personal ideologies and values. Adding to this, Velasquez (2014) posits that since values are the 
standards that people, individually or collectively, use to make judgments as to what is right and what is wrong, they could vary among countries, depending on that society's cultural beliefs. Velasquez's claim is supported by scholars who have explored the cultural and leadership predictors of CSR in top management (Waldman \& Konrad, 2006), and others who have analyzed the effect of cultural differences in CSR discourse (Romero \& Fernandez-Feijoo, 2013), and still others who have studied ethical leadership in cross-cultural settings (Alas, 2006; Eisenbeiß \& Brodbeck, 2014).

The purpose of this chapter is to explore the evolution of the concept of CSR by synthesizing the extant literature in the field, particularly as it relates to SRBL in a multicultural world context. To this end, the first section of this chapter addresses the evolution of the CSR concept from a historical perspective. The second section delves deeper into the ICSRM introduced in Chapter One, which incorporates the various theories that explain support for the practice of CSR into one comprehensive scheme. The third section reviews leadership theory and its link to ethics in order to show the foundational arguments for the support of SRBL. The fourth section explores the concept of culture and cultural clusters in order to demonstrate their influence on CSR initiatives. This literature review provides a theoretical base with which to illuminate the understanding of the findings and discussion presented later in this dissertation.

\section{The CSR Concept and History in a Nutshell}

Since Bowen (1953) first suggested the term more than 60 years ago in his seminal book, Social Responsibilities of the Businessman, there has been not only a host of different CSR definitions (Carroll [2000] has identified more than 25 ways the concept is described in academia) but also the coinage of new vocabularies with similar meanings 
such as corporate citizenship (CC), responsible leadership (RL), social entrepreneurship (SE), and business ethics (BE), among others (Matten \& Moon, 2008). Since then, much has been written, debated, and contested regarding not only CSR's meaning and development but also its applicability, scope, and importance (Blasco, 2010; Kemper \& Martin, 2010). For this reason, and for the purposes of this dissertation, the concept of CSR incorporates all of these terms.

Ten years after the publication of Bowen's (1953) seminal work, Nobel laureate Milton Friedman (1970) published his well-known and controversial article in The New York Times, which suggested that the only responsibility of business was to make as much money as possible for its stockholders. The theoretical discussion that ensued has reframed societal expectations of businesses with the acknowledgement that corporations have responsibilities that go beyond the economic dictum of wealth maximization. Indeed, today, most scholars and practitioners alike assume that the corporation's responsibility to society should be a fundamental feature of any business plan. This claim is supported by the number of companies that devote a large part of their annual report to CSR activities, the increase of CSR inventories found on web pages, the surge in business-nongovernment organization (NGO) partnerships to develop social betterment initiatives, and the popularity of mutual funds that invest in socially responsible businesses (Aqueveque \& Encina, 2010; Austin, 2000; Barnea \& Rubin, 2010; Godfrey, Hatch, \& Hansen, 2010; Kemper \& Martin, 2010; Scherer, 2008).

As a consequence of the dynamic described above, establishing the definition of CSR or its related terms is not just a technical or scholarly exercise; it is also, as was indicated earlier, dependent upon the normative and ideological views of the actors 
involved (Gjølberg, 2010). For example, the cultural norms and existing political and economic institutions in Europe, which call for more government intervention, versus the more neoliberal ${ }^{4}$ model of the United States, create very different interpretations of the term. Moreover, the word social, to which Hayek and Bartley (1989) atribute the quality of weaselness, is famously controversial and ambiguous, having different meanings in the fields of political science, sociology, economy, and anthropology (Dean, 2010).

For the above reasons and because of its simplicity and applicability to any cultural setting, Martin's (2002) description of social betterment initiatives will be used. It suggests that the CSR concept refers to all "the activities that corporations choose to do to serve shareholders' interests while also attending those of the larger community in which the business operates" (p. 203). This definition is based on Freeman and Phillips' (2002) stakeholders' theory, which posits that corporations have responsibilities to all those actors that are, directly or indirectly, affected by the business.

From a historical perspective, most of the literature and theories that were initially developed to justify CSR activities were based on either utilitarian (good business for the firm) or normative (the right thing to do) factors that were internal to the corporations. However, over the last 2 decades, probably prompted by the international financial crisis, the corporate scandals, and the globalization of businesses, several scholars have paid more attention to the external environment, suggesting that the normative and utilitarian factors are contingent upon the political, economic, and social settings in which the organization operates (Basu \& Palazzo, 2008; J. L. Campbell, 2007; Morsing \& Langer, 2007).

\footnotetext{
${ }^{4}$ The term neoliberal is often misused and could have several connotations. For the purposes of this paper, neoliberalism refers to an economic system in which the ethos of competitiveness and individualism is prevalent (Davies, 2014).
} 
To better understand the theoretical literature that supports both the internal and external factors that seem to hinder and promote CSR activities, utilizing Richard Scott's (2001) institutional theory, I developed what I call the ICSRM, which was briefly introduced in Chapter One. What follows is a deeper description of this model.

\section{The ICSRM}

The schematic representation offered in Figure 1 of Chapter One suggests that, according to what most researchers have identified in the CSR literature, multiple factors influence SRBL and these can be ascribed to the following levels: ${ }^{5}$

- Endo-factors (represented in the inner-green circles): Variables related to the internal working of the organization. This level is dependent on both the deontological norms and the teleological calculus of utility internal to the organization, which are, in part, elements of the organization's culture.

- Meso-factors (represented in the middle-blue circles): Variables related to the external environment in which the organization operates. Specifically, these factors comprise the socioeconomic system in which the firm operates, the institutional strength and level of government regulation, and the societal pressure and stakeholders' influence on the organization.

- Ecto-factors (represented in the external-orange circles): Variables related to the cultural values of those within the organization. These include the emic cultural beliefs and values of the nation where the business operates and the etic human values, which are common to all humanity and influence our sense of responsibility to and solidarity with others.

\footnotetext{
${ }^{5}$ Endo, meso, and ecto are prefixes of Greek origin meaning within, middle, and outer, respectively.
} 
Endo-factor in the evolution of CSR as a definitional construct. As the ICSRM depicts, the endo-factor is an internal force that drives CSR, which is rooted in either normative mandates or utilitarian calculus.

The normative causes. The scholars who have supported these theories identify the deontological or moral obligation rationale that seeks to build good will for the organization or simply satisfy the corporate leadership's ethical values as being critical to the long-term interest of the firm (Bowen, 1953; D. T. Campbell \& Stanley, 1966; Carroll et al., 2012; Mitchell et al., 1997). Business leaders who base their decisions on deontological grounds focus on duties, obligations, and universal principles such as honesty, fairness, rights, justice, and respect of property (Bowie, 2013). Other authors highlight that it is important not only to do the right thing but that this be fueled by proper dispositions and motivations for good (Pojman, 2012). For example, the American ethic of giving back to society could easily be traced to the 1886 Carnegie's view regarding the responsibility of the wealthy in reducing inequality (Carnegie \& Nasaw, 2006) and the seminal work of Bowen (1953) regarding the responsibilities of the businessman.

The normative view was widened in the 1980s with Freeman's (1984) Management Theory: A Stakeholders Approach, which widens the normative view and directly challenges Friedman's (1962) agency theory regarding managers' responsibilities. Freeman argues that managers have a fiduciary relationship to all groups - employees, customers, suppliers, and local community — that have a stake in the company or, as previously noted, any group or individual who can affect or is affected by the corporation. This theory is based on the previous work of Mary Parker Follett (1926) and is grounded in concepts of property and distributive justice (Donaldson \& Preston, 
1995) and in libertarian principles of freedom, rights, and consent (Freeman \& Phillips, 2002). Carroll (2000), an enthusiastic supporter of Freeman's perspectives, reinforced the view that corporations are morally and ethically self-motivated to act and contribute to societal needs beyond producing products or services for a profit.

The acceptance of normative social responsibilities of businesses received enthusiastic support from the business community at the World Economic Forum in 1999. In this reputable event, the United Nations presented what is known as the United Nation Global Compact (UNGC) - a proposal that contains nine business principles related to human rights, labor, the environment, and society—which lead to the creation of the certification SA-8000 of social responsibility that many corporations seek to obtain. In fact, since its foundation, the UNGC has witnessed an impressive growth in membership. Today, more than 10,000 participants, mostly multinational companies, form part of this network (Voegtlin \& Pless, 2014). Moreover, it is estimated that the U.S. and European markets have over 2 trillion U.S. dollars and 300 billion Euros in certified socially responsible assets (Kitzmueller \& Shimshack, 2012).

Despite the wide acceptance of normative-based theories, some scholars have pointed out that these initiatives are just window dressing to conceal the greed and avarice of business people. For example, Fleming (2013) has called CSR the "opium of the people," citing various cases in which "the exploitative and colonizing agenda of the corporation is always present" (p. 54). Martelle (2007), recollecting the Ludlow massacre $^{6}$ in 1914, which led to the creation of the well-known and reputable Rockefeller Foundation, argues that John Rockefeller's motivation in this initiative was not based on

\footnotetext{
${ }^{6}$ The Ludlow massacre refers to an attack by security guards on striking workers and their families in a Colorado mine owned and operated by the Rockefeller family in which dozens of people, including 11 children, died.
} 
ethical and moral grounds but rather on the need to dispel bad publicity and strengthen the other family businesses. Bartley and Child (2014) posit similar views regarding the now paradigmatic question of the garment industry sweatshops, particularly the cases of well-known corporations such as GAP, H\&M, and Nike.

From an economic perspective, many businesses and academics in the Western world, as well as internationally, still support Friedman's agency theory and his famous statement that "the only responsibility of business is business" (Friedman \& Ebenstein, 2012, p. 63). For example, Husted and De Jesus Salazar (2006), in their article Taking Friedman Seriously, present a model that argues that it is wiser for a firm to act strategically rather than be constrained by moral considerations that only reduce profits. Bernabou and Tirole (2010) make the case that social responsibility is an individual action, not a corporate one. They agree with Freeman's (1984) stakeholders' notion of corporate responsibility but argue that it is the stakeholders' responsibility, not the managers', unless it is explicitly delegated.

These persistent critiques regarding the normative view of CSR led several scholars to develop CSR theories based not on ethical considerations but on utilitarian ones (Kemper \& Martin, 2010). The next section explores these theories in detail.

The utilitarian theories. The scholars who have supported utilitarian theories have focused on what it means to achieve an economic return through social investments. The core of this argument posits that the allocation of corporate resources for social betterment initiatives should generate benefits to the firm. According to this view, CSR is just a means to the end of generating profits (Drucker, 1998; Freeman, 1984; Porter \& Kramer, 2008; Prahalad, 2010). 
According to Heal (2014), this utilitarian view can take two forms. The first involves taking actions that reduce externalized costs that might lead to internal efficiencies. For example, companies that implement environmental practices also benefit from internal competencies that could reduce supply chain costs (Eichholtz, Kok, \& Quigley, 2010). The second utilitarian approach relies on tapping into markets in which governments and NGOs do not have the capabilities of serving efficiently. An example of this is micro-financing banks that serve poor communities (Maxfield, 2008).

One of the most well-known utilitarian theories that supports the first approach is Porter's (1987) corporate strategy, in which he claims that investing in social activities improves the competitive advantage of a firm because value-creation strategies that link the needs of the community with the capabilities of an organization could have a powerful effect on performance. Many organizations in the Western world have adopted this view as part of their overall business strategy, but not necessarily as a CSR initiative in and of itself. In this case, CSR is defined as any responsible activity that allows a firm to achieve a sustainable competitive advantage, regardless of motive (McWilliams \& Siegel, 2011).

Elkington (2000) introduces a second methodology to the competitive advantage approach with his concept of the triple bottom line - people, profits, and planetrepresenting the social, economic, and environmental dimensions of corporate activities. While this model implies theoretical parity amongst this triad, some scholars have pointed out that, in practice, the financial end has had prominence over the other two, with the social and environmental factors treated as window dressing in many corporations (Banerjee, 2007). 
More recently, Prahalad (2010), in his best-seller, Strategies for the Bottom of the Pyramid, proposes the notion of servicing the poor while making a profit, which illustrates the second approach mentioned above. Prahalad contends that corporations can create wealth while contributing to the eradication of poverty if they see the poor as an opportunity rather than a problem. He argues that with the development of innovative products and services that could serve the needs of deprived markets, the 4 billion people who live below the poverty line in the world could become active consumers. This view was first successfully adopted in India, Prahalad's home country, and has now become popular in the rest of the developing countries (Márquez et al., 2010; Ruffín \& Márquez, 2011).

Although there has been considerable research into the relationship between CSR and profitability, there is still a heated debate among scholars regarding the methodologies used to measure this utilitarian connection. Aupperle, Carroll, and Hatfield (1985), in an empirical study with 241 CEOs of Fortune 500 companies, did not find any relationship between various levels of social orientation and profitability. Nelling and Webb (2009) found little evidence of causality between social initiatives and profitability. On the contrary, they point out that the relationship is, in the best of cases, inverse. That is, companies that are highly profitable may tend to devote more resources to CSR, but CSR is not the source of profitability. Barnett (2007) found that CSR may or may not be profitable depending on the structure and influence that stakeholders have on the firm. Servaes and Tamayo (2013) compare CSR activities with advertising, demonstrating that socially oriented activities are profitable only in situations in which 
there is low consumer awareness or where corporations have a poor reputation as corporate citizens.

This lack of consensus among scholars regarding the likely impact of CSR on profitability and the ambiguous conclusions regarding the reasons companies undertake CSR initiatives have led some scholars to theorize that there must be other motives for businesses to advance social initiatives. For example, Kemper and Martin (2010) suggest that the scope and reach of businesses in social matters are transforming corporations into political actors. This affirms that the behaviors that shape organizations cannot be isolated from the environment because they are sensitive to a multitude of external forces. J. L. Campbell (2005) concurs with this view, pointing out the importance of society, governments, and nonprofits in molding CSR activities. Kemper and Martin's and J. L. Campbell's (2005) seminal work on the influence of these external players resonates with several scholars who have developed further theories that delve deeper into the role of governments, civil society, and nonprofits in influencing the level of businesses' CSR activities (Carson, 2001; Donaldson, 1982; Habermas \& Fultner, 2005; Kostova et al., 2008; Posner, 2009; Richter, 2010; Scherer \& Palazzo, 2007). In the ICSRM developed for this dissertation (see Figure 1), these external influences are labeled the meso-factors. The section that follows describes each one of these in detail.

Meso-factors that mediate corporate behavior. J. L. Campbell (2005) argues that the effort to define responsible behavior is not only a nascent development in the world but that it could have different local meanings depending on external influences and stimuli. What might seem to be responsible in Latin America or Asia might not be in the United States or Europe, and vice versa. Along this line of thought, in his classic 
management book, Institutions and Organizations, Scott (2001) argues that the main driver in corporate behavior is the influence of what he calls the three pillars of institutional life: cognitive, regulatory, and normative. Based on Scott's theory and the extant literature mentioned above regarding these external factors, I further developed the ICSRM to include the following meso-factors: socioeconomic system based on the cognitive pillar, societal influence based on the normative pillar, and government regulation based on the regulatory pillar. Each of these elements has its particular dynamics and ways of influencing businesses, as will now be shown.

Socioeconomic system. Richter (2010) and renowned Massachusetts Institute of Technology (MIT) social scientist Habermas (1989) contend that CSR is possible in countries that are organized democratically and with a free market economic system, which is why, until recently, it has been primarily a Western phenomenon. They reason that the unrestricted market policies and individual political and economic liberties that democratic regimes provide are needed for corporations to prosper and engage in social betterment activities. They support this claim by showing how the CSR concept developed first in the United States and the United Kingdom and then began to spread throughout the world as countries adopted similar governance and economic models.

Austin (2000) and Sanborn and Portocarrero (2005) agree with the above point by showing that, in Latin America, the CSR concept has gained importance as countries move from more authoritarian and centrally controlled economies to more open ones. Matten and Moon (2008) report similar findings in European countries, as do Chapple and Moon (2005) and Fukukawa (2010) in Asia, both of these continents having refocused to more free market economies. 
In brief, the literature seems to indicate that there is a positive relationship between CSR activities and countries that embrace liberal political, economic, and social policies. More recently, however, as ideologies are being replaced by more pragmatic economic policies, a more middle-of-the-road position (the European one, for example) seems to be preferred over the extremes of either complete laissez-faire or centrally planned systems, which Kevin Carson (2001) cleverly called the iron fist behind the invisible hand.

The decrease in ideological fervor has given civil society actors a more defining role in shaping not only the socioeconomic system that a nation chooses to adopt, but also their influence on businesses (Posner, 2009), as will be elaborated next.

Societal influence. In Ties That Bind, Donaldson and Dunfee (1999) apply Hobbes' (1652) concept of social contract to the role of corporations. They argue that the rules of the game that are accepted by all members of society define the proper way that businesses should operate. These rules vary not only in intensity, depending on the societal influence, but also in meaning, depending on the cultural context. As a consequence, the authors argue, members of a community make hypothetical macro contracts with organizations based on hypernorms, ${ }^{7}$ which dictate behavior at the micro level. For example, business environmental initiatives might be greater in societies in which concern for the environment is deeply embedded in the population ethos-as in Europe-versus countries in which other factors, such as development, are more important, such as China.

\footnotetext{
${ }^{7}$ Hypernorms, a term coined by Donaldson and Dunfee (1999), refer to certain fundamental ethical beliefs that a population has, which have the power to dictate the actual norms, laws, and regulations in a given region.
} 
Mitchell et al. (1997) demonstrate that scrutinizing corporate activities by stakeholders and other societal institutions increases the likelihood that corporations will behave in responsible ways. They cite the influences that NGOs such as the World Wildlife Federation, the International Labor Organization, and the World Health Organization have had in establishing codes of conduct and in monitoring corporate behavior. Hamel (2001) concurs with Mitchell's view, providing specific examples of how social movement organizations have been able to modify corporate behavior and labor practices in the apparel industry, or what is known as the sweat shops in Asia. Eesley and Lenox (2006) contend that between one third to one half of businesses targeted by any influential civil society group announce subsequent behavioral changes that are mostly in line with the activists' demands.

Porter and Kramer (2006) show how corporate governance in most developing countries that lack the oversight culture of stock markets in developed countries is greatly improved after institutions engage or societies develop a more monitoring culture. For example, the nonprofit International Corporate Governance Network (ICGN) was created to promote information transparency and disclosure in countries with little stakeholders' oversight. Sanborn and Portocarrero (2005) provide specific examples from Brazil, Mexico, Argentina, and Chile that support this claim.

An important player in this arena has been traditional mass media, and more recently social media. Morsing and Langer (2007) highlights the substantial increase in corporations' budgets that fund activities to monitor the current trends in society to enable corporations to adapt their behaviors to that which is socially acceptable. J. L. Campbell (2005) points out the importance of articles in well-known and highly regarded 
business journals and magazines, such as Harvard Business Review or Forbes and Business Week, in constructing mental models and shaping executives' behavior. In an extensive study of 1,047 firms in the United States, Europe, Latin America, and Asia, Fernandez-Feijoo, Romero, and Ruiz (2014) found that there is a direct correlation between stakeholders' pressure and the quality and trustworthiness of CSR reporting.

These societal pressures not only facilitate responsible corporate behavior, but also act as watchdogs to guarantee that those behaviors and actions match the community's values and norms, which are the basic building blocks of cultures. Needless to say, these values and norms vary significantly among cultures, as was mentioned before, and will be expanded upon later in this chapter. But societal pressure and a free market do not in and of themselves have the capacity to enforce behaviors; some level of regulatory and institutional scaffold seems to be needed to reinforce them.

Government regulation. From a country or region perspective, strict adherence to existing laws and regulations could vary significantly. Kostova et al. (2008) and Schwartz and Carroll (2003) explain that the legal expectations of any particular society influences both the legal framework and the compliance of that nation's existing laws. This is similar to Donaldson and Dunfee's (1999) hypernorms mentioned earlier. In relationship to CSR, the sheer possibility of laws being enacted that could prove detrimental to a firm's activity would be a strong motivator for that organization to behave in certain ways.

For example, Heal (2014) contends that some of the costs of economic activity, such as the spread of pollutants, are externalized to the population as a whole. Therefore, government intervention is necessary to remedy this externalized cost. Schwartz and 
Carroll (2003) argue that General Electric's decision to dredge the Hudson River of the polyvinyl chloride (PVC) that its plants had released over the years was a response that sought to avoid possible lawsuits that could lead to more strict legislation in the future. Innes and Sam (2008) provide evidence that manufacturing plants voluntarily enact environmental policies in an effort to improve their interactions with regulators. Kitzmueller (2012) found that companies intentionally exceed government regulations to build a buffer against accidental violations that could lead to more regulation.

The prevailing culture in a nation, its laws, and the strength of its institutions could greatly determine CSR outcomes. For example, J. L. Campbell (2005) compared the implementation of environmental laws in Sweden with those in the United States. In the Swedish case, the input of all interested parties, including businesses, was promoted and encouraged by the government, whereas in the case of the United States, this inclusion was not promoted. The result was that in Sweden the law is practical and effective, while in the United States — where benchmarks were set too high — the law has ended up being nearly useless. This example highlights the importance of promoting regulation processes in consultation with all parties involved. The resulting rules can be enforced in practice as well as provide balance regarding economic and societal consequences.

Of course, as Stiglitz (2003) emphatically reminds us, no level of regulation will be effective unless public institutions are strong and respond to societal needs, not only enforcing existing rules, but actively promoting and enacting new ones as necessary. He points out that the laissez-faire approach that many governments took in the 1990s, which 
led to the axiom that corporations could self-regulate, was unfortunately a fundamental factor in the corporate scandals and accounting frauds of that decade.

Kemper and Martin (2010) attributes the global financial crisis of 2008 to this lack of regulation and institutional strength. They highlight the current trend to create not only global regulation but also global institutions to serve as watchdogs over corporations as the world becomes more globalized. Even Allan Greenspan (2013), perhaps the most important broker of the relationship between business and society in the last half century, in his role as chairman of the Federal Reserve for 20 years, has admitted that over deregulation and institutional weakness played an important role in the financial crisis and, therefore, a certain level of regulation is needed to encourage responsible behavior. To illustrate, in a study of 2,500 companies in 22 countries, Romero and FernandezFeijoo (2013) found that the most important factor in a regression analysis that accounted for CSR reporting and transparency was precisely the level of government regulation in the country in which the business operates.

As we have seen, these three meso-factors (socioeconomic system, societal influence, and government regulation) play a key role in shaping the normative and utilitarian dimension of the endo-factor. However, in several of the studies presented above, there seem to be hints that culture might also play a role in shaping corporate behavior. This begs the question as to the influence that certain cultural dimensions could have on both the endo- and meso-factors that have been explored up to now. Both practitioners and scholars have minimally investigated the possible cultural influence of CSR. There are several studies that address country-specific CSR issues but ignore or barely touch on the cultural side of them. These possible cultural variables are labeled in 
the ICSRM as the ecto-factors. This issue is explored in more detail in the section that follows.

Ecto-factors: The gap in the CSR literature. At this final level, the ICSRM (see Figure 1) proposes two levels of human values that influence the endo- and mesofactors (represented in the orange circles). The first level refers to the particular values shared by the majority of the population of the nation where the business operates. The cultural studies literature commonly denotes these values as cultural dimensions (Hofstede et al., 2010; Howell, House, \& Reginald, 1993; Triandis, 1995). The second level refers to universal virtues that are common to most human groups in the world. C. Peterson and Seligman (2004) identify the following as common across cultures: wisdom, courage, humanity, justice, temperance, and transcendence. For the purpose of the ICSRM, these two levels are labeled emic cultural beliefs and etic human values respectively. $^{8}$

As mentioned throughout this dissertation, despite the international scholarly interest in CSR, little research has been conducted regarding the cultural impact on SRBL. There is, however, an extensive body of business literature that connects the effect that culture has on individual values and ethical behavior, which, in turn, seems to affect management attitudes and organizational strategies and actions regarding CSR (Koehn, 2001; Lawrence \& Beamish, 2013; Michalos \& Poff, 2013; C. Peterson \& Seligman, 2004). Since the purpose of this dissertation was to explore the impact that particular cultural dimensions have on the attitudes of business students regarding CSR, only the impact of emic cultural beliefs on ethical behavior will be further explored. Thus, before expanding on the literature regarding cultural dimensions, the next section

\footnotetext{
${ }^{8}$ The words emic and etic are borrowed and adapted from anthropology.
} 
offers a possible connection between cultural dimensions and ethics, with particular emphasis on the leadership literature.

\section{The Missing Links: Values, Ethics, and Leadership}

Since at least 1886 when Andrew Carnegie first wrote his controversial article, The Gospel of Wealth, in which he posits the responsibility of the wealthy in reducing social inequality, ethics has been a debated and contested topic in the international business world (Carnegie \& Nasaw, 2006). In fact, a quick Google Scholar search on ethics and business shows hundreds of entries, many of these being articles in highly recognized business journals. However, information regarding ethics' influence on CSR, in general, and SRBL, in particular, is limited to country or industry-specific reports or a few preliminary cross-cultural studies (Alas, 2006; Axinn, Blair, Heorhiadi, \& Thach, 2004; Hemingway, 2005; Secchi, 2009; Singhapakdi, Vitell, Rallapalli, \& Kraft, 1996).

There seem to be two interrelated reasons that explain the lack of literature regarding this link. The first has to do with the discourse on whether organizations can be anthropomorphized - that is, viewed like an individual with values - a debate that is still intense (Ashman \& Winstanley, 2007). The other reason is that the leadership literature, until very recently, has downplayed ethics as a fundamental feature of the different leadership theories (Brown \& Mitchell, 2010). These two reasons are explored next.

Organizational and leadership values' influence on CSR. The belief that ethics and morals can be attached to individuals but not to corporations has been heavily influenced by Nobel prize winner Milton Friedman's radical argument posed below:

What does it mean to say that a business has responsibilities? Only people can have responsibilities. A corporation is an artificial person and in this sense may 
have artificial responsibilities, but businesses as a whole cannot be said to have responsibilities, even in this vague sense. (Friedman \& Ebenstein, 2012 p. 87)

On the other side of the debate, Freeman (1984) and Carroll (2000) have argued that corporations, as social players, do have ethical responsibilities. The purpose of this section is not to dwell on this interminable question regarding whether a business, or any other organization, is a moral agent or not. Neither is it to discuss the different schools of ethics that have existed since the time of Socrates and Confucius or the differences between ethics and morals. The goal here is simply to seek an initial connection between ethics and CSR and SRBL within a cultural context. To achieve this objective, suffice it to say that individuals run organizations, these individuals' values shape organizational culture, and these same individuals make the decisions regarding CSR within the context of the organizational culture. Therefore, if organizations have cultures-as most scholars and practitioners agree - then organizations can be assumed to also have values, including ethical ones.

As an example of the above, Vitell and Paolillo (2004) show how managerial CSR decisions in four different countries were shaped by both the manager's individual ethical perspectives and the organizational culture. Hemingway (2005) corroborates these findings, arguing that when specific universal personal values such as social justice, equality, and unity with nature are present in business executives, these values permeate the organizational culture, generating greater support for corporate ethical behavior and CSR. Carroll (2000), one of the leading CSR scholars, supports this view when he postulates that "values are the individual's concept of the relative worth of certain ideas. One's values, therefore, shape one's ethics" (p. 133). 
Regarding CSR and culture, Velasquez (2014) warns that since values are the standards that people, individually or collectively, use to make judgments as to what is right and what is wrong, these could vary among countries, depending on each society's beliefs. He adds that what might be normal and lawful in one country might be illegal in another and what is considered customary business practice in one society might be considered unethical in another. This variability is precisely why understanding how ethics shapes cultural values could be the missing link in identifying the factors that hinder or promote CSR in different regions of the world.

In trying to establish this link, Singhapakdi et al. (1996) was the first scholar to attempt to develop a reliable instrument applicable in any cultural setting to measure the influence that ethics and values could have on CSR initiatives. His initial study titled Perceived Role of Ethics and Social Responsibility (PRESOR) was initially applied to marketing executives, with the objective of understanding their decision-making process in ethical situations.

The PRESOR questionnaire, based on Kraft and Singhapakdi's (1995) model of corporate efficiency, incorporated 16 statements that reflect the importance of ethics relative to other traditional business measures. This instrument uses a 9-point disagreeagree Likert scale to measure questions such as: "Is social responsibility compatible with profitability?" or "Is being ethical and socially responsible the most important thing a firm can do?" or "If the stockholders are unhappy, then nothing else matters?" This information was then correlated to personal values, or what Singhapakdi et al. (1996) call the personal ethical ideologies of the marketing executives, using multiple regression analysis to further understand the relationships between the different variables. Part of 
this questionnaire was used in the survey of this dissertation, which is explained in detail in the methodology chapter that follows.

Since then, other scholars have refined the PRESOR scale. For example, some scholars have used it in multicultural settings, with the objective of assessing how cultural values correlate with executives' preference for a profit-oriented stockholders' business view versus a more holistic stakeholders' one (Axinn et al., 2004; Shafer, Fukukawa, \& Lee, 2007). In another study, Vitell and Nishihara (2010) used the instrument to measure the relationships between relativism and idealism and CSR. They found that relativism in executives tends to negatively influence CSR perceptions, whereas idealism had the opposite effect. Relativists tended to favor utilitarian CSR initiatives, while idealists favored more normative ones.

The leadership literature and ethics. In the first edition of the well-known book, Ethics: The Heart of Leadership, Joanne Ciulla (1998), University of Richmond distinguished professor of leadership studies, makes the following poignant comment regarding the field's historical lack of interest in ethical issues:

An example of the paucity of research energy expended on ethics is Bass \& Stodgills's Handbook of Leadership (Bass \& Stodgills, 1990). On the book jacket it is hailed by one reviewer as the "the most complete work on leadership" and "encyclopedic." This is considered the source book on the study of leadership. The text is 915 pages long and contains a 162-page bibliography. There are 37 chapters in this book, none of which treat the question of ethics in leadership. If you look ethics up in the index, only five pages are listed ... the reader has to get to a subsection in the last chapter to find a two page exposition on ethics. (p. 19)

Ciulla (1998) notes that Bernard Bass, the editor of the handbook, was very unhappy with her criticism, reminding her that he wrote the subsection on ethics that she referred to, promising a more extensive section regarding the subject in future editions. True to his word, in the fourth edition of the handbook, published just a few months after 
Bernard Bass passed away (Bass \& Bass, 2008), a full 40-page chapter is devoted solely to the topic of ethics and leadership. New leadership theories that highlight ethical conduct were added, and the subject index expanded to more than 20 entries.

This short anecdote regarding two prominent leadership scholars underscores the fact that during most of the 20th century the majority of leadership research and subsequent theories were morally neutral, focusing on the traits and skills that leaders needed to be successful. This pragmatic view of leadership did not mean that ethics was not important; it just was not the priority at the time.

In fact, Bass and Bass (2008), at the outset of their final edition of the leadership handbook, remind us that ethical principles of leadership "go back nearly as far as the emergence of civilization, which shaped its leaders as much as it was shaped by them" ( $p$. 4). Bass and Bass offer the following examples: Ptahhoted's written principles of leadership published in Egypt in 2300 BCE; Confucius and Lao-tzu's leadership's responsibilities and code of conduct manuals in $600 \mathrm{BCE}$; Plato's ideas regarding the requirements for the ideal leader and Socrates's virtue ethics in 300 BCE; and Plutarch's moral principles of leadership, which were extensively used by both Romans and Greeks in $100 \mathrm{CE}$.

It seems then that leadership ethics has been a prominent focus of philosophers since the recording of civilization. This emphasis has regained importance in the last 20 years as new leadership theories have been emerging. In fact, Ciulla (2014) recognizes this development in the fourth and latest edition of her book. What follows is a brief historical timeline of this evolution from the 20th century until today. The purpose of this recollection is to show the progress of ethical concerns in the development of 
leadership theories and their effect regarding CSR. Thus, the subsections that follow are not inclusive of all theories but rather offer a general overview to demonstrate this evolution. With this in mind, selected but relevant leadership theories are presented in the chronological order that they have been developed and classified as early theories, modern theories, and postmodern theories.

The early theories: Late 1800s to 1960s. The seminal leadership theories were based on the traits, skills, and behavior of the leader. The trait approach was initially developed to determine what made people great leaders. These theories were based on the works of Thomas Carlyle (1897), which can be seen in his famous assertion that the history of the world is the bibliography of great men, hence the theory name. Stogdill (1948), and later Mann (1959), identified intelligence, masculinity, initiative, dominance, self-confidence, and extraversion as the primary traits of successful leaders. In the early 1990s, Kirkpatrick (1991) added an ethical dimension for the first time, identifying integrity as a necessary quality for a leader. At the beginning of this century, these theories began to regain popularity with the works of Zaccaro (2007), who introduced traits based on cognitive abilities, conscientiousness, and emotional intelligence, all of which have an emphasis on responsible behavior. Judge, Piccolo, and Kosalka (2009) took these ideas further, pointing out that each of the big five leadership traits—openness, conscientiousness, extraversion, agreeableness, and emotional stability-have their corresponding black sides, which could produce negative and even unethical behaviors.

The theoretical view regarding traits has several weaknesses. First, results of research are ambiguous given the large list and subjectivity of possible traits. Also, the context of the situation or the role of followers is not taken into account. Additionally 
traits are not useful for training and development—for example, intelligence is not fixed and can be developed but not taught. Finally, outcomes seem to be unimportant, particularly ethical ones (Northouse, 2013).

In contrast to trait theories that focus on personality characteristics, skill theories place an emphasis on abilities that can be learned and developed. Katz (1974), in an article first published in 1955, suggests that effective leadership depends on three fundamental skills: technical, human, and conceptual. Of these three, the human aspect hints at ethics because it involves being sensitive to the needs of others, but this is not the central tenant. In the 1990s, Mumford and Connelly (1991) introduced the concept of competencies, which has been used extensively in the business world. They posit that a good leader needs problem-solving abilities, knowledge, and the sensitivity to judge and evaluate social issues. Of these skills, the third addresses ethical issues, emphasizing the need for conflict resolution aptitudes in a leader. However, the focus is on employees and not necessarily other stakeholders of the firm. Years later, Mumford, Zaccaro, Harding, Jacobs, and Fleishman (2000) acknowledged in an article titled Leadership Skills for a Changing World: Solving Complex Social Problems that social judgment skills go beyond employees and should encompass social betterment initiatives.

The set of behavioral theories focuses on what leaders $d o$ rather than what leaders are. In the early 1940s, Kurt Lewin, who is considered the father of modern social psychology, developed what is known as field theory, which proposed that behavior is the result of the individual and the environment (Lewin \& Gold, 1999). This theory emphasized that individual personalities, interpersonal conflict, and situational variables determine if leadership style should be autocratic, democratic, or laissez-faire. In the 
early 1950s and based on the work of Lewin and his associates, researchers from Ohio State University and the University of Michigan began to identify and develop a list of more than 2,000 leadership behaviors (Nahavandi, 2012). However, it was Blake and Mouton's (1964) application of these concepts in their Leadership Grid that made this approach popular. This grid is comprised of two factors: concern for results and concern for people. The former refers to the leader's actions in achieving organizational tasks, while the latter refers to the leader's concern for people, which is needed in order to achieve these results. According to this theory, the ideal leader is the one who tends to score high on both people and results orientations. Although concern for people includes promoting good social relations, these are geared to employees and not necessarily the larger community. In fact, one of the weaknesses of this approach is that it does not measure outcomes from an ethical perspective.

The modern era theories: 1960s to the end of the century. This taxonomy includes what are known as situational, path-goal, leader-member exchange (LMX), and transformational theories. From the situational perspective, well-known management consultants Blanchard, Zigarmi, and Zigarmi (1985) developed a grid with two factors that indicate four ideal behaviors depending on the circumstances. The vertical axis of the grid evaluates the leader's need to be supportive, while the horizontal axis evaluates the need to be more directive, depending on the situation, which includes the subordinate's skills and the complexity of the task. Even though Blanchard et al.'s models are popular with consultants, their proposals have not been well tested and have little empirical research to back them up (Northouse, 2013). 
Contingency theories are similar in the sense that their primary proposition is that leadership effectiveness is contingent on matching a leader's style to the right circumstances. Fiedler(1967), whose theories have been highly researched (Nahavandi, 2012), argues that situations can be characterized in terms of three situational factors. The first is related to the leader-member mutual degree of confidence and trust. The second is related to the structure of the task at hand. Finally, there is the leader's position of power, which refers to his or her ability to reward or punish followers. These three factors are combined into an index of situational control in order to match leaders with particular situations.

The previously mentioned models have been used extensively in many organizations across the world with a certain level of success because they are simple and practical for day-to-day organizational issues. However, these theories do not address ethical issues in any way, nor do they consider the larger effect of different stakeholders in defining what the situation is (Northouse, 2013).

The path-goal theory's main focus is on understanding leaders' actions and behaviors that increase the satisfaction and motivation of followers, with the aim of performing a common task and objective. According to Evans (1996) and House (1996), leaders produce motivation when they make the path to a specific goal easy by removing obstacles and providing support to followers. Here, the focus is on the dynamic of the relationship based on the characteristics of the subordinate and the task at hand. Depending on these two factors, leaders' behaviors should adapt to the followers' needs. These behaviors could then be directive, supportive, participative, or achievement 
oriented. This theory puts more emphasis on the role of the leader than the follower and, over time, could create dependency by subordinates (Northouse, 2013).

LMX theory, first proposed by Dansereau, Graen, and Haga (1975), posits a dyadic interaction between leaders and followers, placing both actors at the same level. This theory was further developed by Uhl-Bien, Graen, and Scandura (2000) who suggest that the leader-follower exchange progresses in three phases. They call the first the stranger phase, in which the relationship is unidirectional and of low quality. The second stage is the acquaintance phase, in which the relationship is mixed and of medium quality. The relationship becomes reciprocal and of high quality once the partnership phase is achieved. This final stage is the ideal for increasing performance and achieving results. Therefore, leaders should concentrate their efforts with those followers with whom they can develop this more mature relationship.

From an ethical perspective, path-goal and LMX theories go one step forward because they position followers and leaders in a dyadic relationship. However, as Northouse (2013) points out, these theories exclude those potential followers who do not belong to the in-group of the leader, which could create discrimination against the outgroups.

The transformational theories first suggested by Downton (1973), and later popularized by Burns (1978), mark a quantum leap in the ethical aspects of leadership because they treat followers not as means to achieve results but as ends in and of themselves. Theories such as charismatic and visionary leadership could also be included in this category (House, 1996). 
In the previously mentioned approaches, the authors distinguish between two types of leadership: transactional and transformational. Transactional leaders are concerned solely with the exchange that occurs with followers in seeking to attain a task that the leader has proposed. A good CEO who achieves the company's annual objectives is an example of this. Transformational leaders seek to transform both leaders and followers, with the objective of accomplishing not only a transformative goal for society but also of enhancing the participants' level of morality and motivation. The classical example of a transformational leader was Mohandas Gandhi.

Despite the highlighting of the ethical dimension that this approach provides, some authors warn that it suffers from heroic leadership bias that might make it elitist and manipulative (Yukl, 1981). Others caution that the charismatic side of transformational leadership could be abused and produce destructive consequences (Howell et al., 1993). Hugo Chavez' leadership in Venezuela is a recent example of this.

The postmodern theories: 2000 to the present. This latest approach includes more recent leadership theories, with concepts such as servant leadership (Greenleaf, 1977), authentic leadership (Gardner, Avolio, \& Walumbwa, 2005), eco leadership (Western, 2013), and integral leadership (Forman \& Ross, 2013). The common elements of these theories is that the leader must engage in deep reflection in order to reveal insights that are not evident, should have a desire to help others, and should embrace a holistic view of all stakeholders in any decision making.

All these theories call for trustworthy leadership that is morally grounded and responsive to society's needs and values. The scholars who propose these theories apply systems thinking, underscoring the connectivity and interdependence that different 
players have in society, which means that possible solutions in one area can potentially create problems in another. As a consequence, these theories are not only grounded in high moral standards but arguably also provide a roadmap for business leaders in their socially responsible business initiatives. However, these theories just assume that reflection will lead to ethical thinking and behavior, which is something that has not been sufficiently researched and supported.

Despite the benefits of the obvious ethical emphasis that these theories provide, they are still in their initial stages of research. More inquiry is needed, not only to substantiate their theoretical underpinnings, but also their practical application (Northouse, 2013). However, these theories do seem to point in a new direction and have higher aims for the practice of SRBL than previous theories had.

This brief review of the literature regarding values and leadership ethics underscores the reciprocal influence that might exist between culture and SRBL (Axinn et al., 2004). With that link established, the next section reviews the main national cultural dimensions proposed by several scholars in the field, followed by examples of its possible influence on CSR initiatives.

\section{Concept and Dimensions of National Cultures}

Culture is defined in a myriad of ways, depending on the background of the scholar proposing it. Traditionally in academia, the word culture has had an anthropological and ethnographic connotation. The most well-known example is that of anthropologist Clifford Geertz (1973) who defines culture as "a system of inherited conceptions expressed in symbolic forms by means of which men communicate, perpetuate, and develop their knowledge about and attitudes toward life" (p. 12). 
From a managerial perspective, Nahavandi (2012) proposes a more colloquial but practical way of understanding the concept of culture, describing it as "the set of norms, customs, values, and assumptions that guide the behavior of a particular group of people" (p. 30). In either case, the common theme is that culture includes shared meaning as the primary aspect that drives communal life among members of a collective.

These shared meanings, which are related to motives, values, beliefs, and identities, are what create cultural dimensions that can be clustered as salient characteristics of a group. Several scholars and researchers have attempted to define these parameters and have provided unique contributions to the field. The most important ones are described next.

History of cultural dimensions. Kluckhohn and Strodtbeck's (1961) seminal work studying variance within cultures is rooted in the anthropological school. They identify six cultural dimensions: nature of humans (good/evil), relationships among people (individual/collective and hierarchical), relation to the environment (mastery/subjugation/harmony), activity (doing/thinking/being), time (past/present/future), and space (public/private).

These ideas created the basis for the work of subsequent scholars. For example, Hofstede et al.'s (2010) work-related value model was an extensive study, conducted with IBM subsidiaries - more than 160,000 interviews in 60 countries - and the first to introduce and correlate the cultural dimensions of individualism/collectivism, power distance, masculinity/femininity, and uncertainty avoidance, and later adding longterm/short-term orientation. However, Hofstede et al.'s work has been criticized by some who argue that IBM employees, the focus of Hofstede et al.'s studies, are a unique group 
that cannot represent national cultural values (McSweeney, 2002) or that because of the studies' Western focus, they contain colonialist elements in their survey methods (Mitra, 2012).

Other scholars have added their own unique perspectives to shedding light on the meaning of culture in the context of other factors. For example, Hall's (2003) cultural context theory is based on communication styles. His categorization of high and low context cultures provides a practical tool to understand these two cultural extremes in the ways that explain how people talk and understand each other. Triandis (1995) emphasizes the relativity of cultural behavior, introducing the concept of loose cultures, in which deviation is allowed, and tight cultures, in which high social expectations are the norm. Finally, Trompenaars and Hampden-Turner (2012) base their cultural theory on the ways a group of people solve problems. They contributed the dimension of neutral or objective versus affective or emotional and the dimension of diffuse or deductive versus specific or inductive. This study relied on project GLOBE (House et al., 2002), which will now be expanded upon.

The GLOBE project. This study is considered one of the most comprehensive analyses of national cultures. It is an ongoing worldwide project in which 170 social scientists from 62 cultures represent all major regions of the world. This project was primarily based on Hofstede et al.'s (2010) taxonomy but also incorporated Trompenaars and Hampden-Turner's (2012) ideas regarding leadership styles and Kluckhohn and Strodtbeck's (1961) emphasis on values in the formation of culture. According to House, Hanges, Javidan, Dorfman, and Gupta (2004), there are two distinct kinds of cultural manifestations - values and practices — and the following nine core cultural dimensions: 
Uncertainty avoidance refers to the extent to which the members of a group attempt to avoid uncertainty by relying on accepted social norms and actively seeking to decrease the probability of unpredictable and negative events. Societies in which strict rules and laws are the norm tend to be high on this dimension, whereas societies in which legal decisions are made based on jurisprudence tend to be less comfortable with uncertainty.

Power distance denotes the level to which members of a group not only expect but also agree that power should be stratified so that some people have (and deserve to have) a higher social status. Highly democratic countries score low on this dimension. Lower power distance enables better access to information and higher upward mobility. Institutional collectivism conveys and gauges the importance that institutions and the collective action have on the just distribution of resources among society. Nepotism, which favors the in-group members of society, tends to be minimized when institutions are strong, a practice the society intensely rejects. High institutional collectivism tends to positively correlate with society being less assertive and having lower power distance practices.

In-group collectivism, in contrast to the previous one, measures the level of acceptance of behaviors that encourage and reward individual loyalty to one's inner group or family and the maximization of rewards to this particular social unit. This is why authority tends to be highly respected in these groups.

Gender egalitarianism is the degree to which a social group encourages male and female equality, thus minimizing differences in gender roles, rewards, status, and influence in society. The more feminine Northern European countries score high on this 
dimension. These societies tend to have greater member longevity and a higher standard of living.

Assertiveness measures the level of societal acceptance of aggressiveness and confrontational behavior as a normal way of solving societal issues and conflicts. Groups whose communication style is low context, which is direct and to the point, tend to emphasize results over relationships and score high on assertiveness.

Future orientation refers to the amount of future-oriented behavior that a group displays as a normal way of life. These actions include planning, saving, and delaying both individual and group gratification. Societies in which doing takes precedence over being tend to be future oriented. Also, individuals in this group tend to be intrinsically motivated.

Performance orientation is related to future orientation and measures the degree to which a group displays more doing than being behaviors and encourages and prizes group members for performance advancement and quality in actions. Societies that score low in this dimension tend to value societal and family relations and have a high respect for quality of life.

Humane orientation is the degree to which groups encourage and value their members for being fair, altruistic, generous, and kind to others. This dimension is also positively correlated with femininity in social groups.

An examination of these differing cultural dimensions provides the opportunity to shed light on the diverse CSR definitions given by the scholars mentioned before and how different cultural groups implement CSR across the world. To facilitate this 
analysis, a description of GLOBE's 10 cultural clusters and examples of CSR activities in some of these groups follows.

\section{Cultural Clusters and CSR Initiatives}

Each country, state, and even ethnic group within a nation has its own unique culture. Thus, there are probably thousands of potentially distinguishable cultures in the world. However, there are societies and regions with similar shared values, behaviors, and norms, which allow for some clustering. The idea of culture clusters was first proposed by Ronen and Shenkar( 1985), who analyzed 42 countries and, based on attitudinal dimensions, identified eight cultural clusters and four countries with their own unique characteristics. Based on this seminal study, project GLOBE analyzed 61 nations and identified the 10 cultural clusters depicted in Figure 2.

\begin{tabular}{|l|l|}
\hline Cultural Cluster & Countries \\
\hline Anglo & $\begin{array}{l}\text { Australia, Canada, England, Ireland, New Zealand, White South } \\
\text { Africa, USA }\end{array}$ \\
\hline Nordic Europe & Denmark, Finland, Sweden \\
\hline Germanic Europe & Austria, Germany, German Switzerland, the Netherlands. \\
\hline Latin Europe & France, Israel, Italy, Portugal, Spain, French Switzerland \\
\hline Eastern Europe & $\begin{array}{l}\text { Albania, Azerbaijan, Estonia, Georgia, Greece, Hungary, } \\
\text { Kazakhstan, Poland, Romania, Russia, Slovenia }\end{array}$ \\
\hline Confucian Asia & China, Hong Kong, Japan, Singapore, South Korea, Taiwan \\
\hline Southern Asia & India, Indonesia, Iran, Malaysia, Philippines, Thailand \\
\hline Latin America & $\begin{array}{l}\text { Argentina, Bolivia, Brazil, Colombia, Costa Rica, Ecuador, El } \\
\text { Salvador, Guatemala, Mexico, Peru, Venezuela }\end{array}$ \\
\hline Middle East & Egypt, Kuwait, Morocco, Qatar, Turkey \\
\hline South Pacific & Fiji, Salomon Islands, Tonga, Vanuatu \\
\hline
\end{tabular}

Figure 2. Major cultural clusters in the world. Data from GLOBE project (House et al., 2004). 
It is important to point out that the categorization of cultures into clusters is not consistent among researchers. In fact, some have argued that simply the idea of cultures being forced into clusters is a negation of the richness of ethnic groups and the constant evolution and change that groups experience. Despite the relative homogeneity that the cultural clusters present, there are within-group differences that have been identified by important research in different fields (Dickson, Castaño, Magomaeva, \& Den Hartog, 2012). However, for the purposes of this paper, the GLOBE clusters provide enough similarities among nations to establish the link between ethics, cultural dimensions, and CSR.

What follows is a brief overview on how the most salient cultural dimensions of each cluster influence local CSR initiatives. To further understand each region, the reader can refer to the cited references.

Anglo. The Anglo cluster scores high on performance orientation and assertiveness, low on in-group collectivism, and medium on the rest. As was mentioned at the beginning of this paper, CSR development probably began in the United States with the ideas of Andrew Carnegie (Carnegie \& Nasaw, 2006), which Bowen (1953) and Freeman (1984) later popularized. It is interesting to note that the two highest scores in this cluster are indicative of action, or, more precisely, of individual action. This was to be expected since one of the countries in this cluster - the United States - had the highest individualism score in Hofstede et al.'s (2010) taxonomy. It seems then that the ethical values that drive this culture are primarily related to the ICSRM meso-factor of society, which provided the fertile soil for the growth of CSR. Since most of the previous literature review refers to this cluster, this brief description should suffice. 
Nordic Europe. This cluster scores high on institutional collectivism and gender egalitarianism and low on assertiveness, in-group collectivism, and power distance. Maria Gjølberg (2010), from the University of Oslo, describes the Nordic model as the Humanitarian Superpower precisely because of these countries' orientation to CSR activities. According to Gjølberg, despite differences between the Scandinavian countries regarding their CSR approach, the high institutional collectivism of this cluster nurtures an ethical ethos based on humanitarian principles, respect of human rights, condemnation of corruption, and avoidance of environmental damages. The long Nordic social democratic political tradition has led to cooperation between state, capital, and labor, including close collaboration between employers and employees in a wellregulated society, in which the government is the main sponsor of CSR policy. Gjølberg contends that these features are that which distinguish the Nordic model from the American, business-driven CSR approach. It seems then that the egalitarian-based ethics of this group leads to the ICSRM institutional meso-factor being the main driver of this more democratic CSR approach.

Germanic Europe. This European cluster scores high on assertiveness, future orientation, and uncertainty avoidance, and low on humane orientation. Kinderman (2013) asserts that German business people have a particularly high voluntaristic attitude toward CSR. He points out that even Confederation of German Employers' Associations (BDA) — the German workers' strongest union—supports this corporate attitude. Moreover, he further argues, German corporations hesitate to advance common European Union CSR agendas and regulations, preferring to stay away from allowing any international association to influence CSR activities within the region. Perhaps the 
Germans' assertiveness and high uncertainty avoidance preference drives this cluster to have their own rules of the game regarding CSR. Their low humane orientation might also be a factor in creating low solidarity with other groups. These characteristics probably negatively impact the ICSRM societal meso-factor as well as the institutional one.

Latin Europe. Latin Europe includes two countries with the highest scores on two dimensions: Spain on assertiveness and France on power distance. In general, the region scores low on performance orientation, future orientation, and humane orientation. Blasco (2010) underscores the influence that Catholic traditions might have had on the CSR practices in the region. This is particularly salient given the societal high power distance and tendency to delegate philanthropic initiatives to religious institutions, which seems to convey a low humane orientation. Additionally, Blasco points out that France is the fourth most active country in CSR reporting, which might be congruent with the high power distance feature of window dressing and the cynical attitude of some French scholars who maintain that "the more a company speaks about ethics the less ethically they act, and vice versa" (p. 235).

In reference to Spain, de la Cuesta González and Martinez (2004) stress the need for government regulation in order for companies to engage in CSR activities. This might correlate with the low performance and humane orientation of the region. Moreover, they point out that Spanish civil society is very fragmented and hierarchical, which decreases the ability to pass laws that support CSR initiatives. For example, when the socialist labor party (PSOE) was in power, it presented a proposal to foster CSR and corporate accountability. This law, similar to the one in the United Kingdom, was not 
even discussed in parliament. It seems then that in order to foster CSR initiatives in this region, it is necessary to increase government intervention. In short, there seems to be a need to increase the ICSRM meso-factor of laws and regulations.

Eastern Europe. This cluster includes Russia, the country with the highest ingroup collectivism and lowest future orientation scores, and Greece, the country with the lowest scores on performance orientation and institutional collectivism. With the exception of Greece, the nations that compose this cluster are just beginning to develop the free market socioeconomic model described in the ICSRM as a necessary condition for the development of the business sector. The limited literature regarding this cluster points to the nascent stage in its development, and it is difficult to establish a cultural connection with CSR initiatives. However, given the cultural dimensions described above, it would not be presumptuous to predict weak CSR development in the years to come.

Confucian Asia. China, as the largest and most influential country in this cluster, has the highest score on performance orientation and institutional collectivism in the world. The region also scores high on uncertainty avoidance, in-group collectivism, and future orientation. It scores low on humane orientation and gender egalitarianism. Japan, a country whose culture and political model differs significantly from that of China, also tends to share similar scores with China, albeit with less intensity. The main element that ties the cultural dimensions of nations of this cluster together is Confucianism.

Kim and Kim (2010) state that Confucianism ethics, which mandates a high sense of collectivism, hard work, and clear rules of behavior, is deeply rooted in the society of 
these countries. For example, S. P. Feldman (2013) explains that the word guanki, which refers to the necessary network that is needed to conduct any business transactions, implies the obligation of economically benefiting all members involved. In the West, this concept could be considered corruption.

In Japan, Kyoko Fukukawa (2010) reports that, since 2002, societal pressure has forced exponential growth of businesses reporting CSR initiatives. Today, more than $80 \%$ of Japanese corporations do so. She suggests the interesting idea that communitarian Confucian ethics leads society to understand that the general public is the real owner of corporations - a stakeholder's view taken to a higher level. As a result, businesses are accountable to society in general, not just to their stockholders. To support this claim, she cites survey results that compared Japanese and American CEOs' assessments of their main business objectives. She found that for the Japanese CEO, the development of new products had a weight of $60.8 \%$, whereas maintaining investor returns weighted only $35.6 \%$. For the American CEO, it was the opposite. The Japanese concept of justice, expressed in the words $y i$ and ren, link the idea of fairness with community, making the Western notion of individual fairness inconceivable without taking into account the community. These societies are willing to sacrifice fairness for harmony, a characteristic that seems to be present in their CSR initiatives as well.

Southern Asia. This region scores high on humane orientation and power distance. The rest of the dimensions falls in the medium range. The most representative country in this cluster is India. Mitra (2012) and Rishi and Moghe (2013) reflect that CSR activities in India draw mainly from a combination of religious values and Gandhian thought, combined with the government's paternalistic postcolonial economic policies. 
Rishi and Moghe call this approach benign paternalism, assessing that it is based on humane orientation and power distance, which were identified as salient cultural dimensions. However, Mitra warns that the rapid expansion of neo-liberal economic policies is distorting the traditional Indian ways, reducing the human part of paternalism and increasing the power distance side through social inequalities.

There are two contradictory examples in this Indian progression towards development. On the positive side is Tata Corporation, a $\$ 100$ billion family-owned conglomerate, with thousands of employees around the world. This company is well known for its ethical standards, responsible leadership, and extensive CSR programs, which reflect the Indian humane orientation. At the other extreme, there is the minimal accountability that Union Carbide, Coca-Cola, and Chevron—all multinational companies - have displayed after the unfortunate accidents in which hundreds of people were affected. This shows little societal pressure on corporations and a lack of government enforcement of its regulations, which might indicate a postcolonial power distance syndrome (Mitra, 2012; Rishi \& Moghe, 2013).

Latin America. This cluster scores high on power distance and in-group collectivism and low on future orientation and institutional collectivism. On the rest of the dimensions, the scores tend to be in the middle of the range. Puppim de Oliveira (2006) affirms that in Latin America CSR had its basis in the long history of Catholic philanthropy and social values, which were spread throughout the continent. For example, he contends that the common practice of social betterment initiatives from small and medium-sized businesses are derived more from the social and religious values of their owners than from an understanding of modern CSR concepts. These initiatives, 
in contrast to those of multinational companies in the region that tend to be based on environmental concerns, are instead oriented to solve social problems.

Schmidheiny (1992), founder of the World Business Council for Sustainable Development (WBCSD), agrees with de Oliveira (2006) when he states that outsiders to the region only see a plethora of biodiversity to be taken care of, whereas Latin Americans confront persistent poverty, corruption, criminality, and informality in their daily life, which drive local companies to implement urgent but short-term CSR initiatives. This view summarized quite well the low future orientation of the region and the focus on philanthropic initiatives, which, by definition, reinforce the power distance dimension.

The Middle East. The Middle East includes Egypt, which has the highest score on humane orientation and the lowest score on gender egalitarianism. The region also scores high on in-group collectivism. The rest of the cultural dimensions falls on the medium range of the scale. Ali and Al-Aali (2012) explain that the CSR concept in the Middle East had evolved in a distinctive way from the traditional Western model because it is rooted in the Islamic teaching that social responsibility is an obligation of all citizens. This religious belief promoted CSR activities mainly from a normative basis, not a utilitarian one.

In a different study, Jamali and Mirshak (2007) corroborate this idea, highlighting that one of the consequences of this deontological view is the strict voluntary aspect of CSR that corporations expect. Moreover, both scholars suggested that in-group collectivism is evident because the CSR obligation is in reference to fellow Muslims, excluding other groups. 
In an interesting article regarding gender inequality in Egypt, Saudi Arabia, and the United Arab Emirates (UAE), Karam and Jamali (2013) underscore the effect that some CSR initiatives are having on the advancement of women's rights in the Arab Middle East world. Corporations are the main drivers that empower women and facilitate their integration into both the economic and political realms. According to Karam and Jamali, these CSR initiatives create an isomorphic pressure on other institutions in society to adopt similar gender attitudes. These examples suggest that the ICSRM societal meso-factor, based mainly on religious beliefs, is one of the principal elements influencing CSR initiatives, including the traditional normative value towards women's role in society.

\section{Conclusion}

In their latest book, The Unfinished Leader: Balancing Contradictory Answers to Unsolvable Problems, well-known business consultants Dotlich, Cairo, and Cowan (2014) argue that many important business and social problems are not puzzles that can be solved. Rather, they explain, they are paradoxes that need to be understood as nonsolvable and thus managed on an ongoing and perpetual basis. For this reason, effective leaders are those who are able to hold what apparently are two opposing ideas and move forward integrating them as much as possible. Maximizing profits while contributing to social betterment initiatives seems to be one of these paradoxes. The very ingenuity of business knowledge could be the driving force in redefining business activity and education so that social policies and moneymaking become integrated.

Applying this idea to the CSR concept, business experts and Harvard Business School professors Porter and Kramer (2006) posit that to make good by doing good you 
need to reconcile what seem to be two opposing ideas. On the one hand, every corporate decision that affects profitability should also factor in social issues. Similarly, every significant social or economic policy decision should also consider profitability measures. This dichotomy gets even more complex when seen from the perspective of the internationalization of businesses and the spread of business education globally, given the cultural influences on the values that frame social issues in different countries.

For these reasons, this dissertation suggests that the study of CSR, in which the firm is the main unit of analysis, must extend beyond the corporation-centric approach that has dominated the field up to now. The ICSRM posits that CSR is not solely the product of an individual company's values or strategic orientation but is the result of societal, governmental, and socioeconomic factors interacting to influence the firm's strategic stance and ultimate behavior. Moreover, the particular cultural beliefs and interpretation of the etic human values of the social forces in which the firm operates heavily influences these three factors, ultimately shaping the normative and utilitarian stance of a firm regarding CSR.

This then implies that CSR activities are not solely the responsibility of businesses. Instead, external social actors seem to be a fundamental force that shapes an organization's socially responsible leadership. As suggested at the onset of this chapter, business schools are one of the social actors that play a key role in forming future corporate leaders, yet only recently scholars have begun to look into the relationship of leadership and CSR (Jones, Mackey, \& Whetten, 2014). Thus, deepening the understanding of the link between leadership ethics, cultural values, and CSR initiatives should be a fundamental goal in any business education program. 
Given the complexity that the different conceptualizations of ethics has had over the last 3 millennia and the relative newness of the field of cultural analysis and research, establishing the link between ethics, cultural values, and CSR seems to be a herculean anthropological endeavor. In this dissertation, the intention is simply to generate enough intellectual curiosity about the subject to initiate a fruitful discussion that could lead to more research on this topic. This will require a cross-cultural and multidisciplinary approach, which is always a difficult task, yet given the challenges that the world faces today and the role that businesses could play in solving them, it is worth the effort. The next chapter describes the methodology used in this study to contribute a grain of knowledge for this challenging and complex endeavor. 


\section{CHAPTER THREE}

\section{METHODOLOGY}

The intent of this study was twofold. First, the study examined the ways in which MBA students' motives and views differed, if at all, across various cultural clusters regarding the factors that affect CSR. Second, the study tested specific cultural dimensions to determine their relationship, if any, to business students' motives and views regarding these factors. The cultural clusters were derived from project GLOBE (House, 2011), and the CSR factors were based on a review of the literature, which resulted in the ICSRM presented graphically in Figure 1 in Chapter One of this dissertation.

This chapter first provides an overview of the research methodology and addresses its appropriateness for this project. Next, it describes site and sampling procedures and explains the relevance of the three selected business schools for the purpose of this study. It then provides a description of data collection techniques, including an explanation of the survey questions' origin, validity and reliability, and the procedures used to conduct focus group interviews. Finally, the chapter outlines the process used to analyze the data and generate the findings.

\section{Overview of Research Methods}

To achieve the study's objectives described above, an explanatory mixed methods research design that included two separate phases was employed (Creswell \& Clark, 2011). The first phase yielded quantitative data that provided general answers to the research questions based on comparisons of survey results from students attending each of three different business schools in Europe, Latin America, and the United States. The 
second qualitative phase built on, refined, and deepened the understanding of these results through focus group interviews with a smaller number of students from each site.

The selection of an explanatory mixed methodology for this study was warranted for two reasons. First, a quantitative approach makes sense when a researcher is seeking to determine the differences between groups and establish statistical relatedness between factors that other research suggests are likely to be representative of an entire population (Fowler, 2014). Although statistical generalizability to an entire population is an eventual aspiration that cannot be realized in a single study, this project did determine differences between groups that other research suggests represent different cultural dimensions. In this way, the study was consistent with Fowler's (2014) rationale for a quantitative approach.

Additionally, since culture is a complex phenomenon, it made sense to employ a more qualitative approach in order to explore the nuances of cultural variables, or even the lack of nuance. This combination of methods provided a richer understanding of the research questions than either approach would have offered by itself (Creswell \& Clark, 2011; Teddlie \& Tashakkori, 2009).

In short, the research questions called for a combination of both objective and subjective ways of knowing to better understand the issues. This is what Dewey and Boydston (1983) call the dictatorship of the research questions based on their contention that the nature of the research questions always drives the methodology that should be used.

The second reason for having employed a mixed methods research design is related to what Guba and Lincoln (2005) describe as the philosophical assumptions that 
guide inquiries, or what Creswell and Clark (2011) refer to as the researcher's worldview. Researchers' philosophical assumptions or worldviews are composed of beliefs, values, and assumptions that a particular group of professionals hold about ontology and epistemology.

I am a businessperson by education and practice, and, as a consequence, my worldview is shaped by the pragmatism that is common in the business world. Specifically, this means that the quest for knowledge (epistemology) can be rooted in either subjective/constructivist or objective/positivist methods, depending on which is most efficacious for the situation at hand, or, in other words, whatever methods produce results that are practical as well as conducive to action and problem solving. Thus, as a businessperson, the use of mixed methods makes sense; however, from an ontological perspective, it may create limitations, which will be addressed specifically in Chapter Five. Table 1 provides a summary of the methodology, procedures, and end product.

\section{Site and Sample Selection}

The study employed a combination of purposeful and convenience sampling in order to provide information that is rich and instructive of the phenomenon of interest (Patton, 2002). The objective of this study was to generate insight into possible differences in the views of business students from supposedly different cultural clusters toward the factors that seem to determine socially responsible business practices as well as how these views relate to their personal motives toward CSR. Therefore, the selection of sites that could provide the required number of students from different cultural backgrounds was a critical step in this project. 
Table 1

Summary of the Methodology

\begin{tabular}{lll}
\hline \multicolumn{1}{c}{ Phase } & \multicolumn{1}{c}{ Procedure } & \multicolumn{1}{c}{ End Product } \\
\hline Quantitative data collection & $\begin{array}{l}\text { Paper and electronic based } \\
\text { survey }\end{array}$ & Numeric data \\
Quantitative data analysis & $\begin{array}{l}\text { Data screening. ANOVA } \\
\text { and regression analysis }\end{array}$ & $\begin{array}{l}\text { Descriptive and inferential } \\
\text { statistics }\end{array}$ \\
$\begin{array}{l}\text { Interview protocol } \\
\text { development }\end{array}$ & $\begin{array}{l}\text { Selecting sample based in } \\
\text { responses and variation }\end{array}$ & Focus group protocol \\
Qualitative data collection & $\begin{array}{l}\text { Focus groups in-depth } \\
\text { interviews }\end{array}$ & $\begin{array}{l}\text { Focus groups transcripts } \\
\text { and data }\end{array}$ \\
Qualitative data analysis & $\begin{array}{l}\text { Coding and thematic } \\
\text { analysis }\end{array}$ & $\begin{array}{l}\text { Thematic matrix and } \\
\text { elaboration of stories }\end{array}$ \\
Integration of methods & $\begin{array}{l}\text { Interpretation and } \\
\text { explanation }\end{array}$ & $\begin{array}{l}\text { Corollaries or meta- } \\
\text { inferences }\end{array}$ \\
\hline
\end{tabular}

Note. Information from Creswell and Clark (2011).

In order to assure the above objective, the study took place at business schools in three countries: Costa Rica, Spain, and the United States. As explained in Chapter Two, according to project GLOBE (House, 2011), each of these sites presumably has identifiable and distinctive cultural dimensions. For example, Costa Rica belongs to the Latin American cultural cluster, which, according to project GLOBE, scores high on power distance and in-group collectivism and low on performance orientation and uncertainty avoidance. Spain represents what GLOBE calls the Latin European cultural cluster, which scores medium on power distance, in group-collectivism, performance orientation, and uncertainty avoidance. Finally, the United States is the most important country in what GLOBE calls the Anglo cultural cluster, which scores high on 
individualism, performance orientation, and uncertainty avoidance and low on power distance.

In short, each of these sites yielded a sufficient number of students representing a unique and distinctive culture and, as such, could shed light on whether views regarding factors that affect CSR differ across cultural clusters and how, if at all, cultural dimensions relate to those views. It is important to highlight that the unit of analysis was the particular cultural cluster to which the individual MBA student belonged, not the business school. Thus, students were grouped according to their cultural cluster criterion, regardless of the business school they attended. More details on this will be provided in the participant selection section that follows.

The sample also can be considered, at least in part, a convenience sample. I have had a long professional and personal relationship with the business schools selected, which allowed broader access to professors, students, and the institutions' facilities.

Site selection. The first research site was the INCAE Business School, located in San José, Costa Rica. This business school, founded in 1963 in partnership with the Harvard Business School, is considered one of the top institutions for business education in Latin America. The school's MBA student body is composed primarily of Latin Americans who represent more than 20 countries in the region. All students who participated at INCAE were from the Latin American cluster, which provided a valuable perspective in the effort to determine whether there was a relationship between the Latin American cultural dimensions and motives toward CSR and, if so, what that relationship was. 
The second research site was the ESADE Business School, located in Barcelona, Spain. This institution was founded in 1958 when a group of Spanish entrepreneurs and the Catholic order of the Jesuits joined forces to create the first business school in the country. Even though the school's student body is international, the majority of the students are from what project GLOBE categorizes as Latin Europe. In fact, a majority of the students at ESADE constituted a representative sample of a cluster that is shaped by the four cultural dimensions that were the object of this study.

The third and final institution was the graduate business school at the University of San Diego (USD), California. This Catholic institution was founded 40 years ago and, according to the Financial Times, ranks among the top 100 business schools in the world (Financial Times, 2015). The regional and homogeneous student body of the institution, comprised primarily of American students, made it a good site in which to explore the Anglo cluster identified in project GLOBE, providing a rich glimpse into how those influenced by these cultural dimensions perceive CSR and the factors that influence its practice.

It is important to highlight that the site selection was critical to assure the number of necessary students from each cultural cluster. However, the context in which the business school is located could influence the attitudes of students who did not belong to that cultural cluster and were, therefore, grouped in a different one. For example, an Anglo student attending the ESADE Business School who was grouped in the Anglo cluster could have different attitudes than one who has never traveled outside of the United States. The limitations section in Chapter Five addresses this issue in more detail. 
Participant selection. All participants who were invited to participate in the study were full-time MBA students. To be assigned to a particular cultural cluster, both the students and the parents who raised them had to have been born in a country that belongs to the specific cultural cluster. A total of 290 students completed the surveys.

At INCAE, 107 students, all from the Latin American cluster, completed the survey, resulting in a response rate of $63.3 \%$ of the entire MBA population. At ESADE, 110 students completed the survey, resulting in a response rate of $66.0 \%$ of the entire MBA population. Of these 110 students, 63 met the criteria to be included in a specific cultural cluster, with the breakdown as follows: Latin European cluster-45, Anglo cluster-six, and Latin American cluster-12. Forty-seven of these students came from a variety of other cultures and were thus not included in this study.

At USD, 72 students completed the survey, resulting in a response rate of $37.0 \%$ of the entire MBA population. In this case, 46 were representative of the Anglo cluster, four met the criteria to be considered Latin Americans, there were no Latin Europeans, and there were 22 students from diverse parts of the world. As noted, data from students not belonging to the cultural clusters that were the object of this study were discarded. Thus, the final count of valid surveys per cultural cluster can be seen in Table 2 .

Table 2

Number of Responses by School and Cultural Cluster

\begin{tabular}{lcccc}
\hline & INCAE & ESADE & USD & Total \\
\hline Anglos & 0 & 6 & 46 & 53 \\
Latin American & 107 & 12 & 4 & 123 \\
Latin European & 0 & 45 & 0 & 45 \\
Others & 0 & 47 & 22 & 69 \\
\hline Total & 107 & 110 & 72 & 290 \\
\hline
\end{tabular}


As noted earlier, while there is a potential for a contextual effect on students who attended school outside of their cultural cluster, Table 2 reveals that these numbers are quite small. This will be addressed more specifically in the limitations in Chapter Five.

Those who responded to the survey at each site were invited to participate in the qualitative focus group phase of the study and were notified that the first 15 students to accept the invitation were going to be selected. This method of selection of similar and active participants is what Patton (2002) calls purposeful intensity homogenous sampling, which elicits broader responses from a small sample of those who were surveyed to better understand how they make meaning of quantitative results. Discussions at each site were quite rich, as students knew each other because they had taken one or more courses together. Morgan (1998) points out that having participants in focus groups who know each other and belong to a particular organizational setting (in this case, each business school) is highly desirable because it "re-creates part of the context that you are trying to understand" (p. 49).

This method of selection did not assure that all participants in each site belonged to the cultural cluster that was the object of the study nor did it provide a representative sample of the students who took the survey because the main motivation to participate in the focus groups was student interest in the subject.

At INCAE, since all survey participants were Latin Americans, the 14 students who participated in the focus group were also Latin Americans. At ESADE, 12 students participated in the focus group. However, only nine students were representative of the Latin European cluster, one was from India, and two were from Japan. Similarly, at USD, 10 students participated in the focus group, but only eight students could be 
identified as belonging to the Anglo cluster, with one from India and the other from the Latin American cluster. Notes were taken to single out and discard the comments and opinions from those students who did not belong to the specific cultural cluster since the object of the study was to understand the specifics of each cultural cluster. However, this diversity of students at ESADE and USD probably had an effect on the group's overall dynamic and results, given that the rules of a focus group are that all members have an equal voice (Morgan, 1998). This issue is addressed in more detail in the limitations section of Chapter Five of this study.

\section{Instruments and Data Collection}

As explained above, an explanatory mixed methodology often consists of one quantitative phase followed by a qualitative one. For this study, the quantitative data collection was obtained through the use of a paper survey administered onsite at INCAE and ESADE and an electronic Qualtrics survey sent to the entire MBA student list at USD. As mentioned earlier, the qualitative data were gathered through focus group interviews, which took place onsite at each business school.

Phase one: Survey. Because this study represented an initial attempt to learn about known concepts from a population, such as motives toward CSR and views of the described meso- and endo-factors that influence its practice, a survey was a highly appropriate method of data collection (Fowler, 2014). Additionally, Fowler (2014) contends that surveys are an excellent tool for self-reporting personal feelings and attitudes, while avoiding interviewer-induced bias, particularly when the participants are insightful and cooperative — characteristics that were expected from graduate college students who are invested in their education. 
The questions posed in the survey instrument of this study (see Appendix A) were compiled from several sources. Some questions were drawn from preexisting surveys that have successfully analyzed different dimensions regarding business ethics and CSR in different parts of the world (Alas, 2006; Churchill, 1979; Kraft \& Singhapakdi, 1995; Sigurjonsson, Vaiman, \& Arnardottir, 2014; Singhapakdi et al., 1996). Other questions were adapted from surveys of the Pew Research Center (2014a) and the World Values Survey (2012) that have measured people's attitudes regarding their preferred economic model, their level of acceptance of government regulation, and their attitudes toward the role of other social players in society. The cultural dimensions questions were derived from both Hofstede et al.'s (2010) cultural surveys and project GLOBE (House et al., 2004). The remainder of the questions generated data about the demographics of the participants.

The reputation of the research-oriented institutions from where the survey items were derived provided a certain level of reliability and face and content validity to the questionnaire (Fowler, 2014). In fact, the questions derived from GLOBE (House et al., 2004), the World Values Survey (2012) and the Pew Research Center (2014a) have demonstrated Cronbach's alpha reliability scores over .80 .

Moreover, to assure the soundness and proper understanding of the different constructs contained in the research questions, the survey was piloted with a select group of 14 doctoral students from the USD School of Leadership and Educational Sciences. While these students were not archetypal of the MBA students who were the object of this study, their expertise in the constructs to be surveyed and their doctorate methodological training enabled them to provide valuable feedback, resulting in greater 
face and content validity for the survey. This pilot test led to the refinement and adjustment of some of the questions before the survey was taken to the field.

The survey questions were written in both English and Spanish. Some translation problems might have created differences in how information was processed and questions answered (Hantrais \& Mangen, 2007). However, my own cultural background and linguistic knowledge served to minimize possible cross-cultural misinterpretations of the constructs studied due to language translation problems and the culturally influenced idiosyncratic interpretation of the concepts.

The survey was structured in seven segments that contained 52 questions. First there was an introduction that contained both the local business school and USD logos (in order to provide credibility) and asked for the student's help-factors that have shown to increase response rates and data accuracy (Dillman, Smyth, \& Christian, 2009). The introduction to the survey closed with assurances about the confidentiality and anonymity of the instrument and the time it would take to complete it, highlighting that there were no wrong or right answers (see Appendix A).

The first section (see Appendix A) contained four questions regarding the student's understanding of the CSR construct, the number of courses that the participant had taken related to the subject, the exposure to ethical issues in the core business courses the student had taken, and his or her participation in social betterment activities. The overall objective of this section was to measure the student's exposure to the subject that was being investigated (i.e., CSR and responsible business leadership practices) Also, a definition of CSR was provided to help assure that all respondents operationalized the construct in a similar way for the purpose of the survey. 
The second section (see Appendix A) contained eight items regarding the degree to which the student held normative or utilitarian motives regarding CSR (the endo-factor of the IMCSR). A 7-point Likert scale was used to measure the participant's level of agreement with sentences that addressed the belief-related items in this section. For questions five, seven, eight, 10, and 12, the higher the level of agreement, the stronger the relativity, or profit orientation, of CSR beliefs that the respondent held. For questions six, nine, and 11, reverse scores were used to produce the opposite effect, that is, the higher the level of agreement, the weaker the relativity of the CSR beliefs.

Each of sections three, four, and five (see Appendix A) contained eight items and also used a 7-point Likert scale to explore the student's views toward the three mesofactors, which assessed their preferred economic model, the societal and stakeholders' role, and the government regulation level in modeling business behavior. For the first five questions of each section, the higher the level of agreement with the stated questions, the stronger the participant's belief in the role of these factors in shaping business leaders' socially responsible behavior. The last three questions of each of these sections used reverse scores.

Section six (see Appendix A) contained 12 questions, three for each of the cultural dimensions that this study measured at the individual level. Questions one, five, and nine referred to the level of performance orientation; questions two, six, and 10 referred to in-group collectivism; questions three, seven, and 11 referred to uncertainty avoidance; and questions four, eight, and 12 referred to power distance.

The final section (see Appendix A), which was placed at the end to retain the participant's interest, contained four demographic questions addressing gender, country 
in which the student and his or her parents were born, country in which the student was socialized, and age. Table 3 shows a sample of the survey questionnaire with one question for each of the four constructs and the four cultural dimensions that were explored.

Table 3

Sample of Survey Items for Each of the Factors Under Study

\begin{tabular}{|c|c|}
\hline Construct & Survey Item Sample \\
\hline $\begin{array}{l}\text { Normative versus } \\
\text { utilitarian view of CSR }\end{array}$ & $\begin{array}{l}\text { Businesses should participate in socially responsible } \\
\text { practices only if a profit can be made from it }\end{array}$ \\
\hline Societal role & $\begin{array}{l}\text { Corporations should openly report their CSR activities to } \\
\text { the public }\end{array}$ \\
\hline Economic model & Governments are almost always wasteful and inefficient \\
\hline Performance orientation & $\begin{array}{l}\text { In this society, mayor rewards are based on performance } \\
\text { rather than seniority or political connections }\end{array}$ \\
\hline Uncertainty avoidance & $\begin{array}{l}\text { The way to be successful in this society is to plan ahead, not } \\
\text { take life events as they occur }\end{array}$ \\
\hline In-group collectivism & $\begin{array}{l}\text { In this society, children generally live at home with their } \\
\text { parents until they get married }\end{array}$ \\
\hline Power distance & $\begin{array}{l}\text { In this society, subordinates are generally afraid to express } \\
\text { disagreement with their bosses }\end{array}$ \\
\hline
\end{tabular}

Phase two: Focus group interviews. According to Morgan (1998), the dynamic of focus groups allows one to further explore quantitative research data such as that which was obtained in phase one of this study. Also, he indicates that a focus group is a time-efficient instrument because, in a short period of time, participants with similar backgrounds and interests can interact to further explore elaborated constructs. In short, 
in this phase, the participants' rationale and ways of thinking regarding the quantitative results were explored in much more detail (Creswell \& Clark, 2011).

For each site, the focus group was conducted at a facility with recording capabilities to assure that participants' comments were accurately captured and transcribed in full. To promote a more systematic and comprehensive discussion, data were collected following the qualitative general interview guide approach. Patton (2002) states that this method allows one to center the discussion on the research topic, demarcating the subjects to be investigated but also allowing for spontaneous responses. Thus, a general interview guide was used as an outline from which information about the survey results were structurally explored, while leaving free time to pursue the unforeseen topics that came up in this multifaceted study.

In order to bring greater trustworthiness to the information gathered, member checking of the information after each of the focus groups was conducted with a selected group of the participants (Glesne, 2011). That is, a couple of students from each site read the focus group transcripts to attest to their accuracy. The interview guide at each site was based on both the theoretical model derived from the literature and the quantitative data generated from the cultural cluster at each business school. The entire interview guide can be found in Appendix B.

\section{Data Analysis}

Data analysis for this research study consisted of three distinct phases. The first phase involved analyzing the quantitative data using statistical analysis methods to derive descriptive and inferential information. The analyses of these statistics informed the data collection for the qualitative research. The second phase involved analyzing how the 
qualitative data helped explain and enrich the quantitative findings. The third phase involved the consolidation of these two strands of data analysis to generate corollaries, or what Teddlie and Tashakkori (2009) define as meta-inferences. A description of each of these phases follows.

Phase one: Survey data analysis. After the paper and electronic surveys were completed at each site, the raw data were manually grouped and categorized before being exported to IBM SPSS statistical software 22.1 to generate the descriptive and inferential statistics required to answer the research questions.

The descriptive part included the number of students, gender breakdown, country of origin, age, and major. The inferential part of the survey analysis consisted of four steps. In the first step, the main statistical assumptions that supported the validity of the data were run. In the second step, eight ANOVA analyses were run to determine the students' motives and views regarding each of the endo-, meso-, and ecto-factors and the differences, if any, between the three cultural clusters for each one of these factors, which addressed research question one. In the third step, five regression analyses were run to determine the possible relatedness between the factors that support CSR, according to the ICSRM, which addressed research question two. In the final step, other findings related to gender, specialization, and years of work experience were analyzed. A detailed description of these four steps follows.

Statistical assumptions. To effectively run ANOVA and multiple regression analyses, the data have to comply with certain statistical assumptions. The following tests were run to check these rules: presence of outliers, normal distribution of the data, 
homogeneity of variance, independence of observations, homoscedasticity and linear relationships, and multicollinearity.

Differences in students' motives and views. The ICSRM posits that there are eight factors that seem to influence CSR behavior. Specifically, these factors are:

- Endo-factor CSR: the degree to which the students have a normative versus a utilitarian view of CSR.

- Meso-factor society: the degree to which students believe that different stakeholders have an influence on a business leader's socially responsible behavior.

- Meso-factor economy: the degree to which students believe that the economic and political models have an influence on a business leader's socially responsible behavior.

- Meso-factor regulation: the degree to which students believe that the level of regulation and the institutional strength of the nation have an influence on a business leader's socially responsible behavior.

- Ecto-factor performance: the degree to which students believe they are motivated by performance orientation.

- Ecto-factor collectivism: the degree to which students believe they are collectively or individually motivated.

- Ecto-factor uncertainty: the degree to which students believe they are motivated by uncertainty avoidance.

- Ecto-factor power: the degree to which the students believe they are motivated by their perspective of power distance. 
For each one of these factors, a one-way ANOVA was run using SPSS to determine if there were significant variations between the mean scores of the three groups of students regarding each of the dependent variables. Consistent with well-established standard operating procedures, the null hypothesis, which states that there is no significant variation between the groups and, if there is, it is due to variations within each group, not among them, was tested. In other words, the null hypothesis implies that the dependent variables, which are the endo-, meso-, and ecto-factors, do not change across cultural dimensions. To reject the null hypothesis, an $F$-test statistic was calculated and compared with its $F_{\mathrm{cv}}$ at $\alpha=0.05$ (Meyers, Gamst, \& Guarino, 2013).

If a significant level of variation was determined, then a Tukey post-hoc test analysis of multiple comparisons was run to establish where the differences between the groups lied. Also, a measure of association, or $\omega^{2}$, was run to determine the strength of the relationship between the independent and dependent variable, that is, the proportion of the variance in the endo-, meso-, or ecto-factors that is accounted for by the cultural cluster to which the students belong (Meyers et al., 2013).

Relatedness between the ICSRM factors. Research question two in this study addressed the gap in the CSR literature regarding the possible influence, if any, of certain cultural dimensions on MBA students' motives toward CSR and/or their views regarding the factors that influence its practice. Additionally, the ICSRM posits that all these factors might be interrelated and have an effect on the students' personal motivation toward CSR. To answer these questions, four regression analyses and one hierarchical regression analysis were run using SPSS. For the first four regression analyses, the independent variables were the individual students' cultural beliefs regarding 
performance orientation, collectivism, uncertainty avoidance, and power distance and the dependent variable was each of the endo- and meso-factors.

For the hierarchical regression, the dependent variable was the students' view toward CSR, and the independent variables were all the meso- and ecto-factors. Gender was also included as an independent variable in all regressions. Since, in this case, the unit of analysis was the individual student's motives and views regarding CSR and the factors that influence its practice, regardless of the cultural cluster to which the student belonged, all students who completed the survey were included in the analyses. A detailed explanation of each regression follows.

1. Endo-factor CSR to all four ecto-factors: The regression model assessed how MBA students' views regarding performance orientation, collectivism, uncertainty avoidance, and power distance influenced whether they were motivated by either a normative or utilitarian approach toward CSR.

2. Meso-factor society to all four ecto-factors: The regression model assessed how the MBA students' views regarding performance orientation, collectivism, uncertainty avoidance, and power distance influenced their attitudes regarding the role that civil organizations should play in promoting CSR activities in businesses.

3. Meso-factor economy to all ecto-factors: The regression model assessed how MBA students' views regarding performance orientation, collectivism, uncertainty avoidance, and power distance influenced their attitudes regarding the spectrum of a centrally controlled and planned economy on the one end to a totally free market on the other. 
4. Meso-factor government regulation to all ecto-factors: The regression model assessed how MBA students' views regarding performance orientation, collectivism, uncertainty avoidance, and power distance influenced their attitudes regarding the level of governmental laws and regulations that affect businesses and their CSR activities.

5. CSR motive to all ecto- and meso-factors: In this hierarchical regression, model one assessed how MBA students' views regarding all three mesofactors (society, economy, and government) influenced whether they were motivated by a normative or utilitarian view of CSR. In model two, the ectofactors (performance orientation, collectivism, uncertainty avoidance, and performance orientation) were added as independent variables in order to determine whether this improved the prediction of motivation toward CSR over and above the meso-factors alone.

Other findings. The survey included demographic questions regarding the students' specialization, years of work experience, and gender. To determine differences among students within these categories regarding their motivation toward the endo-factor CSR, one ANOVA and two independent samples $t$-test comparisons were also run.

Phase two: Focus groups data analysis. The purpose of this phase was to explore and understand how the participants made meaning of the results from the quantitative phase. To this end, the researcher employed what Myers (2013) describes as a top-down approach of analysis. That is, the theoretical factors that seem to affect CSR activities, which were presented in Chapter One (see Figure 1) and represented in the quantitative research questions, were initially used to generate categories and codes for 
organizing and indexing the focus group interview transcript. This made sense because the survey was structured and based on the endo-, meso-, and ecto-factors described in the ICSRM, and the students' responses were linked to these categories.

The participant comments made during the focus group interview were transcribed verbatim. Because the amount of qualitative data from three focus groups was relatively small (three focus groups of approximately 90 minutes each), no software was necessary to analyze the limited amount of information. Rather, as was explained above, a content analysis based on factors that drive CSR behavior was plotted in a twoaxis matrix. This process was a combination of what Saldaña (2013) describes as in-vivo coding followed by axial coding to find the dominant themes across the three different cultural cluster groups. In Figure 3, the vertical side represents the four categories that make up the endo- and meso-factors that seem to promote CSR, according to the IMCSR (normative and utilitarian factors, stakeholders influence, government regulation, and economic model), plus an extra column for other unidentified factors based on participant response. The horizontal axis represents the cultural clusters that were the object of this study, which theoretically represented the ecto-factors in the IMCSR (Figure 1).

A sample of the categorizing and coding that took place using this matrix follows.

1. Ethical reasons or business opportunities were categorized as an endo-factor and coded as normative/utilitarian.

2. Social pressure was categorized a meso-factor and coded as stakeholders' influence.

3. Laws were categorized as a meso-factor and coded as government regulation. 


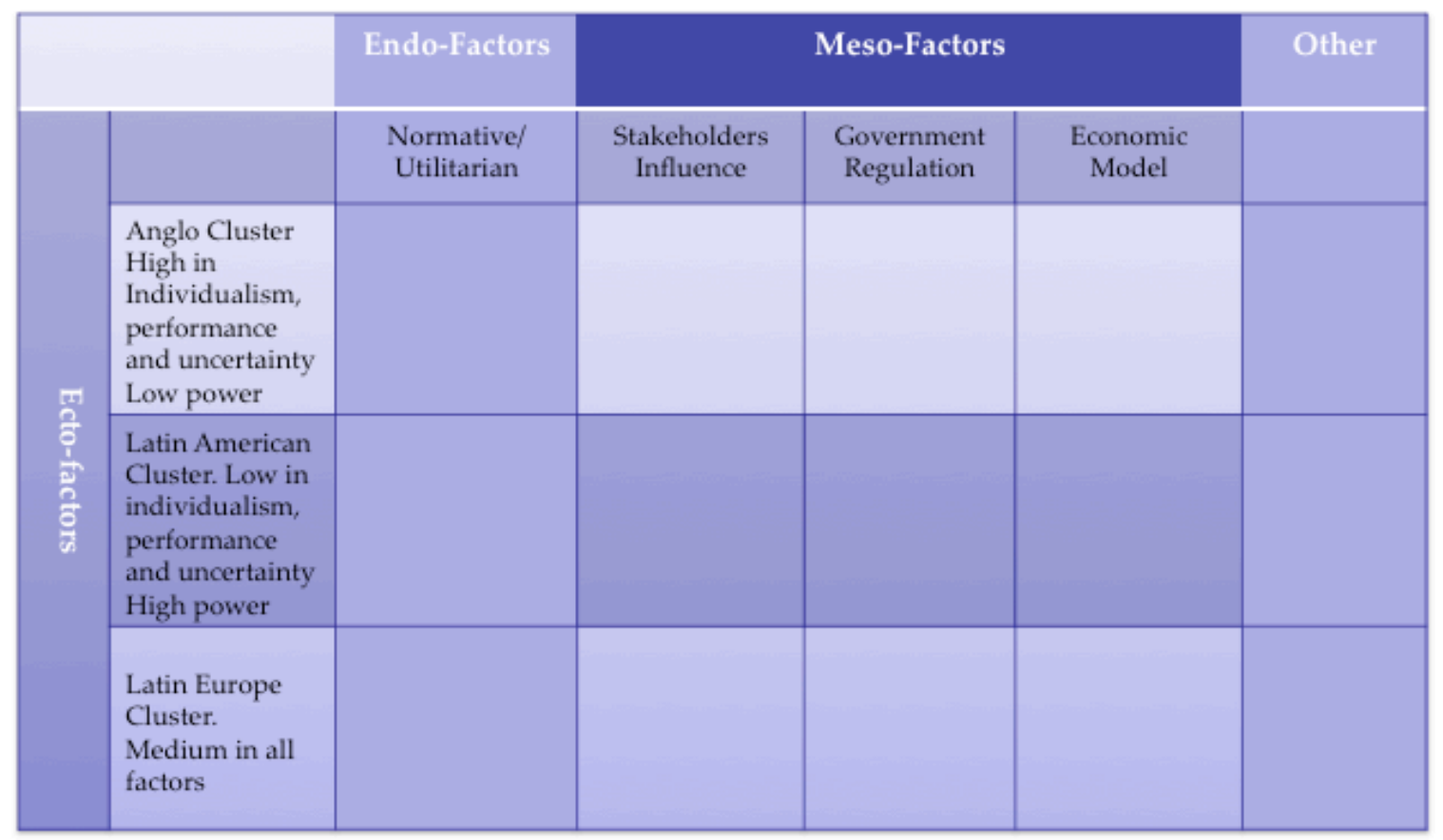

Figure 3. Focus group data analysis.

4. Free market policies were categorized as a meso-factor and coded as economic model.

5. Other factors were categorized as other and coded as unidentified factors.

Once the matrix was completed in the above manner, the validity of the groupings was verified using Patton's (2002) concepts of internal homogeneity, which calls for holding together the data that belong to a group in a significant way, and of external heterogeneity, which verifies that the differences among categories are well defined.

The information plotted in the final matrix then served to create fictional stories drawn from focus group comments that describe the meaning that the participants attributed to the quantitative results. In these stories three imaginary students, each representing one of the cultural clusters that were the object of the study, interact using the actual comments from the focus groups, creating a plot that deepens the 
understanding of each of the endo-, meso-, and ecto-factors. This approach to qualitative research is what Polkinghorne (1995) describes as narrative analysis, that is, the creation of coherent stories based on different elements of the data gathered during the data collection that produces an interesting and explanatory description of the phenomena. $\mathrm{M}$. S. Feldman, Sköldberg, Brown, and Horner (2004) argue that stories are the best way to understand organizational life because they are the basic tool that individuals use to communicate and make sense of situations. Myers (2013) provides several examples that illustrate the explaining power that this technique has in business matters, above and beyond the use of solely quantitative data. He argues that stories can be combined with quantitative research without compromising the richness of the qualitative data or the robustness of the statistical data.

Phase three: Corollaries. In this final phase, the quantitative and the qualitative data were consolidated and integrated to generate corollaries, or what some scholars call meta-inferences (Teddlie \& Tashakkori, 2009). This was equivalent to qualitizing quantitative data, which enriched the interpretation of the quantitative findings by using the more in-depth information that the qualitative phase generated (Creswell \& Clark, 2011). In this way, the study sought to integrate all the data into a coherent whole for each of the endo-, meso-, and ecto-factors.

This concludes the methodology section of this study. The chapters that follow explain the findings regarding these issues for each of the cultural clusters and discusses their applicability to CSR teaching and practice. 


\section{CHAPTER FOUR}

\section{FINDINGS}

Exploring and analyzing business students' attitudes toward CSR is a complex endeavor. This becomes even more challenging when the particular cultural beliefs and values of the MBA students are taken into consideration. This study addresses these challenges by attempting to measure and explain the differences, if any, between the motives and views of MBA students from three different cultural clusters regarding certain factors that influence CSR behaviors as well as the possible relationships among these factors. To that end, as previously noted, this study applied an explanatory mixed methods approach that first yielded quantitative data, followed by a qualitative phase that refined and deepened the understanding of these phenomena. This chapter will describe the statistical findings that emerged from the surveys as well as the meanings that the MBA students in the focus groups attributed to the survey results, as described in the previous chapter.

\section{Overview of Purpose and Research Questions}

The purpose of this study was to generate empirical data regarding the relationship, if any, between four specific cultural dimensions and MBA students' motives toward CSR and their views regarding the factors that appear to affect the promotion of CSR and SRBL. This is depicted in the ICSRM presented in Figure 1 of Chapter One. 
Specifically, the following research questions were investigated:

1. How do business students from three different cultural clusters differ, if at all, in their motives toward and views regarding the factors that support CSR, according to the ICSRM?

a. In what ways, if any, do students' motives toward CSR, as defined by the endo-factor (normative and utilitarian), differ?

b. In what ways, if any, do students' views regarding the meso-factors (societal, economic, and regulatory) differ?

c. To what degree, if at all, do students' cultural dimensions, referred to as ecto-factors (collectivism, power distance, performance orientation, and uncertainty avoidance), differ?

2. How do individuals from each of the three cultural clusters make meaning of the factors that support CSR, according to the ICSRM?

3. To what degree, if at all, do cultural dimensions relate to business students' motives toward and views regarding the factors that support CSR, according to the ICSRM?

a. To what degree, if at all, do cultural dimensions relate to business students' motives toward CSR, as defined by the endo-factor (normative and utilitarian)?

b. To what degree, if at all, do cultural dimensions relate to business students' views regarding the meso-factors (societal, economic, and political)? 
c. How do individuals from each of the three cultural clusters make meaning of the relationship between the cultural dimensions and the factors that support CSR, according to the ICSRM?

As noted in the research questions, the unit of analysis for this study was the individual MBA students grouped in a certain cultural cluster, regardless of which business school they attended. Therefore, this chapter unfolds as follows: First, participant demographics are presented by business schools, followed by a display of the data according to the three cultural clusters that were the object of this study. Based upon these groupings, the general statistical assumptions required for data analysis are examined. Next, a general summary of the ANOVA results in order to offer an overview of the differences regarding the students' motives and views for each one of the endo-, meso-, and ecto-factors presented in Figure 1 is presented, followed by a detailed explanation of each factor. After this description of the results for each cultural cluster, the relatedness between the factors using six multiple regression analyses is explored. The chapter ends with a presentation of other findings derived from the surveys as well as concluding remarks that will serve as a frame for the discussion chapter that follows.

\section{Survey and Focus Group Participants}

Three business schools located in countries with distinctive cultural dimensions were purposefully selected. The objective was to obtain a substantial number of MBA students who were archetypal of the cultural clusters, as defined in project GLOBE and explained in Chapter Two, which were the object of the study (Patton, 2002). The research sites were the campuses of INCAE Business School in Costa Rica and Nicaragua, representing the Latin American cluster; the ESADE Business School located 
in Barcelona, Spain, representing the Latin European cluster; and the business school of the University of San Diego in California, representing of the Anglo cluster.

From the field research, a total of 290 surveys from the three business schools were obtained. However, due to the criteria upon which students were assigned to a cultural cluster, ${ }^{9}$ there were only 221 valid surveys for the purpose of this study. It is important to note that since the sample size for each cultural cluster was not the same, this produced an unbalanced design. However, the SPSS program automatically detected this issue, making the necessary adjustments to the output. Table 4 provides an outline of these results. Other demographic information for the participants, including their gender, age, work experience, specialization, and country of identity can be found in Appendix C.

Table 4

Number of Responses by School and Cultural Cluster

\begin{tabular}{lcccc}
\hline & INCAE & ESADE & USD & Total \\
\hline Anglos & 0 & 6 & 46 & 53 \\
Latin American & 107 & 12 & 4 & 123 \\
Latin European & 0 & 45 & 0 & 45 \\
Others & 0 & 47 & 22 & 69 \\
Total & 107 & 110 & 72 & 290 \\
Response Rate & 63.3 & 66.0 & 37.0 & 55.3 \\
\hline
\end{tabular}

Note. Response rate is the percentage of students who completed the survey out of the total MBA list from each school.

\section{Statistical Assumptions}

Before the specific and detailed results for each of the research questions are presented, it is important to review the main statistical assumptions that support the

\footnotetext{
${ }^{9}$ For a survey to be considered valid, the student had to be born and raised by parents who were also born in a country that belongs to the specific cultural cluster.
} 
validity of the data. To effectively run ANOVA and multiple regression analyses, the data have to comply with six statistical assumptions, which are addressed below.

Presence of outliers. There were a few individual responses that could be considered outliers in the data, as assessed by inspection of boxplots for values greater than 1.5 lengths from the edge of the box. That is, outliers are responses that fall well away from the mean of the distribution. For example, the mean of the students' motives toward CSR was 3.30 and the average standard deviation was 0.64 , but there were a few responses with scores close to 1 or to 7 . Specifically, there were seven outliers in the corporate social responsibility factor, three in the society factor, four in the economy factor, three in the regulation factor, four in the performance factor, five in the collectivism factor, two in the uncertainty factor, and four in the power distance factor. Since all of these outliers were less than 2 standard deviations from the mean and they represented a very small portion of the total data, albeit an important one, they were included in the analysis.

Normal distribution of the data. Several tests were run to test the normal distribution of the data. First, as assessed by the Wills-Shapiro test $(p>.05)$, all scores were normally distributed. Also, a visual inspection of the histograms and the normal QQ tests for each of the factors showed normally distributed curves. For the regression analysis, P-P plots were run to check the standardized residuals, confirming that the residuals were normally distributed.

Homogeneity of variance. The Levine test for homogeneity of variance was run for each one of the factors. There was homogeneity of variance for all the factors $(p>$ $.05)$ except for the ecto-factor collectivism $(p=.047)$. Since only one factor failed to 
meet this test and the $p$ value was close to 0.05 , the study did not include the GamesHowell posttest for the multiple comparison analysis because the Tukey post-hoc test for multiple comparisons should suffice.

Independence of observations. There was independence of residuals (the difference between the observed and the predicted values) as assessed by a DurbinWatson statistic of 2.007, which is almost identical to the ideal critical value of 2.0. This means that the distribution of errors was random and not correlated to errors in prior observations; thus, the model had predictive validity.

Homoscedasticity and linear relationships. Scatter plots of standardized residuals versus unstandardized predicted values and partial regression plots were run. The graphs showed a somewhat linear relationship for all the factors. This means that the variance around the regression line was basically the same for all values of the predictor variable, confirming the predictive validity of the model.

Multicollinearity. None of the independent variables showed correlations greater than .70. More importantly, all variance inflation factor (VIF) values were between 1.04 and 1.29 (VIF values greater than 10 are problematic), confirming that there was no collinearity or multicorrelations between the predictor variables in this dataset. This assumption is particularly relevant to assess the degree to which each independent variable by itself has a predictive capacity.

Having confirmed that the data did not violate the statistical assumptions necessary to fit the ANOVA and regression models, the next section presents the results related to the differences in students' motives and views by cultural groups regarding the 
endo-, meso-, and ecto-factors and the relatedness among these factors, as articulated in the research questions for this study.

\section{Differences in Students' Motive and Views}

The presentation of results of this section begins with a general summary of the ANOVA results in order to offer an overview of the differences regarding the students' motives and views for each one of the endo-, meso-, and ecto-factors. These results provide a valuable framework for delving into the specifics of each of the factors for each cultural cluster. However, since ANOVA model only tells whether groups in the sample differ but not which ones, then the results of a more detailed Tukey post-hoc test for multiple comparisons that shows which groups have significant differences will be presented.

Table 5 summarizes the ANOVA results for each one of the factors. As can be seen, there were no statistically significant differences across cultural clusters in motives toward the endo-factor CSR (normative versus utilitarian attitude) and views regarding the meso-factor regulation (level of required business regulation), and thus the null hypothesis cannot be rejected $(p>.05)$. This means that all the students, regardless of their cultural background, had similar attitudes toward CSR and toward the level of government regulation in business activity.

For the remaining six factors, there were significant statistical differences across cultural clusters and thus the null hypothesis could be rejected $(p<.05)$, indicating that the populations differed from one another. That is, the students' views about the mesofactors regarding the role of society as watchdog of business behavior and the ideal 
economic model to promote CSR differed. Similarly, the students' views regarding the four ecto-factors - performance orientation, collectivism, uncertainty avoidance, and Table 5

Summary of ANOVA Results

\begin{tabular}{|c|c|c|c|c|c|c|}
\hline Factors & & Cluster & $M$ & $S D$ & $F$ & $p$ \\
\hline \multirow[t]{3}{*}{ Endo } & CSR & LE & 3.38 & 0.68 & .89 & .409 \\
\hline & & LA & 3.33 & 0.67 & & \\
\hline & & $\mathrm{A}$ & 3.21 & 0.59 & & \\
\hline \multirow[t]{9}{*}{ Meso } & Society & LE & 5.07 & 0.65 & 6.47 & $.002 *$ \\
\hline & & LA & 5.53 & 0.71 & & \\
\hline & & A & 5.38 & 0.77 & & \\
\hline & Economy & LE & 4.29 & 0.57 & 7.43 & $.001 *$ \\
\hline & & LA & 4.74 & 0.69 & & \\
\hline & & $\mathrm{A}$ & 4.41 & 0.97 & & \\
\hline & Regulation & LE & 3.05 & 0.85 & 1.75 & .840 \\
\hline & & LA & 3.04 & 0.65 & & \\
\hline & & $\mathrm{A}$ & 2.98 & 0.74 & & \\
\hline \multirow[t]{12}{*}{ Ecto } & Performance & $\mathrm{LE}$ & 5.44 & 0.69 & 28.81 & $.000 * *$ \\
\hline & & LA & 6.17 & 0.63 & & \\
\hline & & A & 5.46 & 0.83 & & \\
\hline & Collectivism & $\mathrm{LE}$ & 3.59 & 0.75 & 33.00 & $.000 * *$ \\
\hline & & LA & 4.61 & 1.03 & & \\
\hline & & A & 3.62 & 0.71 & & \\
\hline & Uncertainty & LE & 3.92 & 1.01 & 23.62 & $.000 * *$ \\
\hline & & LA & 4.39 & 1.00 & & \\
\hline & & A & 3.30 & 0.84 & & \\
\hline & Power & LE & 2.17 & 0.72 & 6.21 & $.002 *$ \\
\hline & & LA & 2.60 & 1.04 & & \\
\hline & & A & 2.13 & 0.88 & & \\
\hline
\end{tabular}

Note. LE: Latin Europeans, $n=45$. LA: Latin Americans, $n=123$. A: Anglos, $n=53$. $* p<.05 . * * p<.001$. 
power distance - also differed. As mentioned previously, it is important to note that the ANOVA model determines only whether the mean scores across groups differ statistically, but it does not show where the differences between groups lie. Therefore, the study included Tukey's post-hoc tests for multiple comparisons and $\omega^{2}$ analyses to show the size of the effect of the cultural cluster on each factor (Meyers, 2013).

What follows is a discussion of the detailed quantitative results, with a reliance on data from the focus groups to demonstrate how the students made meaning of them. Thus, each set of quantitative data will be followed by a fictional story of three imaginary students, using comments made by participants in the focus groups from each of the sites that represent each of the cultural clusters, as defined in project GLOBE and explained in Chapter Three. These are: José representing the Latin American cluster, Pierre representing the Latin European cluster, and Claire representing the Anglo cluster. Although each of the opinions these fictional characters offer is based on actual quotes from students belonging to their respective cultural cluster as they participated in the focus group held at each site, they do not represent any one cultural cluster group member.

Endo-factor. The endo-factor considered here is the motivation of individuals within an organization toward the practice of CSR, which the literature suggests falls on a continuum. On one end is the deontological perspective in which a person seeks to comply with moral and ethical codes (normative), and, on the other, is a teleological calculus of utility motive (utilitarian) in which the individual pursues an economic return on socially responsible investments (Bowen, 1953; Carroll et al., 2012; Porter \& Kramer, 2006; Prahalad, 2010). 
For this factor, the lower the survey scores, the more normative the motive of the MBA student toward CSR. The higher the survey score, the more the student favored a return on the CSR investment.

The numbers. As can be seen in Figure 4, data for each group showed a balanced view between the normative and utilitarian motive regarding CSR. The three groups fell in the middle of the scale, with the Anglos showing a slightly more normative motive than the other two groups.

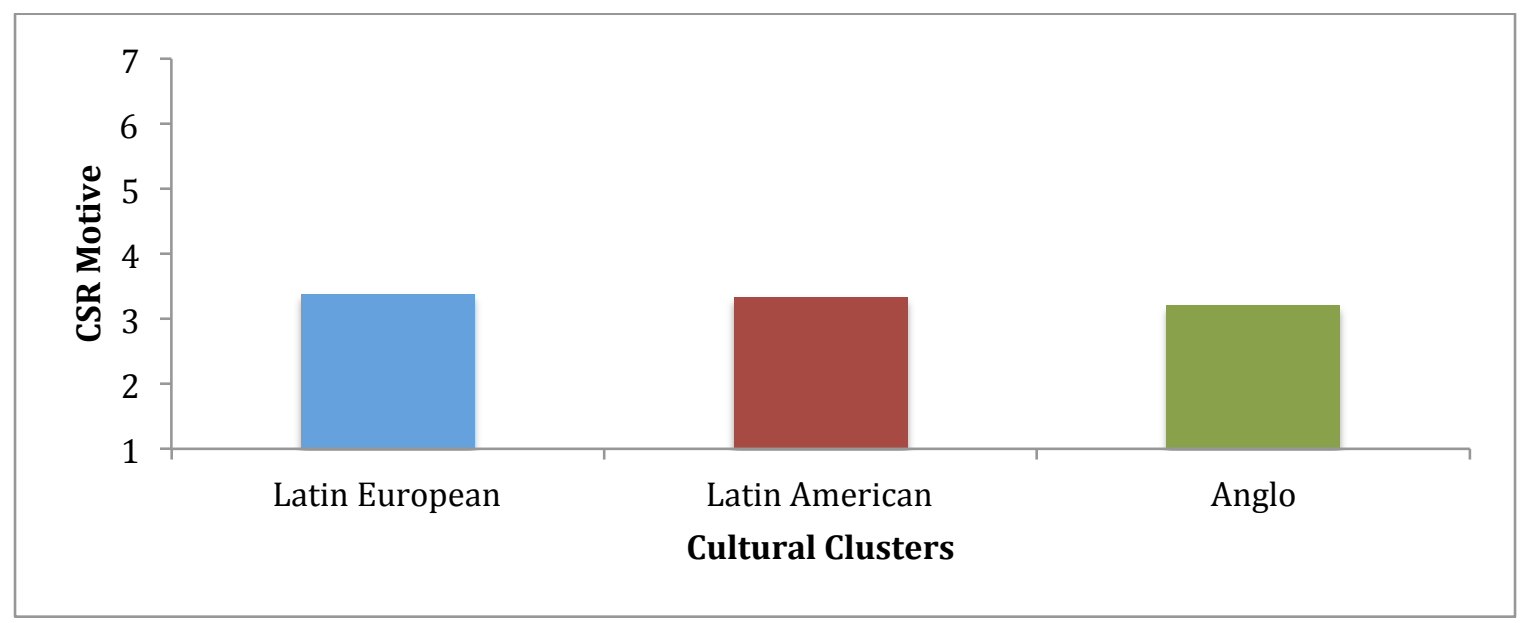

Figure 4. Means results for motive regarding CSR. Scale from 1 to 7 . One represents a normative motive regarding CSR, whereas 7 represents a more utilitarian one.

However, the ANOVA results shown in Table 6 indicate that there were no significant differences among the three groups, $F(2,219)=.899, p>.05$. Moreover, the relatively small standard deviations demonstrated a strong homogeneity within each group. Therefore, the Tukey post-hoc test that showed multiple comparisons were not significant. Similarly, the $\omega^{2}$ that showed the effect of the cultural clusters over the endofactor CSR was close to 0 . 
Table 6

ANOVA Results for Motive Regarding CSR

\begin{tabular}{lccccc}
\hline Cultural Cluster & $M$ & $S D$ & $F$ & $p$ & $\omega^{2}$ \\
\hline Latin European & 3.38 & 0.68 & & & \\
Latin American & 3.33 & 0.67 & .899 & .409 & N/A \\
Anglo & 3.21 & 0.59 & & & \\
Total & 3.31 & 0.65 & & & \\
\hline \multicolumn{2}{l}{ Tukey post-hoc Test: N/A } & & & & \\
\hline
\end{tabular}

The narrative that follows illustrates the meaning that the students attributed to these results and deepens understanding regarding the homogeneity between groups.

The story. José, Pierre, and Claire had just returned from an international job fair in which they interviewed for several companies. All three were excited because most of the companies were interested in continuing the interviewing process with them and they offered challenging and high paying positions. However, none of them knew which company held values that aligned with their own, which was a critical factor in their decision-making process. That evening, over dinner, the following conversation took place.

José was the first to comment: "You know, we have to be careful about trusting what companies publicly state regarding CSR; they might be just pretending in order to look good, but, in the end, they will put profits above all else."

Pierre looked at him thoughtfully and said: "Yes, you are right, but remember that different companies look at CSR and advertise it in very different ways. Maybe a petroleum company has to be more outspoken regarding environmental issues than a technology one, but they just do it to protect themselves, not as a social responsibility." 
Claire intervened, challenging Pierre: "Well, you might be right, but even if they do it to protect themselves and to avoid costs, it is a good thing. Just imagine if they did not care when an oil spill happened."

Pierre and José nodded at each other in agreement. José then commented: "It seems to me that it really does not matter what industry you are in; nowadays, there is so much awareness about social issues that if companies do not contribute in some way to solve them, then the problem will come back and bite them."

At that moment Claire received a message on her iPhone. After looking at it, she said, with some amusement: 'You know, in our parents' generation, people sent telegrams; now, communication across the world is instantaneous. That is why the social awareness that you mention is global; it does not matter where you are from."

"So true," Pierre commented, adding: "Let's be clear; the millennial generation to which we belong will not work just for money. We need to feel that we are contributing to society. We need to have a sense of purpose."

José and Claire nodded in agreement.

The corollary. Combining the qualitative and quantitative data, three themes seemed to emerge. First, the millennial generation across cultural clusters is willing to trade pay for a meaningful job that contributes to society, beyond producing quality products and generating profits. Second, mass and instant communication has contributed to an awareness and sensitivity toward social issues. Finally, globalization of corporations, including business schools, contributes to business professionals across cultural clusters having similar motives regarding the endo-factor CSR. 
Meso-factors. The CSR literature identifies three factors related to the environment in which the organization is embedded that have an influence on its CSR activities. The first is the societal effect on company decisions (Donaldson \& Preston, 1995; Mitchell et al., 1997; Morsing \& Langer, 2007). The second is the socioeconomic system in which the firm operates (Fukukawa, 2010; Matten \& Moon, 2008; Richter, 2010). The third is the institutional strength and level of regulation in the region where the firm does business (Kostova et al., 2008; Schwartz \& Carroll, 2003). The results for each of these factors follow.

Society: The power of one. For this factor, the higher the survey score, the more the student's belief that civil society should play a role in monitoring business behavior.

The numbers. The mean results regarding the students' views toward the role of society as a mechanism to influence businesses CSR practices and the differences between the three cultural clusters are reflected in Figure 5. As can be seen, all clusters showed a strong favorable view towards the role of this meso-factor.

The ANOVA results presented in Table 7 showed that there were statistically significant differences between the three cultural clusters, $F(2,219)=6.776, p<.05$. The Tukey post-hoc test showed a significant difference between Latin Americans and Latin Europeans but not a significant one from Anglos. That is, Latin Americans had the strongest positive view regarding the importance of civil organizations, whereas the views of Anglos and Latin Europeans seemed to be similar. The $\omega^{2}$ indicated a weak effect size of the dependent variance accounted for by the independent variable in the population. Thus, the cultural cluster to which the student belonged explained only $4.9 \%$ of the variance. 


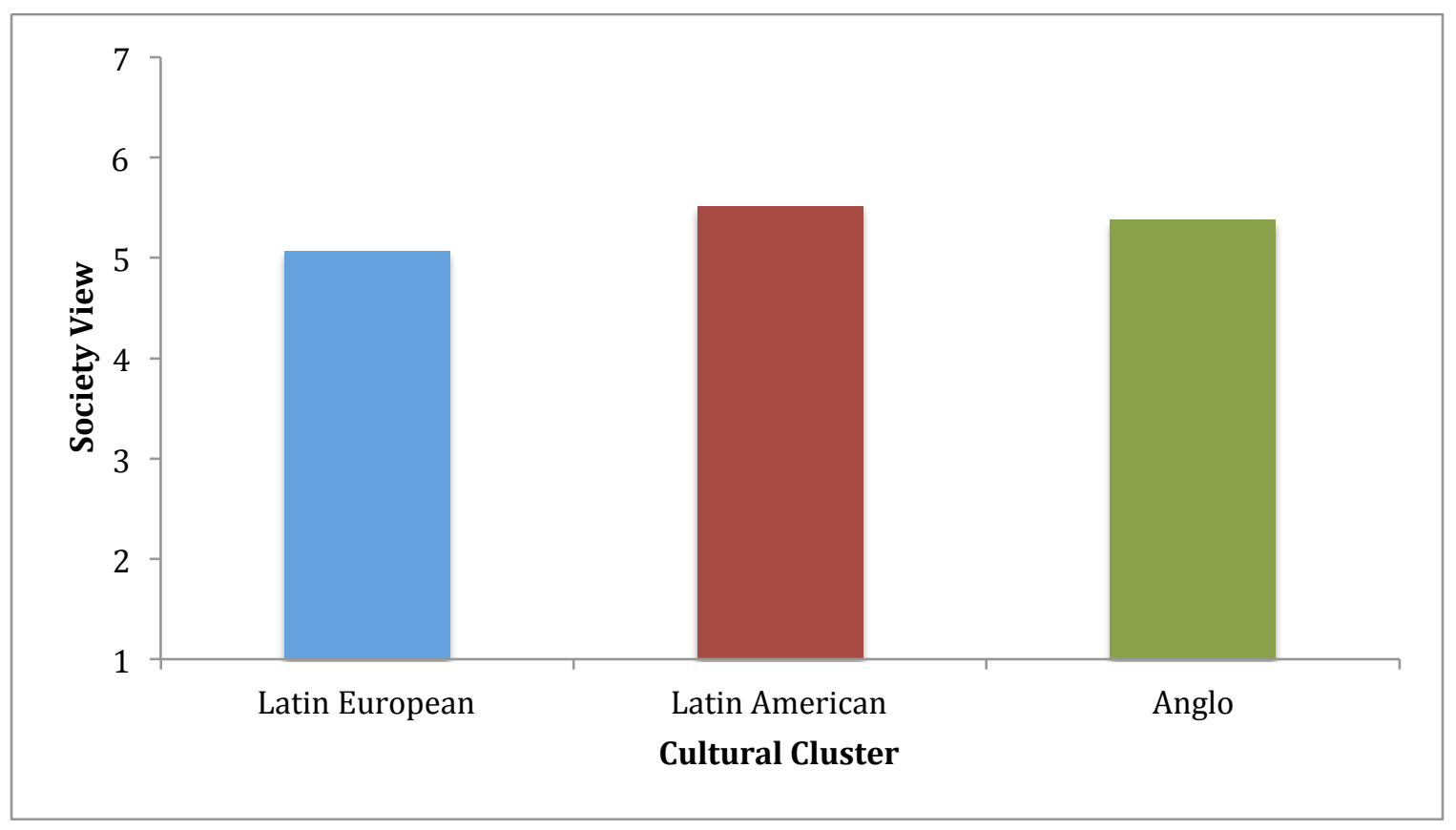

Figure 5. Mean results for views regarding role of society. Scale from 1 to 7 . The higher the score, the more the students' belief in the importance of civil organizations as business regulators.

\section{Table 7}

ANOVA Results for Views Regarding Society

\begin{tabular}{lccccc}
\hline Cultural Cluster & $M$ & $S D$ & $F$ & $p$ & $\omega^{2}$ \\
\hline Latin European (LE) & 5.07 & 0.65 & & & \\
Latin American (LA) & 5.51 & 0.71 & 6.476 & $.002 *$ & .049 \\
Anglo (A) & 5.38 & 0.77 & & & \\
Total & 5.39 & 0.73 & & & \\
\hline Tukey post-hoc Test: & & & & $.001^{*}$ & \\
LE to LA & & & & .079 & \\
LE to A & & & & \\
LA to A & & & &
\end{tabular}

The narrative that follows illustrates the meaning that the students attributed to these results and deepens understanding regarding the difference between the three cultural clusters. 
The story. Claire was very excited; her boyfriend of more than 4 years proposed to her last night and she could not wait to share this news with José and Pierre. When she told them, they were very happy for her, but José looked at her hand and asked: “And where is the ring?"

Claire stared at him and replied: "Well, you know how I feel about blood diamonds. I know that not all jewelry companies are involved in that practice, but I'd rather be safe than sorry."

Pierre looked doubtful, commenting: "I understand your point Claire, but if you were to apply the same thinking to all the things you need, you might not be able to buy anything."

At that moment, José interrupted: "But that is not the point, Pierre; the idea is that we as individuals have the power to change business behaviors if we act together."

Claire smiled at José's comment and asked: "Do you remember who the TIME magazine person of the year was in 2006?"

Nine years had gone by since then and José and Pierre did not remember.

Mischievously, Claire declared: "You, you, and me. All of us individually were the person of the year. We, as members of society, have the power to make a difference in ways our parents never dreamt of."

Pierre's face brightened as he concurred: "You are right, Claire; even in Europe, where government and legislation tends to be very strong, the influence of social media and social organizations have been critical in keeping companies environmentally conscious." 
José looked enviously at Pierre and commented: "I wish Latin America had the quality of government and institutions that Europe and the States have. In my country, civil society organizations have somehow made up for the lack in many of the government failures and, in the process, gained legitimacy."

With this last comment, they all raised their hands exclaiming: "The power of one!"

The corollary. The focus group conversation and the ANOVA results indicate two themes that seem to account for the students' views toward the importance of society in influencing business behavior, including the differences between the Latin American cluster and the Latin European and Anglo clusters. The first is the power that social media has given to the individual in making him or her an active player in society. The second is the legitimacy that civil society groups have gained, given what is perceived as government failure across the world, but particularly in Latin America.

Economy: Free market as possible, government as necessary. With this factor, the higher the number, the more the student's belief that a free market economy is the best system to promote CSR activities.

The numbers. The mean for each group presented in Figure 6 showed a somewhat strong view regarding the importance of free markets for economic development and the practice of CSR but with certain areas where government intervention was desirable. Of the three groups, Latin Americans seemed to have the highest preference for economic models in which free markets are the norm, whereas Latin Europeans seemed to prefer a somewhat stronger government intervention in economic matters. 


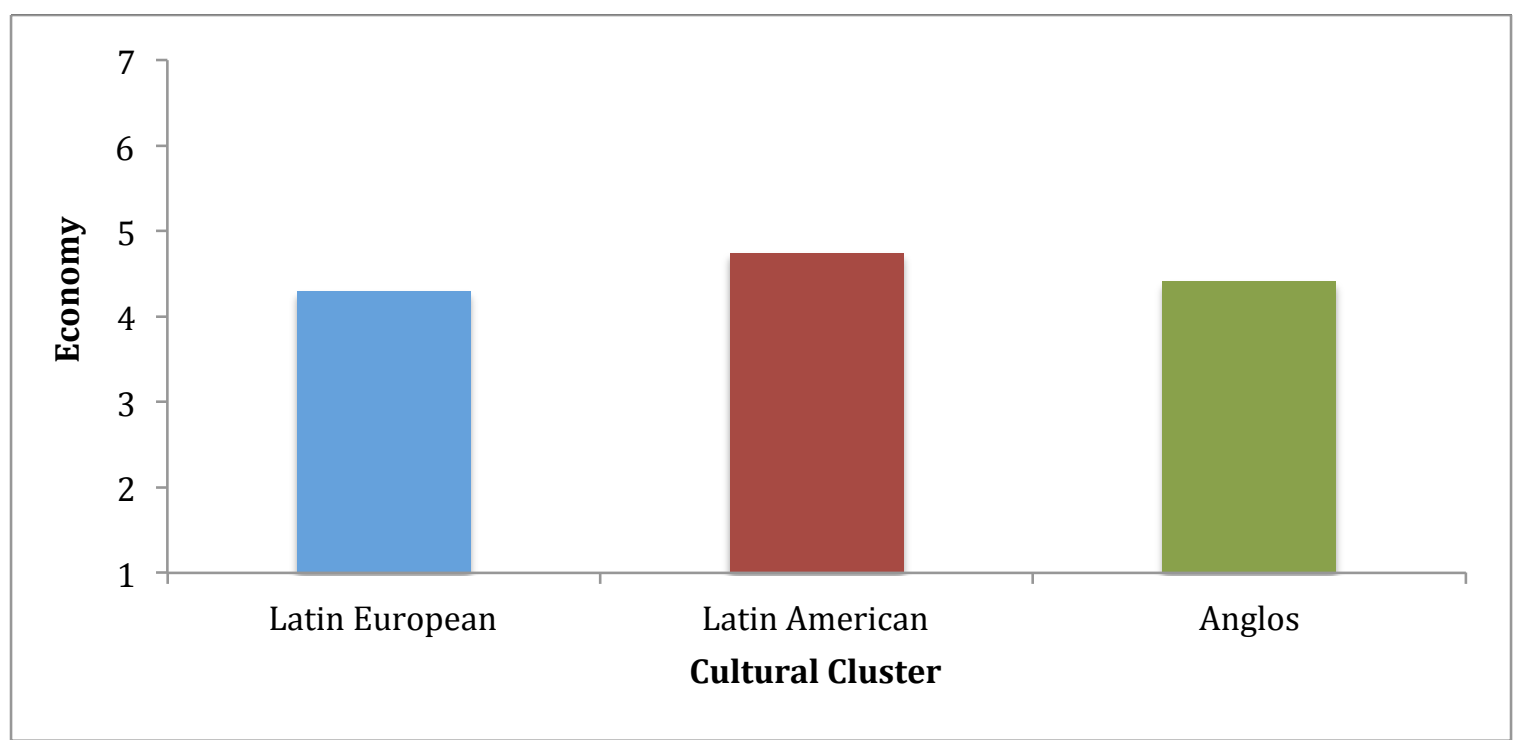

Figure 6. Mean results regarding the economic model. Scale from 1 to 7 . The higher the score, the more the students' belief in the importance of free markets for economic and CSR development.

In fact, the ANOVA results shown in Table 8 indicated that there was a statistically significant difference between the three groups, $F(2,219)=7.428, p<.05$. The Tukey post-hoc test showed a significant difference between Latin Americans and Latin Europeans and Anglos. There was not a significant difference between Anglos and Latin Europeans. That is, Latin Americans tended to prefer more free market policies than Latin Europeans and Anglos did, and these latter two groups had similar views. The $\omega^{2}$ indicated a weak effect size of the dependent variance accounted for by the independent variable in the population. Thus, the cultural cluster to which the student belonged explained only $5.5 \%$ of the variance.

The narrative that follows illustrates the meaning that the students attributed to these results and deepens understanding regarding the difference between the three cultural clusters, especially the possible reasons behind the higher score for Latin Americans. 
Table 8

ANOVA Results for Views Regarding the Economic Model

\begin{tabular}{lccccc}
\hline Cultural Cluster & $M$ & $S D$ & $F$ & $p$ & $\omega^{2}$ \\
\hline Latin European (LE) & 4.29 & .57 & & & $.001^{*}$ \\
Latin American (LA) & 4.74 & .69 & 7.428 & & .055 \\
Anglo (A) & 4.41 & .97 & & & \\
Total & 4.57 & .77 & & $.002 *$ & \\
\hline Tukey post-hoc Test: & & & & .680 & $.025^{*}$ \\
LE to LA & & & & \\
LE to A & & & & \\
LA to A & & & &
\end{tabular}

The story. José had just finished reading an article in The Economist regarding the positive effect that the free market policies proposed by the Washington Consensus ${ }^{10}$ has had on the rapid economic growth of Latin America. He was thrilled, thinking that sooner rather than later the region would be able to reduce its endemic poverty levels.

Looking at Claire and Pierre, José commented: "If Latin America keeps these free market policies in place, we will soon be developed as a region just as your own countries are."

Pierre considered this comment for a while and replied: "Well, I do not think that free market policies are a magic bullet; look at what is happening in Europe and the States. Yes, there has been growth, but there has also been an increase in inequality." Claire, who was listening attentively, said: "The States is considered the best example of a free market system, but inequality is also growing at unbearable levels. Free markets might produce GDP [Gross Domestic Product] growth, but they do not assure a fair wealth distribution."

\footnotetext{
${ }^{10}$ The Washington Consensus refers to a set of broadly free market economic ideas supported by prominent economists and international organizations.
} 
Confused, José asked: "How can you achieve economic growth without creating inequalities; it just cannot be done! First you have to produce wealth, and then you worry about distribution. You cannot distribute what you do not have."

Pierre, thinking about how the French system works, said: "Look, without education and a good health system, economic growth is not sustainable; those services cannot be subject to supply and demand because the people at the bottom of the pyramid will be left out."

Claire, who knew the economic history of the United States, added: "You have to understand the country's economic development before you decide what to leave to free market forces. In the 18 th century, the United States had what we call Hamiltonian ${ }^{11}$ economic policies in which free market policies and government development policies were balanced. At the time, the States was poor, the population uneducated, and industry nonexistent. You have to take this into consideration."

José thought for a while and said by a way of conclusion: "You are right; I might be over optimistic because I have seen the results of free market policies in Latin America. In short, what is needed is as much free market as possible but as much government as necessary."

The corollary. The focus group narrative and the quantitative results show that two themes seem to account for the students' views regarding this factor. The first is a shared belief that a free market economy, albeit with limitations, is the best system to achieve sustainable economic growth because it promotes individual freedom and initiative. However, there also seems to be a conviction that the system creates

\footnotetext{
${ }^{11}$ Alexander Hamilton was one of the U.S. founding fathers and Secretary of the Treasury (17891795) under President Washington.
} 
inequalities because not all have the same opportunities and skills, and these needs to be addressed by government intervention.

Regulation: A response to past abuses and corruption. For this factor, the lower the scores, the higher the student's belief that government regulation and the strength of institutions are necessary to assure socially responsible business practices.

The numbers. The mean results regarding students' views of government regulation as a tool to promote socially responsible business practices presented in Figure 7 showed a somewhat strong positive view regarding the importance of government regulation on some economic activities. These views seemed to be homogeneous in all three cultural clusters.

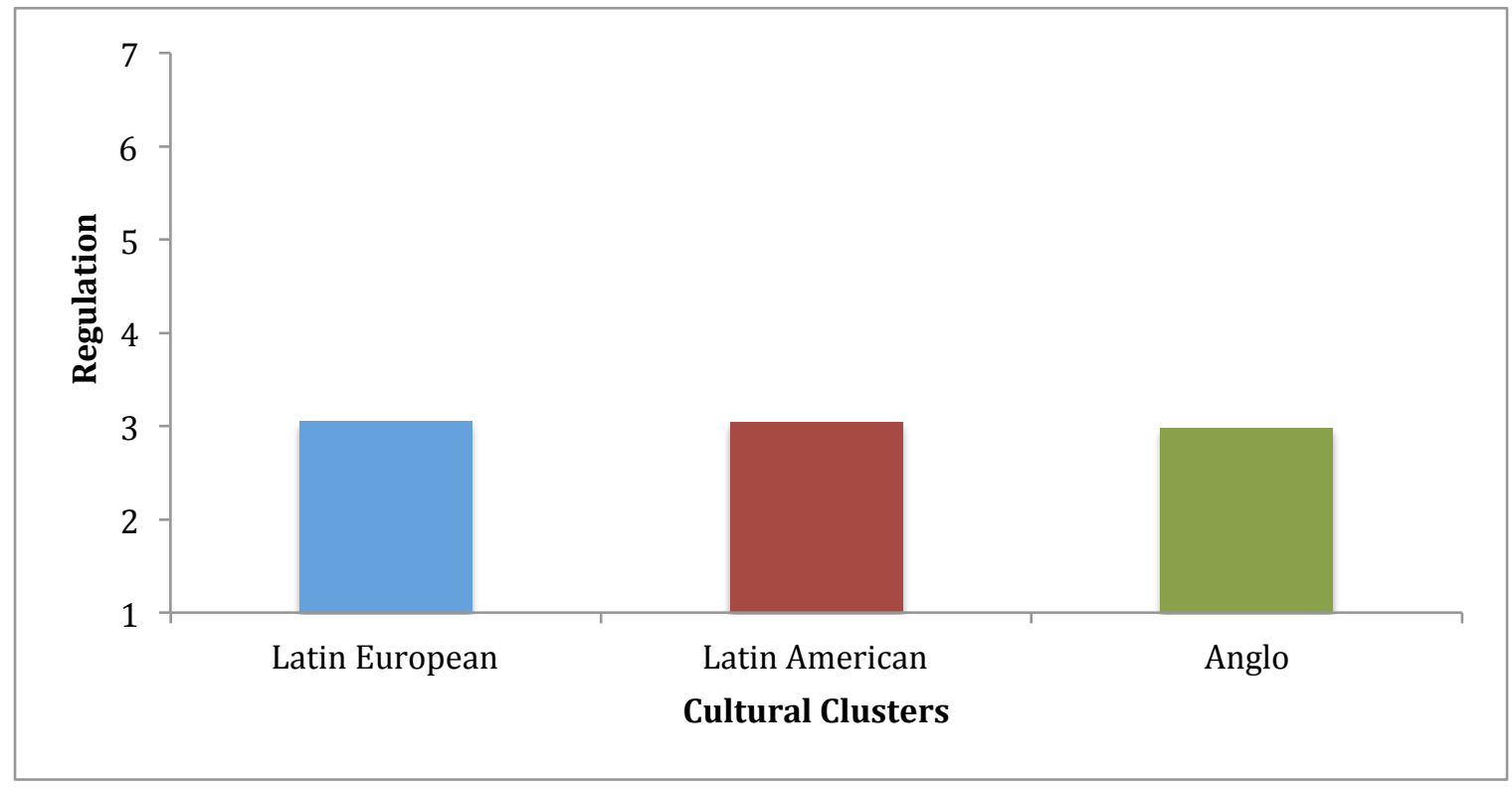

Figure 7. Mean results for views regarding regulation. Scale from 1 to 7 . The lower the score, the more the students' belief in the importance of government regulation for CSR development. 
The ANOVA results presented in Table 9 confirmed that there were no statistically significant differences between the three groups, $F(2,219)=.175, p>.05$. That is, the students, regardless of the cultural cluster to which they belonged, had identical views regarding government regulation of businesses. As a consequence, the Tukey post-hoc test and the $\omega^{2}$ were irrelevant for this factor.

Table 9

ANOVA Results for Views Regarding Government Regulation

\begin{tabular}{lccccc}
\hline Cultural Cluster & $M$ & $S D$ & $F$ & $p$ & $\omega^{2}$ \\
\hline Latin European & 3.05 & 0.85 & & & \\
Latin American & 3.04 & 0.65 & .175 & .840 & N/A \\
Anglo & 2.98 & 0.74 & & & \\
Total & 3.03 & 0.71 & & & \\
\hline
\end{tabular}

Tukey post-hoc Test: N/A

$* p<.05$.

One would expect that business students would prefer little government regulation of corporations. The following narrative helps in explaining what seem to be these counterintuitive results.

The story. Pierre, José, and Claire were discussing and preparing several cases for their business ethics class. Pierre was a bit frustrated because most of the examples were from American companies, particularly from the financial sector. With disdain, he commented: "You know, unfortunately business corruption is not limited to these big and well-known U.S. cases that we are analyzing in the course. France has not escaped from this disease. Technic and Alcatel, both well-known French companies, are two good examples of corporate corruption." 
José commented cynically: "If we want to talk about business corruption, unfortunately, Latin America is very high up in the list. Maybe the cases are not so well known because companies are smaller, but it is a widespread phenomena."

Claire was deep in thought and finally said: "Corruption is a multifaceted issue, not easy to solve. But precisely because of this complexity, and acknowledging that we, as business people, do not like regulation, I have to accept that it is inevitable."

"But it is not only corruption," Pierre said, adding: "Regulation is necessary to keep order and make sure all businesses play by the same rules. For example, environmental laws assure that all companies have the same obligations and, therefore, the same costs associated with this issue."

José interrupted, saying: "Speaking of the environment — in Latin America, we are overexploiting our natural resources and the only way to stop it is through strong government regulation and institutional strength; otherwise, future generations will suffer the consequences."

As Claire was pouring herself a fresh cup of coffee, she asked: "Do you believe that companies will voluntarily join fair trade ${ }^{12}$ practices if they do not feel the pressure of potential regulation? Some might, like Starbucks in their coffee supply chain system, but others will not."

In conclusion, José said: "We have to admit that regulation levels the playing field for all businesses. As it is, the system is broken. Enforcing regulations and enacting new ones should reduce corruption and bring order."

Claire and Pierre nodded in agreement.

\footnotetext{
${ }^{12}$ Fair trade is a social movement whose stated goal is to help raw material producers in developing countries achieve better trading conditions.
} 
The corollary. Two themes seemed to emerge from this shared support for a strong level of government regulation of business activity. The first is a recognition that deregulation, or the lack of legislation, has been one of the factors that led to many of the corporate scandals and the government corruption that has occurred in the last couple of decades. The students seem to believe that laws are essential for curbing corporations' and governments' deceit and fraud. The second seems to be a desire for order and the proper use of raw materials. The students see a world that is more interconnected and getting less sustainable, particularly regarding the utilization of natural resources.

Ecto-factors. The ICSRM presented in Figure 1 suggests that the culture in which a firm operates might be a final and external level with the potential to influence the perception and practice of CSR. Understanding this factor was the primary objective of this study. To that end, the study examined four out of the nine cultural dimensions presented in project GLOBE: performance orientation, in-group collectivism, uncertainty avoidance, and power distance (House, 2011). These dimensions were selected because, according to the GLOBE study, they present significant differences between the three cultural clusters represented in this study.

Performance: From analog to digital improvement. In this cultural dimension, the higher the number, the more the student valued competiveness over harmony and societal relationships.

The numbers. The data displayed in Figure 8 showed that all the MBA students in the sample, regardless of their cultural cluster, had a very strong performance orientation, with the Latin Americans displaying the highest score and Latin Europeans and Anglos about the same. 


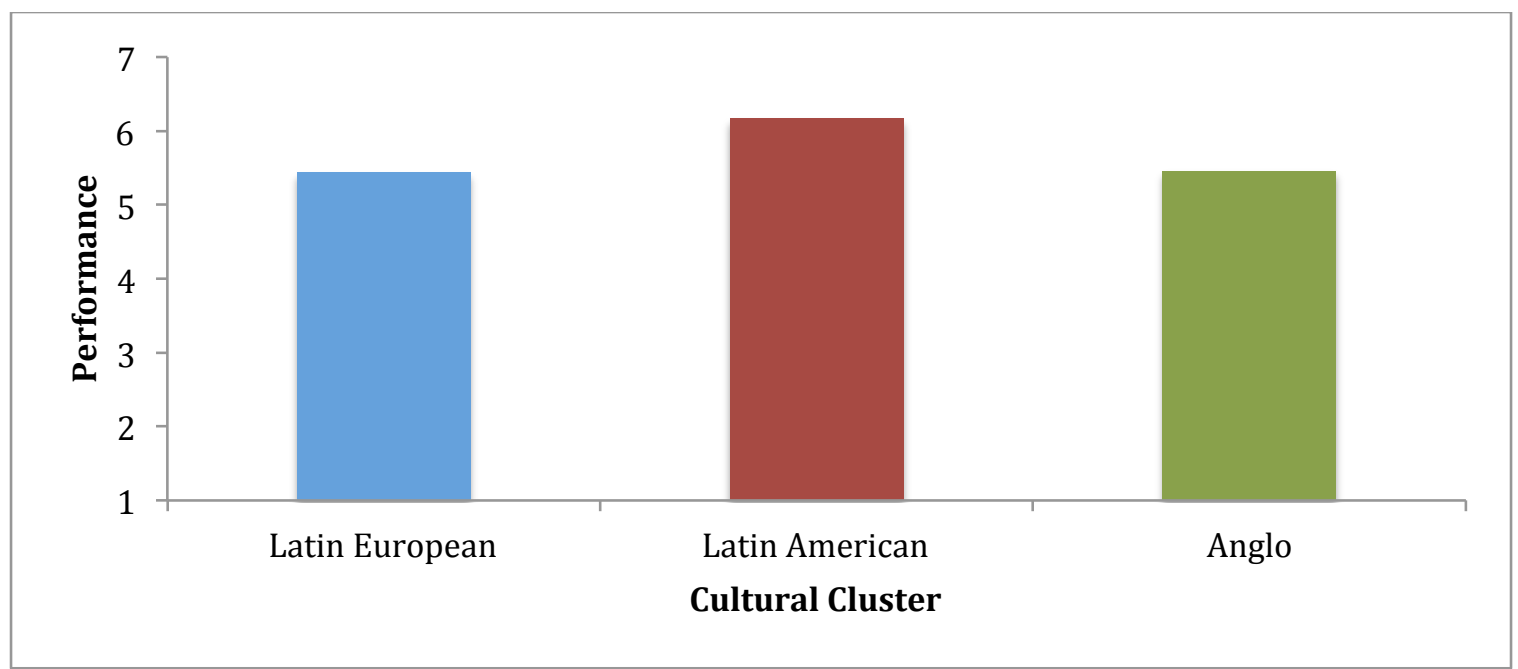

Figure 8. Mean results for views regarding performance. Scale from 1 to 7 . The higher the score, the more the student values competiveness over harmony and societal relationships.

The ANOVA results displayed in Table 10 indicated that there was a statistical difference between the three cultural clusters, $F(2,219)=13.996, p<.05$. The Tukey post-hoc test showed that Latin Americans' higher score was statistically different from both Europeans' and Anglos' scores. However, there was no statistically significant difference between Anglos and Latin Europeans. That is, Latin Americans had a slightly stronger attitude towards the importance of performance orientation than Anglos and Latin Europeans, whereas these latter two groups had almost identical attitudes. The $\omega^{2}$ indicated a considerable effect size of the dependent variance accounted for by the independent variable in the population. That is, the cultural cluster to which the student belonged explained $20.3 \%$ of the variance in performance orientation.

These results are to be expected from MBA students. The following narrative provides deeper understanding of the meaning that the students attributed to this cultural dimension and the reasons why Latin Americans display a higher score. 
Table 10

ANOVA Result for Views Regarding Performance Orientation

\begin{tabular}{lccccc}
\hline Cultural Cluster & $M$ & $S D$ & $F$ & $p$ & $\omega^{2}$ \\
\hline Latin European (LE) & 5.44 & 0.69 & & & .203 \\
Latin American (LA) & 6.17 & 0.63 & 13.996 & $.000^{*}$ & \\
Anglo (A) & 5.46 & 0.83 & & & \\
Total & 5.85 & 0.78 & & & \\
\hline Tukey post-hoc Test: & & & & $.000^{*}$ & .987 \\
LE to LA & & & & $.000^{*}$ & \\
LE to A & & & & \\
LA to A & & & &
\end{tabular}

The story. José had just finished reading an article regarding the history of management. He was very impressed with Taylor's ${ }^{13}$ (1911/1967) management theories of time and motion in which he described organizations and their people as machines.

Pondering these ideas, he asked Claire and Pierre: "Do you think that the pressure for efficiency and results in the business world has changed much in the last 100 years?"

Claire responded immediately: "Well, you know that business schools truly believe that what cannot be measured does not exist. That is the way we have been trained. You measure your results to always keep shooting for better results."

Pierre hesitated a little bit and then added: "But it is not the same as it used to be. The business school focus is still on delivering results, but that does not necessarily mean just doing what you currently do better but also adapting to change and coming up with new ways of solving problems."

\footnotetext{
${ }^{13}$ Frederick Taylor, with the publication of The Principles of Scientific Management in 1911, is considered one of the fathers in the field.
} 
Claire responded: "Well, I am glad that we are receiving this training. Things are changing so fast and competition is so fierce in the market place that if you do not perform, you are out the door, no matter how long you have worked in a company."

With some hesitation, José asked: "Now that you mention seniority in the work place, are any of you planning to work for one single company your whole life?" Then he added: "My father worked in the same company for 30 years until his pension kicked in. Then he retired with his gold watch for his years of service."

Claire asserted strongly: "I do not think loyalty means much of anything these days."

Pierre responded: "Yeah and it goes both ways in that companies are not being loyal to their employees, so they no longer expect loyalty from people."

José firmly interjected: "I am glad it is that way nowadays. In Latin America, nepotism and cronyism has always been confused with loyalty." Pausing for a while, he added: "In the old times, the majority of positions were not awarded for merit but rather for political connections or seniority. That practice is now changing, but we still have a long way to go."

Concluding, Claire said: "The good thing is that performance does not necessarily mean putting in a lot of hours; it is more about delivering results. With today's technology, we can do that in a more flexible way."

The corollary. Two conclusions can be drawn from the quantitative and qualitative data. The first is that students perceive business school training as an important factor in their performance orientation or, looking at it another way, high performing individuals tend to pursue MBA degrees. The second is an apparent shifting 
of values, particularly in Latin America, to more strongly value meritocracy over class privilege or personal relations, which might explain the higher scores relative to the other two groups.

Collectivism: One for all, all for one. In this cultural dimension, the higher the number, the more the individual believed in duties and obligations to the group as determinants of social behaviors. The lower the number, the higher the individual needs were valued in the individual decision-making process.

The numbers. The data shown in Figure 9 regarding the collectivistic cultural dimension denoted the views of the MBA students for each cultural cluster. As can be seen, Anglos and Latin Europeans had a fairly balanced view between individualism and collectivism. Latin Americans' score was somewhat skewed toward collectivistic beliefs.

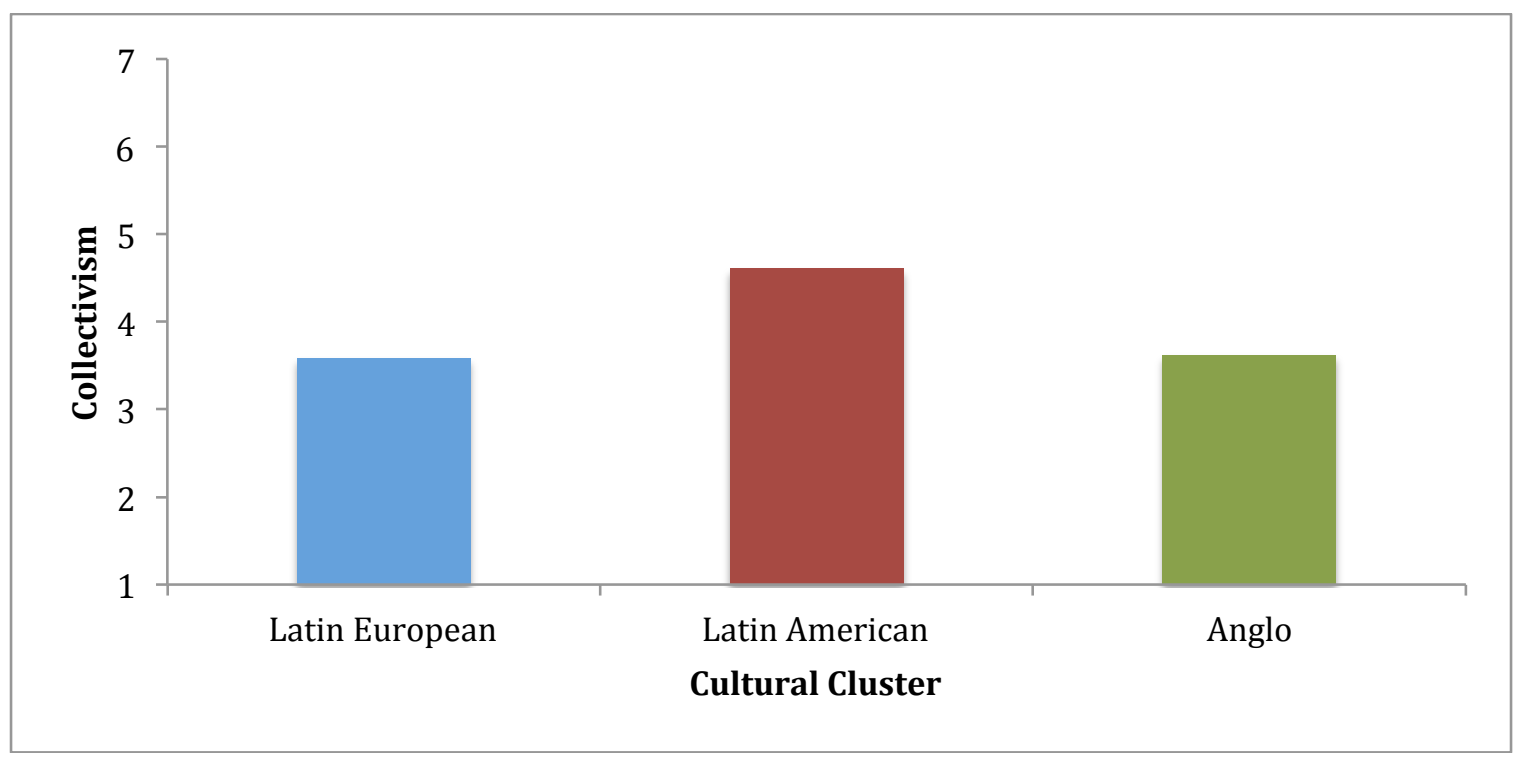

Figure 9. Mean results for views regarding collectivism. Scale from 1 to 7 . The higher the score, the more the student values collectivism over individualism. 
The ANOVA results shown in Table 11 confirmed these differences, $F(2,219)=$ 33.009, $p<.05$. The Tukey post-hoc test corroborated that the higher score of Latin Americans was statistically different from those of Latin Europeans and Anglos and that there was no statistically significant difference between Anglos and Latin Europeans. It is interesting to note that the standard deviation in the Latin American cluster was relatively high, which indicated a wide variability in the individual scores. The $\omega^{2}$ indicated a considerable effect size of the dependent variance accounted for by the independent variable in the population. That is, the cultural cluster to which the student belonged explained $22.3 \%$ of the variance in performance orientation.

\section{Table 11}

ANOVA Results for Views Regarding Collectivism Versus Individualism

\begin{tabular}{lccccc}
\hline Cultural Cluster & $M$ & $S D$ & $F$ & $p$ & $\omega^{2}$ \\
\hline Latin European (LE) & 3.59 & 0.75 & & & \\
Latin American (LA) & 4.61 & 1.03 & 33.009 & $.000^{*}$ & .233 \\
Anglo (A) & 3.62 & 0.71 & & & \\
Total & 4.16 & 1.03 & & & \\
\hline Tukey post-hoc Test: & & & & $.000^{*}$ & .988 \\
LE to LA & & & & $.000^{*}$ & \\
LE to A & & & & \\
LA to A & & & &
\end{tabular}

The narrative that follows deepens understanding of these results and explains why, contrary to expectations, these groups of MBA students showed a fairly balanced view in the continuum of these two constructs.

The story. As a common practice in the MBA program, José, Claire, and Pierre were working on a group project. They had decided to divide the workload equally and now they were in the process of putting it all together. 
In a joyful manner, José said: "I am so glad that the school has so many group projects. I like to work in teams; they remind me of my family."

Claire nodded her head in agreement and said: "Yes, we have a great camaraderie and collaboration in our group, but I wonder if we are going to find this same environment in our professional life."

Pierre hesitated a little and said: "Remember that in this program you are rewarded for working together as a group, but in the business world you tend to be rewarded individually."

José, as if trying to clarify Pierre's comment, said: "For sure, 25\% of our final grade depends on this project and on peer evaluation, but that is not what motivates me to participate; it is rather the sense of family that the group provides. I have been fortunate enough to have worked in different teams where everyone was willing to share with me what they knew and had done."

Claire vacillated a little and said: "I think that ultimately we all understand that it is impossible to do it all by ourselves and achieve the things we want. But, let's be clear; in a job interview, you are going to say that, yes, you worked in a group, but you will also say that you led the group. At the end, what is important is the individual achievement."

Pierre, trying to reconcile their comments, said: "I think we all enjoy and see the benefits of working in groups, but I know that, in the end, it is beneficial for me as well." Claire's body language communicated agreement with Pierre's remark, but José's facial expression indicated a bit of hesitation.

The corollary. Two ideas can be drawn from the quantitative and qualitative data. The first is that the school the students attend plays an important role in their 
collectivistic values because the institutions give a high significance to group projects. However, the individualistic culture of the business world somewhat mediates the school's influence. The second theme is that the students' family values from their country of origin seem to influence their views regarding this factor, particularly for Latin Americans.

Uncertainty: Planned entrepreneurship. In this cultural dimension, the higher the number, the more the individual relies on formalized processes and procedures. Also, risk is calculated and there tends to be a higher resistance to change. The lower the number, the more informal and risk taking the individual tends to be.

The numbers. For this factor, as shown in Figure 10, Anglos displayed the least avoidance, Latin Americans the most, and Latin Europeans tended to have a more balanced attitude.

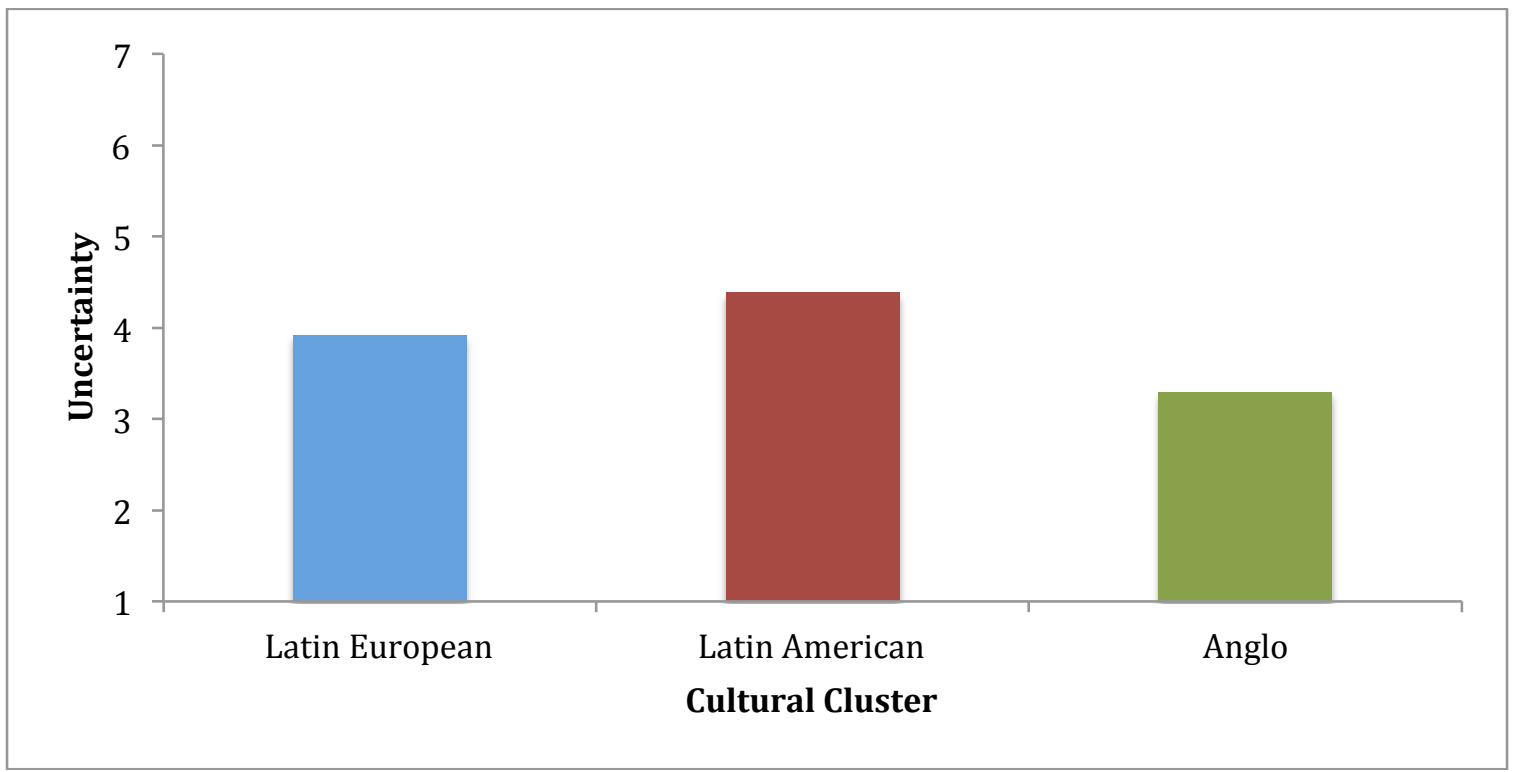

Figure 10. Mean results for views regarding uncertainty. Scale from 1 to 7 . The higher the score, the more the student displays an uncertainty avoidance preference. 
The ANOVA results shown in Table 12 corroborated that there was a marked difference between the cultural clusters regarding the students' views about uncertainty avoidance, $F(2,219)=23.627, p<.05$. The Tukey post-hoc test confirmed that these differences were statistically significant in all the cases. The $\omega^{2}$ indicated a medium effect size of the dependent variance accounted for by the independent variable in the population. That is, the cultural cluster to which the student belonged explained $16.2 \%$ of the variance in uncertainty avoidance.

\section{Table 12}

ANOVA Results for Views Regarding Uncertainty Avoidance

\begin{tabular}{lccccc}
\hline Cultural Cluster & $M$ & $S D$ & $F$ & $p$ & $\omega^{2}$ \\
\hline Latin European (LE) & 3.92 & 1.01 & & & \\
Latin American (LA) & 4.39 & 1.00 & 23.627 & $.000^{*}$ & .162 \\
Anglo (A) & 3.30 & 0.84 & & & \\
Total & 4.03 & 1.06 & & & \\
\hline Tukey post-hoc Test: & & & & & $.018^{*}$ \\
LE to LA & & & & $.005^{*}$ & \\
LE to A & & & & $.000^{*}$ & \\
LA to A & & & &
\end{tabular}

The narrative that follows provides deeper understanding regarding the differences in the students' attitudes toward this factor.

The story. One evening, over dinner, José, Pierre, and Claire were comparing notes on how different their financial planning and entrepreneurship courses were.

Claire expressed her enthusiasm about the entrepreneurship course, stating: "I just love this course; the constant changes and surprises that an entrepreneur has makes me feel alive. Financial planning is so boring; besides, who can really predict what will happen 5 years down the road?" 
Pierre added: "Well, I guess you have to have balance, which is why the school teaches both courses. That is the training we are receiving. Imagine a company without planning; it would be total chaos."

José, who was doing quite well in financial planning, claimed: "You know, in Latin America, we have had so much political and economic instability that the last thing we need is more surprises; I like to plan, even if I have to change plans every year."

Pierre was a bit confused with José's comment and challenged him: "But you have demonstrated to us that you are good at improvising; you always find a way to do things with little resources."

José responded: “Oh sure, but that does not mean that I like it. There are enough uncertainties out there already, especially for businesses."

Claire, who had experience in managing businesses in developing countries, intervened: "I see your point, José; in the United States, we take many things for granted. We do not wake up one morning to find a new government or a radical change in laws that affects business."

Somewhat defensively, José said: "I believe that the need for certainty is like a stability prescription drug that enables countries to be able to finally develop."

Pierre added happily: "Well, I am so glad that we are getting a balanced training in this program - that way we will be able to feel comfortable with any level of uncertainty anywhere in the world and be able to plan too."

With that final comment, the three of them continued enjoying their evening meal. The corollary. Two themes can be drawn from the qualitative data. The first is that the school program has a marked influence on the students. The curricula offer a 
variety of courses that emphasize both the need for planning and the importance of managing uncertain events and risk. The second is that the external environment, especially the political and economic stability in a country, impacts the desire for more planning as a way to balance these macro-instabilities.

Power distance: From centralized control to flat hierarchies. In this cultural dimension, the higher the number, the more the individual believes that society should be differentiated by social class and that power is a way to provide social order. The lower the number, the less hierarchical the individual tends to be.

The numbers. As Figure 11 shows, the MBA students from these three cultural clusters displayed a very low score in the power distance dimension.

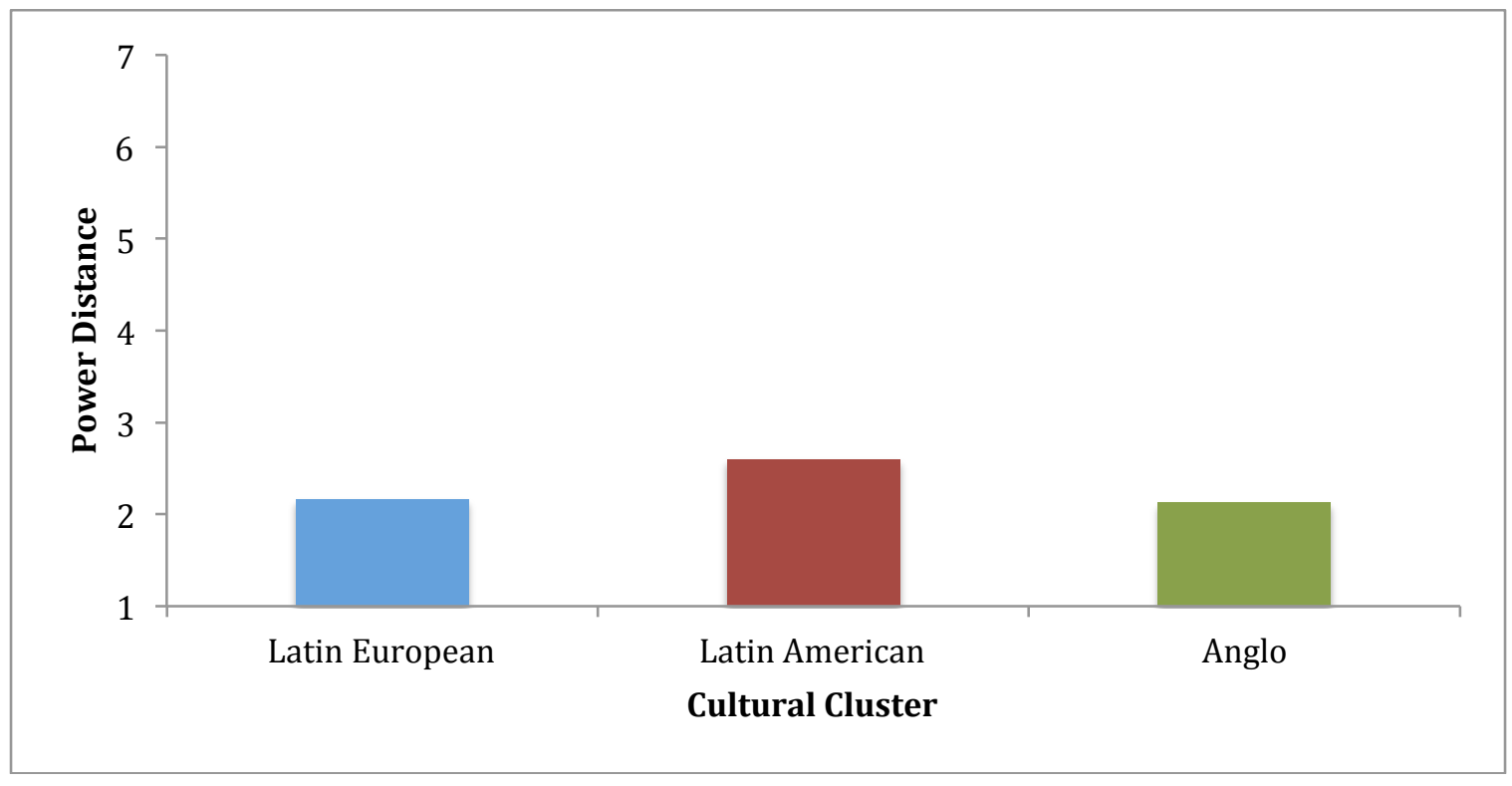

Figure 11. Mean results for views regarding power distance. Scale from 1 to 7 . The higher the score, the more the student displays a power distance attitude. 
However, the ANOVA results shown in Table 13 indicated that there were statistically significant, albeit small, differences between them, $F(2,219)=6.221, p<$ .05. The Tukey post-hoc tests confirmed that differences were not statistically significant between Anglos and Latin Europeans but that these two groups differed from Latin Americans, who tended to have a slightly higher attitude toward power distance. As mentioned above, all cultural clusters displayed a relatively low mean regarding this cultural dimension. However, in all cases, the standard deviations were large relative to the mean. This element might explain the significance in the differences. The $\omega^{2}$ indicated a small effect size of the dependent variance accounted for by the independent variable in the population. That is, the cultural cluster to which the student belonged explained $4.3 \%$ of the variance in power distance.

Table 13

Power Distance ANOVA Results

\begin{tabular}{lccccc}
\hline Cultural Cluster & $M$ & $S D$ & $F$ & $p$ & $\omega^{2}$ \\
\hline Latin European (LE) & 2.17 & 0.72 & & & \\
Latin American (LA) & 2.60 & 1.04 & 5.614 & $.000^{*}$ & .043 \\
Anglo (A) & 2.13 & 0.88 & & & \\
Total & 2.40 & 0.97 & & & \\
\hline Tukey post-hoc Test: & & & & $.026^{*}$ & \\
LE to LA & & & & .977 & $.008^{*}$ \\
LE to A & & & & \\
LA to A & & & &
\end{tabular}

These low scores in power distance views from MBA students might seem counterintuitive. However, the following narrative explains the meaning that the participants attributed to this construct. 
The story. The business school auditorium was packed with MBA students attending a guest speaker lecture on a new management system called holacracy, ${ }^{14}$ which was gaining popularity in business circles. After the lecture, Pierre exclaimed: "Wow, incredible how things are changing! Before joining the MBA program, I worked for 5 years at the accounting firm Deloitte. There, the hierarchies were so marked that even your chair got more comfortable as you went up the organizational ladder. So the message was clear: If you are a junior, it is okay if you have back pain!"

Claire laughed and said: "My experience was the total opposite; I worked in a tech startup company where not even the founder and CEO had a different office. You knew who the boss was, but it was not evident by just looking at the offices."

José said hesitantly: "You know, I really love the idea of flat hierarchies, but I wonder if it will work in any situation; it could be very confusing in certain circumstances."

“Oh, I agree,” Pierre interrupted, adding: "There are still many old-fashioned companies that work that way, but it is going to be hard for them to hire new people. It is a widespread generational issue. In the past, power was based on the amount of information you controlled; that is not the case anymore."

Claire, recalling her previous work experience, added: "I think the Internet revolution has opened access to information to everyone, so companies have to be more transparent."

\footnotetext{
${ }^{14}$ Holacracy is a management system in which authority is distributed in circles and processes
} instead of the traditional static structure of boxes and lines. 
José thought for a little while and said: "I also think that as people get more educated and the middle class expands, there is a lot less willingness to accept power structures. At least that is what is happening in Latin America."

"That is a good point," Claire said, adding: "I recently read an article that argued that the infamous Indian class system is finally disappearing as the population gets more educated and the middle class expands. I suppose that applies to other regions of the world as well."

As they were parting ways, Pierre jokingly said: "In France, we got rid of nobility more than 300 years ago; I am glad this generation has learned from us."

The corollary. Two themes can be drawn from the qualitative data. The first is that the Internet revolution has been democratizing access to information, which seems to be influencing this generation's views regarding hierarchies and centralization of control. As information is shared, so is power. The second is the rapid expansion and access to higher education across the world, which has led to the growth of the middle class, particularly in Latin America. As people get more educated and affluent, there seems to be less tolerance for hierarchies and class differences.

The previous ANOVA results indicated that it was clear that there were some significant differences but also critical similarities regarding students' motives and views toward each of the ICSRM factors. This raised an important question, which was what, if any, might be the relationship between these various factors? This is addressed next.

\section{Relatedness Between the ICSRM Factors}

One of the primary objectives of this study was to address the gap in the CSR literature regarding the possible influence, if any, that the four project GLOBE cultural 
dimensions mentioned previously have on MBA students' motives toward CSR and their views regarding the factors that, according to most scholars, influence its practice. If there were a relationship, this would indicate whether the ICSRM depicted in Figure 1 has validity as a predictor of a normative or utilitarian motive towards CSR in MBA students.

Below are five regression analyses that provide an answer to this question. The first four regressions display the relatedness between the ecto-factors (cultural dimensions) as independent variables and each of the meso-factors and the endo-factor as the dependent variables. The fifth regression, which is a compendium of all the factors depicted in the ICSRM, shows the relatedness between the students' views regarding the ecto- and meso-factors as independent variables and their motives toward the endo-factor CSR as the dependent one. In the final regression, the results are presented utilizing hierarchical methodology to distinguish the effect of the meso-factors, which have been derived from the literature, on the ecto-factors, which are the object of this study.

Since the regression analyses were performed after collecting all the survey data and after the focus groups were held at the three schools, no qualitative data showing student opinions regarding the regression results were available, as there were with the ANOVA data. For this reason, there will be no fictional stories to illustrate the meaning that the students attributed to the scores. However, relevant comments from the focus groups are used to provide meaning and better understanding of the regression analyses.

Cultural dimensions to endo-factor. In this first regression, the objective was to predict motives toward the endo-factor CSR, as the dependent variable, with the independent variables being the four cultural dimensions that constitute the ecto-factor. 
Specifically, the regression model assessed quantitatively how the MBA students' values regarding performance orientation, collectivism, uncertainty avoidance, and power distance influence their motives toward the normative versus the utilitarian view of CSR.

The results showed that the regression model significantly predicted CSR attitudes, $F(5,264)=2.760, p=.019$. However, as indicated in Table 14, when taken independently, none of the factors except power distance was significant. A 1-point increase in power distance moved CSR motives toward utilitarianism by .12 points or $1.7 \%$ on a 7 -point scale. The regression model indicated that the cultural dimensions could explain $5 \%$ of the variance in the students' CSR motivation.

Table 14

Regression Model of Cultural Dimensions to CSR Attitudes

\begin{tabular}{lcccrc}
\hline Coefficients & \multicolumn{2}{c}{$\begin{array}{c}\text { Unstandardized } \\
\text { Coefficients }\end{array}$} & $\begin{array}{c}\text { Standardized } \\
\text { Coefficients }\end{array}$ & & \\
\cline { 1 - 4 } & $B$ & Std. Error & $\beta$ & \multicolumn{1}{c}{$t$} & Sig. \\
\hline Constant & 2.888 & .364 & & 7.933 & .000 \\
Performance & .002 & .055 & .003 & .045 & .964 \\
Collectivism & -.045 & .041 & -.073 & -1.085 & .279 \\
Uncertainty & .038 & .041 & .063 & .923 & .357 \\
Power & .117 & .043 & .174 & 2.708 & $.007^{*}$ \\
\hline
\end{tabular}

Note. $R^{2}=.05$.

$* p<.01$.

These results are to be expected since the ANOVA scores shown in the previous section indicated that there were no statistically significant differences in the mean scores of the students' motives regarding the endo-factor CSR, $p=.409$. Moreover, all the individual student's scores were less than 1 standard deviation from the overall mean of 3.31, which showed not only a motivation that was balanced between a normative and 
utilitarian approach toward CSR but also a fairly comparable attitude among all the students.

In the qualitative portion of the study, students of all cultural clusters discussed their motives toward CSR in a similar way, emphasizing the influence of their business school education on this factor. For example, a student from the ESADE Business School commented:

I feel that over the last 5 to 10 years there has been a massive effort in business schools to educate people in this subject [CSR]. Everyone at the school, no matter where they are from, has been exposed to the importance of CSR practice.

A student from the INCAE Business School concurred with this opinion, stating:

I think that in our business education it is no longer one versus the other [CSR versus profits]. For me and the majority of my classmates, there is no distinction between making a profit and being a socially responsible citizen.

A couple of students, however, felt that the data might be somewhat biased, given the strong emphasis that their school attributes to CSR issues. As a student from the USD School of Business Administration said, "You have to take into consideration for your results that, no matter the cultural background of the student, we chose this particular school for the CSR component."

In short, there seem to be three potential explanations. First, these particular schools might have a strong influence on their business students based on their socially oriented approach to business education. Second, this group of students was already socially oriented and chose these particular schools for their stated stance regarding CSR. Third, and perhaps most likely, it is a combination of the two.

Cultural dimension to meso-factors. The ICSRM depicts three meso-factors. The first is the influence that social players have on business behavior. The second is the 
economic model that is prevalent in the region where the business operates. Finally, there is the level of government regulation and strength of the institutions in enforcing business laws in the market where the firm operates. The results regarding the possible relatedness between the students' views toward each of the meso-factors and the cultural dimensions are presented next.

Cultural dimensions and society. The objective of this multiple regression was to predict the students' views regarding the ideal level of societal influence on business behavior, as the dependent variable, with the independent variables being the four cultural dimensions that constitute the ecto-factor. Specifically, the regression model assessed quantitatively how the MBA students' values regarding performance orientation, collectivism, uncertainty avoidance, and power distance influence their views regarding the role that civil organizations should play in promoting CSR activities in businesses.

The results shown in Table 15 indicated that the regression model predicted the students' views toward society as a business arbitrator with statistical significance, $F(5,264)=7.072, p=.000$. However, as indicated in Table 15, when taken independently, none of the factors except performance orientation was statistically significant. A positive change in performance orientation increased the students' attitudes regarding societal actors having a greater role by .224 points or $3.2 \%$ on a 7 point scale. The regression model indicated that the cultural dimensions could explain $11.8 \%$ of the variance in the students' attitudes toward civil society as business arbitrator.

It is interesting to note that from the three meso-factors, the students' views regarding the power that civil society should have over business behavior was the highest, with a total mean of 5.39 out of 7 . Similarly, of the four cultural dimensions, or 
Table 15

Regression Model of Cultural Dimensions to Civil Society Attitudes

\begin{tabular}{lrccrc}
\hline Coefficients & \multicolumn{2}{c}{$\begin{array}{c}\text { Unstandardized } \\
\text { Coefficients }\end{array}$} & $\begin{array}{c}\text { Standardized } \\
\text { Coefficients }\end{array}$ & & \\
\cline { 1 - 4 } & \multicolumn{1}{c}{$B$} & Std. Error & $\beta$ & \multicolumn{1}{c}{$t$} & \multicolumn{1}{c}{ Sig. } \\
\hline Constant & 4.061 & .385 & & 10.538 & .000 \\
Performance & .224 & .058 & .245 & 3.842 & $.000^{*}$ \\
Collectivism & .071 & .044 & .104 & 1.618 & .107 \\
Uncertainty & .016 & .043 & .025 & .377 & .706 \\
Power & -.060 & .046 & -.081 & -1.310 & .191 \\
\hline
\end{tabular}

Note. $R^{2}=.118$.

$* p<.01$.

ecto-factors, the mean for performance orientation for all students was also the highest, with a score of 5.85 out of 7 . Additionally, there was a medium correlation of .301 between these two factors, which indicated a somewhat strong relationship between the students' views toward civil society's power over business behavior and performance orientation.

The qualitative data provided some clues that might explain and give meaning to this relationship. In fact, students from the three cultural clusters agreed that civil society organizations, along with businesses, are efficiently filling the void created by government failures. Efficiency was also commonly mentioned in the students' comments regarding performance orientation. A student vehemently made this link, expressing:

Unfortunately, there is not much government action $^{15}$ in the places more in need where more help is needed. So that is when civil society and business organizations turn to help people because they really know how to deliver results and be accountable.

\footnotetext{
${ }^{15}$ Italics are to emphasize the orientation to performance and achievement.
} 
Another student expressed the following to exemplify how society has the capacity to influence business performance:

The power of civil society helps in keeping businesses performing at higher levels of efficiency. If it weren't for the environmental pressure that comes from NGOs, businesses might not have discovered that being environmentally conscious is also good business. Conscious environmental practices bring incredible savings in the whole supply chain of a firm.

The above two quotes are just a sample of many others that support the idea that there is a relationship between students' high performance orientation and their belief in a strong civil society.

Cultural dimensions and economic model. The objective of this regression was to predict the students' views regarding the best economic system to promote CSR activities, as the dependent variable, with the independent variables being the four cultural dimensions that constitute the ecto-factor. Specifically, the regression model assessed how the MBA students' values regarding performance orientation, collectivism, uncertainty avoidance, and power distance influence their views regarding the spectrum of a centrally controlled and planned economy on the one end and a totally free market on the other.

The results showed that the regression model significantly predicted students' views toward the influence that the economic system had on business behavior, $F(5,264)$ $=3.287, p=.007$. However, as indicated in Table 16, when taken independently, none of the factors except performance orientation was statistically significant. A positive change in performance orientation increased the students' views towards a free market economic system by .247 points or $3.5 \%$ on a 7 -point scale. The regression model indicated that 
Table 16

Regression Model of Cultural Dimensions to Economic System

\begin{tabular}{|c|c|c|c|c|c|}
\hline \multirow[t]{2}{*}{ Coefficients } & \multicolumn{2}{|c|}{$\begin{array}{c}\text { Unstandardized } \\
\text { Coefficients }\end{array}$} & \multirow{2}{*}{$\begin{array}{c}\begin{array}{c}\text { Standardized } \\
\text { Coefficients }\end{array} \\
\beta\end{array}$} & \multirow[b]{2}{*}{$t$} & \multirow[b]{2}{*}{ Sig. } \\
\hline & $B$ & Std. Error & & & \\
\hline Constant & 3.108 & .436 & & 7.129 & .000 \\
\hline Performance & .247 & .066 & 247 & 3.758 & $.000^{*}$ \\
\hline Collectivism & .004 & . 049 & .005 & .072 & .943 \\
\hline Uncertainty & -.032 & .049 & -.044 & -.653 & .514 \\
\hline Power & .055 & .052 & .069 & 1.072 & .284 \\
\hline
\end{tabular}

Note. $R^{2}=.059$.

$* p<.01$.

the cultural dimensions could explain $5.7 \%$ of the variance in the students' views supporting a free market economic system.

From the information gathered in the focus groups, we can deduce that the students tended to equate the concept of freedom with both liberal market economies and performance orientation. As one Anglo student plainly stated:

Well, you know, as personal freedom is necessary for an individual to innovate and progress, so it is for a country. An economy that is centrally planned will never provide the incentives and rewards for economic growth, much less for CSR activities.

This view was further reflected in another focus group held many miles away. With enthusiasm, a Latin American student said, "In Latin America, we have tried everything; it is only now that we are embracing free market policies that you see economic growth and, more importantly, people taking responsibility for their own actions."

The mean of this factor for all students was 4.57 out of 7 with a relatively small standard deviation of 0.77 . This indicated that the students embraced free market policies but with some limits. However, they seemed to connect these restrictions to the freedom necessary to be able to perform. As one Latin European student warned: 
No doubt that free market policies assure the best economic system, but it is also a system that creates inequalities. These inequalities are not, as some will like to believe, caused by people laziness but instead for lack of education, training, sickness, or family issues. You cannot be expected to perform under those circumstances.

In short, the results of this multiple regression showed a somewhat medium relatedness between the individual capacity to deliver results and the benefits that a free market system provided for the practice of CSR.

Cultural dimensions and government regulation. The objective of this multiple regression was to predict students' views regarding the proper level of government regulation to promote CSR activities, as the dependent variable, with the independent variables being the four cultural dimensions that constitute the ecto-factor. Specifically, the regression model assessed how the MBA students' values regarding performance orientation, collectivism, uncertainty avoidance, and power distance influenced their views regarding the level of governmental laws and regulations that affect businesses and their CSR activities.

The results shown in Table 17 indicated that the regression model significantly predicted the students' attitudes toward the role that government regulation should play in business behavior, $F(5,264)=5.170, p=.000$. As indicated in Table 17, when taken independently, none of the factors except power distance was statistically significant. A positive change in power distance increased the students' views regarding the need for government regulation by .187 points or $2.7 \%$ on a 7 -point scale. ${ }^{16}$ The regression model indicated that the cultural dimensions explained $8.9 \%$ of the variance in the students' views regarding the ideal level of government regulation to promote CSR activities.

\footnotetext{
${ }^{16}$ In the case of government regulation, the higher the score, the less the student agrees with government regulation of business activities.
} 


\section{Table 17}

Regression Model of Cultural Dimensions to Government Regulation

\begin{tabular}{lrccrl}
\hline Coefficients & \multicolumn{2}{c}{$\begin{array}{c}\text { Unstandardized } \\
\text { Coefficients }\end{array}$} & $\begin{array}{c}\text { Standardized } \\
\text { Coefficients }\end{array}$ & & \\
\cline { 1 - 4 } & $B$ & Std. Error & $\beta$ & \multicolumn{1}{c}{$t$} & \multicolumn{1}{c}{ Sig. } \\
\hline Constant & 2.694 & .388 & & 6.938 & .000 \\
Performance & -.088 & .059 & -.098 & -1.508 & .133 \\
Collectivism & .033 & .044 & .049 & .753 & .452 \\
Uncertainty & -.007 & .044 & -.011 & -.165 & .869 \\
Power & .138 & .046 & .189 & 2.996 & $.003^{*}$ \\
\hline
\end{tabular}

Note. $R^{2}=.089$.

$* p<.01$.

It is interesting to note that, in general, the students' mean score on power distance was a low 2.40. However, the standard deviation of 0.97 was somewhat large.

On the other hand, students' mean score on views of government regulation was 3.03 , with a standard deviation of 0.71 , suggesting their agreement that a medium level of regulation was needed to control business activities.

The students' comments in the focus groups could explain this apparent contradiction. For example, a Latin American student, commenting on widespread corruption in the region, said, "To me, governments represent a father figure; its authority is critical to assure that everyone behaves properly." An Anglo student, referring to the corporate scandals in the United States, had a similar view when he stated, "As any other human activity, businesses are subject to temptations to behave improperly; government supervision is the equivalent of an authority figure to keep everyone in check." From a different perspective, but along the same line of thought, a Latin European student said, "Whether we like it or not, we cannot deny our royalist heritage; we expect authority from our governments." 
In summary, there seems to be a relationship, albeit small, between the students' power distance values and their belief in government's authority to control business activities.

All factors to the CSR motive. In both models one and two, the dependent variable was the student's motive towards CSR, or the endo-factor (normative vs. utilitarian). In model one, the independent variables were the student's views regarding the role of society, economy, and regulation in the practice of CSR, or the meso-factors. In model two, the GLOBE cultural dimensions, or ecto-factors (power distance, uncertainty, collectivism, and performance), were added as independent variables in order to determine whether these significantly improved the prediction of motives towards CSR over and above the meso-factors alone.

The results showed that the first regression model significantly predicted students' views toward the role that the meso-factors play in their motives regarding CSR practices, $F(3,266)=8.991, p=.000$. This significance was maintained in the second model after adding the ecto-factors, $F(3,266)=4.967, p=.000$. However, as shown in Table 18, when taken independently, the only factor statistically significant was government regulation, $p<.05$. In the first model, a positive change in views regarding government regulation increased the CSR score by .213 points. In the second model, this increase was lowered to .187 points.

The addition of the ecto-factors to the first model increased the predictability value from .092 to .117 , a difference in $R^{2}$ of .025 . However this variance was not statistically significant, $F(4,262)=1.861, p=.118$. Therefore, the second model 
Table 18

Hierarchical Regression Model of Meso- and Ecto-Factors to CSR

\begin{tabular}{lcccrc}
\hline Coefficients & \multicolumn{2}{c}{$\begin{array}{c}\text { Unstandardized } \\
\text { Coefficients }\end{array}$} & $\begin{array}{c}\text { Standardized } \\
\text { Coefficients }\end{array}$ & & \\
\cline { 1 - 4 } Model 1 & $B$ & Std. Error & $\beta$ & $t$ & Sig. \\
\hline Constant & 2.885 & .423 & & 6.816 & .000 \\
Society & -.101 & .057 & -.111 & -1.785 & .075 \\
Economy & .085 & .050 & .102 & 1.703 & .090 \\
Regulation & .195 & .058 & -.213 & 3.346 & $.001^{*}$ \\
\hline Model 2 & & & & & \\
\hline Constant & 2.645 & .468 & & 5.652 & .000 \\
Society & -.095 & .059 & -.104 & -1.616 & .107 \\
Economy & .087 & .051 & .104 & 1.690 & .092 \\
Regulation & .172 & .059 & .187 & 2.890 & $.004^{*}$ \\
Power & .084 & .042 & .125 & 1.967 & .050 \\
Uncertainty & .047 & .039 & .078 & 1.192 & .234 \\
Collectivism & -.048 & .040 & -.077 & -1.196 & .233 \\
Performance & .014 & .056 & .017 & .250 & .803 \\
\hline
\end{tabular}

Note. $R^{2}$ model $1=.092 . R^{2}$ model $2=.117 . \Delta R^{2}=.025$.

${ }^{*} p<.01$.

indicated that the cultural dimensions did not seem to have a meaningful influence on the students' CSR attitudes.

These results did not necessarily indicate that the factors depicted in the ICSRM were not related. The similarity on the students' scores, as analyzed through the ANOVA tests, and the similarity regarding the cultural factors as gleaned from the qualitative data provided during the focus groups, confirmed that the MBA students in this study had similar motives and views regarding CSR and each of the factors that influence its practice. Hence, a hierarchical multiple regression analysis of this sample was not likely to capture the relatedness that might exist in a less homogenous sample. 


\section{Other Findings}

Other interesting and relevant information was obtained by reviewing the demographic data collected through the survey. This section presents the differences in students' motives toward the endo-factor CSR, classifying the students by specialization, years or work experience, and gender.

Specialization. The students were classified according to their specialization in the MBA program. The following categories and number of students were recorded: 31 in supply chain, 41 in marketing, 34 in management, 72 in finance, and 36 in others. The mean results indicated in Figure 12 corroborated the previous findings in which all students had a balanced view between a normative and utilitarian motive regarding CSR. Students specializing in finance showed a slightly higher score, whereas students specializing in marketing showed the lowest.

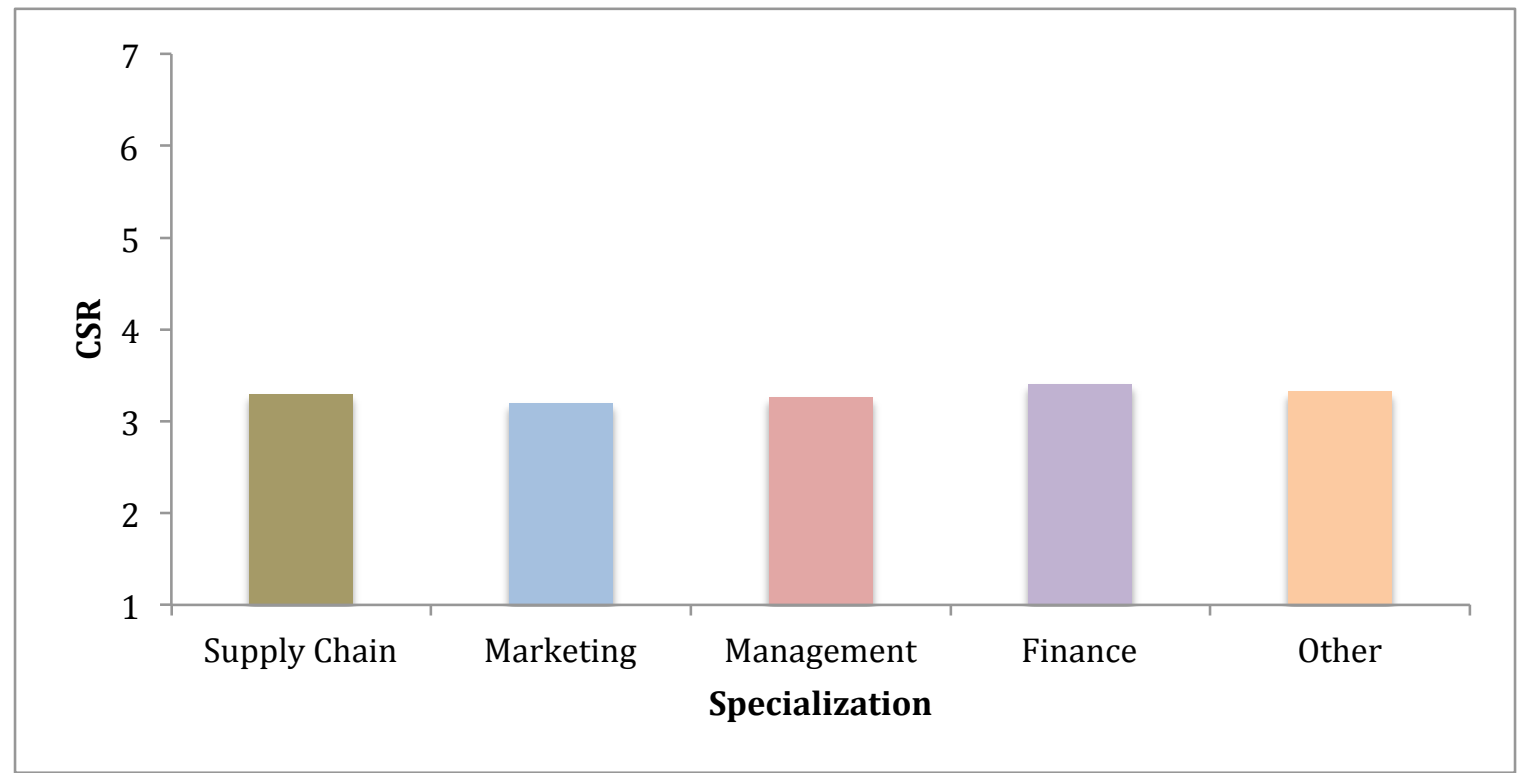

Figure 12. Mean results for motive regarding CSR. Scale from 1 to 7 . One represents a normative motive regarding CSR, whereas 7 represents a more utilitarian one. 
However, as can be seen from Table 19, the ANOVA results showed that there was no statistically significant difference in the CSR score between the different specializations of study, $F(4,209)=1.054, p>.05$.

Table 19

ANOVA Results Regarding CSR Motive by Specialization

\begin{tabular}{lccccc}
\hline Mayor & $M$ & $S D$ & $F$ & $p$ & $\omega^{2}$ \\
\hline Supply Chain & 3.29 & 0.59 & & & \\
Marketing & 3.19 & 0.58 & 1.054 & .380 & N/A \\
Management & 3.26 & 0.48 & & & \\
Finance & 3.40 & 0.57 & & & \\
Other & 3.32 & 0.63 & & & \\
\hline Tukey post-hoc Test: N/A & & & & \\
\hline$* p<.05$. & &
\end{tabular}

Work experience. The survey inquired about years of work experience in three categories: less than 2 years, between 2 and 5 years, and more than 5 years. However, since only four students in the entire sample answered less than 2 years of work experience, an independent samples $t$-test comparison for the remaining two groups was conducted. There were 94 students with work experience between 2 and 5 years and 115 students with work experience of more than 5 years. Figure 13 shows almost identical mean scores regarding the motives toward CSR of the two groups of students.

The independent samples $t$-test comparison corroborated that there was not a statistically significant difference in mean CSR score between the group of 2 to 5 years of work experience $(3.27 \pm .59)$ and the group of more than 5 years of work experience $(3.31 \pm .57), t(195.888)=-.522, p=.602$ 


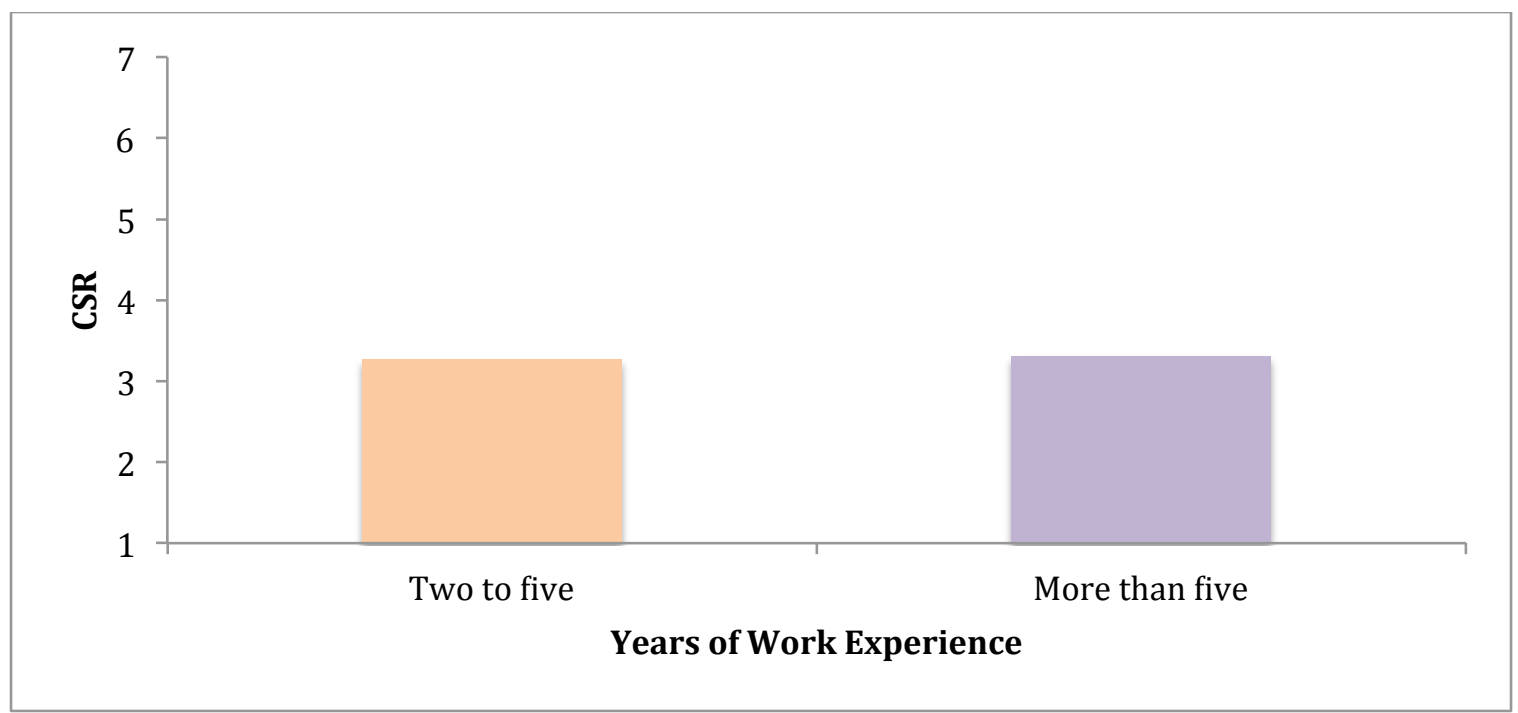

Figure 13. Mean scores for motive regarding CSR. Scale from 1 to 7 . One represents a normative motive regarding CSR, whereas 7 represents a more utilitarian one.

Gender. Two hundred and fourteen students answered the gender question, of whom 83 were females and 131 were males. Figure 14 shows that the mean scores due to gender were almost identical.

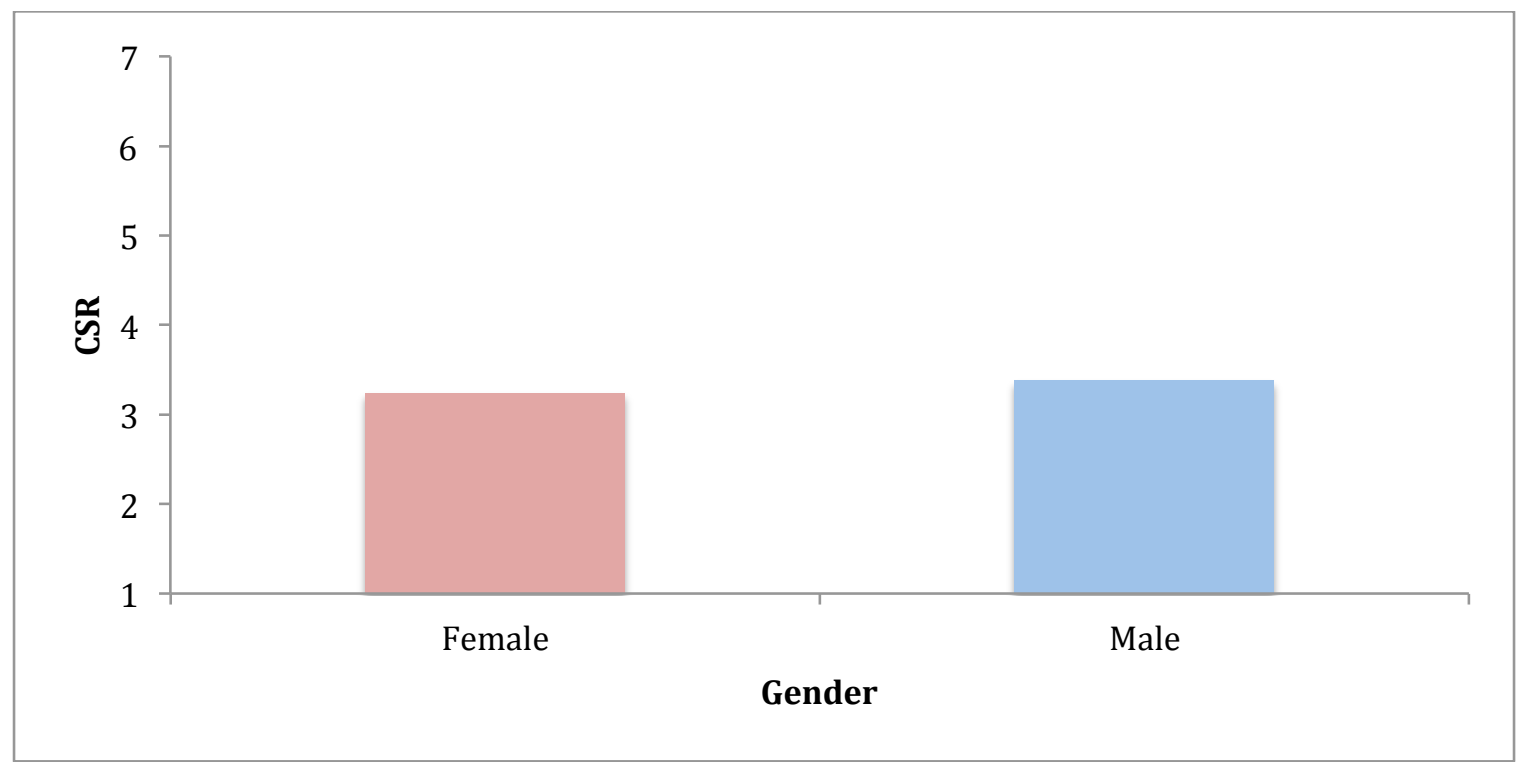

Figure 14. Mean scores regarding CSR and gender. Scale from 1 to 7 . One represents a normative motive regarding CSR, whereas 7 represents a more utilitarian one. 
An independent samples $t$-test comparison corroborated that at the $5 \%$ level of significance, there was not a statistical difference in mean CSR score between females $(3.24 \pm .73)$ and males $(3.38 \pm .59), t(191.844)=-1.671, p=.096$. However, it is interesting to note that at $p<.10$, which is a less rigorous statistical level but used in some cases, females tended to be slightly more normative in their CSR motives than males.

\section{Conclusion: Clones in the MBA Classroom}

In summary, the survey scores seemed to indicate that the MBA students from the three cultural clusters had fairly similar mean scores for the motive toward the endofactor CSR and their views regarding the meso- and ecto-factors. However, the ANOVA analyses showed that there were significant, albeit small, statistical differences among all factors except CSR and government regulation. Moreover, the Tukey post-hoc tests indicated that Anglos and Latin Europeans tended to differ from Latin Americans when a difference was present. However, these dissimilarities were not, from an attitudinal perspective, large enough to conclude that the students from the three different cultural clusters substantially differed in their motives regarding CSR and their views regarding the factors that influence its practice. In short, according to the sample from this study, MBA students from these three cultural clusters had a comparable mindset regarding the role of businesses in social betterment initiatives as well as comparable cultural values.

According to the qualitative data, four factors seemed to serve as the glue that holds these values together. First, there seemed to be a common generational attitude towards addressing social issues, sharing power, increasing individual freedom, and achieving a personal purpose in life. The second was the impact of social media, the 
Internet, and globalization, as they have made the world smaller and more alike. The third was the influence that the school's curricula and values had on students to attain business results, but in a socially responsible manner. Finally, there seemed to be recognition that governments, civil society, and businesses each have a complementary role to play as social actors.

Given the similarity in the students' views, the multiple regression analysis of relatedness was hardly conclusive. From a purely statistical point of view, the relatedness between the factors seemed to be negligible. However, from the qualitative information and the ANOVA results, we can infer, without assuming causality, that students who had a balanced motive between a normative and utilitarian view of CSR also had a relatively high regard for the power of civil society in monitoring businesses; a favorable view of free market economies, provided that inequalities are addressed; and a sensible view regarding government regulation, particularly in controlling corruption and fraud. Additionally, these students tended to be highly performance oriented, slightly more collectivistic than individualistic, somewhat risk averse, and low in power distance beliefs. The discussion that will follow in the next chapter explains the possible factors that might influence these conclusions. 


\section{CHAPTER FIVE}

\section{DISCUSSION AND IMPLICATIONS}

The success of the U.S. MBA program, as we know it today, has become the dominant model for business schools across the world. In fact, the American style of business education in an academic setting has become an increasingly global phenomenon. Student demand for this approach to business education surpasses the ever increasing supply offered by new business schools in most countries of the world (Moldoveanu \& Martin, 2008). However, a number of business academics and practitioners have cautioned that the current MBA programs' approach provides a limited understanding of the ethical and social considerations that are essential to SRBL, which they claim was one of the main factors that contributed to the major corporate scandals and the 2008 world financial crisis (Amann, 2011; Datar et al., 2010; Moldoveanu \& Martin, 2008; Morsing \& Sauquet, 2011; Swanson \& Fisher, 2008). This globalization of the American MBA program, as well as the call by scholars and practitioners for a more holistic view of business in which social issues become a fundamental tenet of the curricula, increases the need to understand the extent to which cultural variables influence MBA students' motives and views regarding CSR.

The purpose of this two-phase explanatory sequential mixed methods study was to take a first step in generating comprehensive empirical data regarding this issue. Specifically, this dissertation was guided by two overarching questions. The study first sought to determine the extent to which business students from three different cultural clusters differed, if at all, in their motives toward and views regarding the factors that support CSR. Once these differences were assessed, the study then looked into potential 
relationships between certain distinctive cultural dimensions and these business students' motives toward and views regarding these factors. In short, this study followed a deductive approach to test the ICSRM presented in Chapter One (Figure 1), which theoretically incorporates the factors that, according to the literature, influence CSR practice.

This chapter first presents a summary and discusses the general findings of the study. Then, it provides a detailed examination of the outcomes regarding the differences in students' motives and views toward each of the factors that influence CSR. It follows with an analysis of the relationship between the cultural dimensions that were the object of this study and the factors that theoretically drive CSR practice. After positing the limitations of the study, this chapter ends with implications and suggestions for future research.

\section{Summary of Findings: Clones in the MBA Classroom}

Two significant findings can be derived from the surveys and focus group results. The first indicated that the MBA students in this study had almost identical motives toward CSR and very similar views regarding the factors that drive its implementation. The quantitative analyses, which will be discussed in detail in the next section, did show statistically significant differences in six of the eight factors (society, economy, performance, collectivism, uncertainty, and power distance). However, in terms of personal attitudes, the differences were quite small and did not impact the overall direction of each factor. Figure 15 offers an aerial view of the similarities and differences between cultural clusters. 


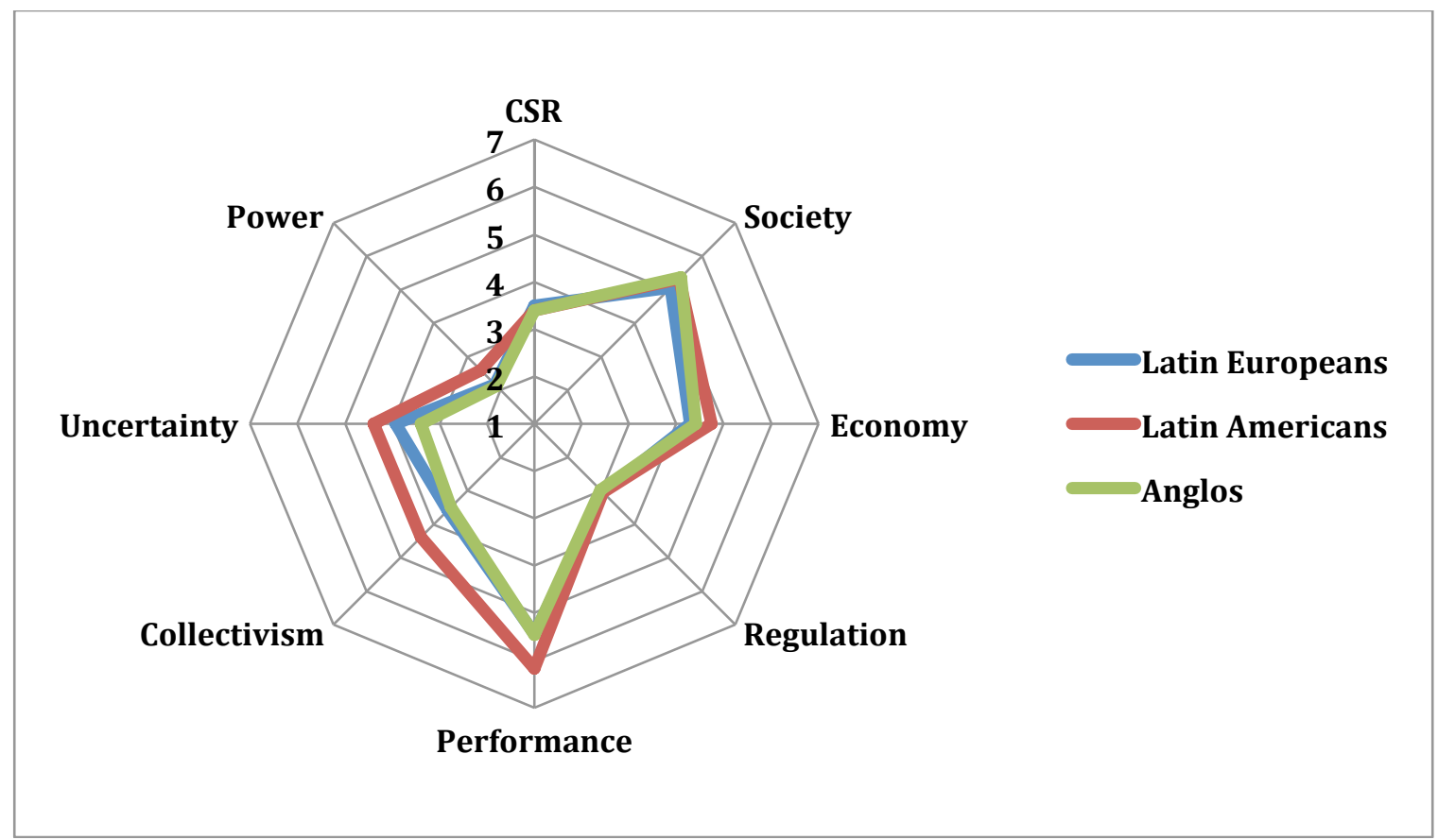

Figure 15. Mean scores for all ICSRM factors. For detailed results, see Table 5.

The second major finding was also related to the similarity of the students' scores at both the individual and group level of analysis, as indicated in the results of the ANOVA tests and gleaned from the qualitative data provided during the focus groups. As a consequence of this homogeneity in the sample, the regression analyses did not capture the relatedness between the ICSRM factors that might exist in a less homogenous sample. Therefore, for this group of students, the cultural dimensions of collectivism, uncertainty avoidance, performance orientation, and power distance do not seem to have a meaningful influence on the students' CSR motives and their views regarding the mesofactors of society, government, and economy. These results do not necessarily indicate that the factors depicted in the ICSRM are not related; they might very well be, but a more heterogeneous sample might be needed to be able to probe the strength of such relationships. 
There seem to be three possible explanations for these results. The first has to do with the attitudes of what is known as the millennial generation ${ }^{17}$ (Caraher, 2015; Notter \& Grant, 2015). The second is related to the concept of the three levels of cultural values, that is, the ones held at the individual or personal level; the ones that develop at the group or organizational level; and, finally, the societal values held at the national level (Harrison \& Huntington, 2006; Schein, 2010; Thomas \& Peterson, 2015). Finally, globalization and the effect of the Internet seem to play a role in the homogenization of values across specific segments or groups in the world (Minkov, 2013; Naím, 2013). The sections that follow delve deeper into the discussion of the reasons that might undergird the results regarding each one of the endo-, meso-, and ecto-factors.

\section{Research Questions One and Two: Differences in Students' Motives and Views}

The following were the overarching research questions posited to assess the possible differences in the students' motives and views toward CSR:

1. How do business students from three different cultural clusters differ, if at all, in their motives toward and views regarding the factors that support CSR, according to the ICSRM?

a. In what ways, if any, do students' motives toward CSR, as defined by the endo-factor (normative and utilitarian), differ?

b. In what ways, if any, do students' views regarding the meso-factors (societal, economic, and regulatory) differ?

c. To what degree, if at all, do students' cultural dimensions, referred to as ecto-factors (collectivism, power distance, performance orientation, and uncertainty avoidance), differ?

\footnotetext{
${ }^{17}$ Born between 1982 and 2004 and thus most of the current MBA students.
} 
2. How do individuals from each of the three cultural clusters make meaning of the factors that support CSR, according to the ICSRM?

As a consequence, this section will first address the similarities in students' motives regarding the endo-factor CSR, which was a central goal of the study. Then, the results regarding each of the meso-factors - societal influence, government regulation, and socioeconomic model-will be discussed. This section ends with an examination of the students' views regarding the cultural dimensions represented by the ecto-factorscollectivism, uncertainty avoidance, performance orientation, and power distance.

Students' motives regarding the endo-factor CSR. Many of the issues that seem to explain the results regarding the students' motives toward CSR (the endo-factor) are also pertinent to the issues of societal influence, government regulation, and socioeconomic model (the meso-factors) as well as those of collectivism, uncertainty avoidance, performance orientation, and power distance (the ecto-factors). Thus, several arguments in the following discussion could apply to the all three factors. For this reason, this section delves into more detail than the ones that follow, which discuss only specifics unique to the meso- and ecto-factors.

As far as the endo-factor, or students' motives toward the concept and practice of CSR, the results showed that not only did all three groups land in the center of the spectrum between normative and utilitarian motives but their scores were almost identical on this factor. Most MBA students in this sample believe that businesses should engage in CSR activities, holding the tension between wanting businesses to be both profitable and socially responsible at the same time. As one of the students commented during one of the focus groups, "It seems to me that it really does not matter what industry you are 
in; nowadays, there is so much awareness about social issues that if companies do not contribute in some way to solve them, then the problem will come back and bite them."

The study results suggest, as management scholar Mintzberg (2004) has pointed out, that a new generation of MBA students seems to understand that their role as business leaders goes beyond the contested and narrow agency theory that focuses almost exclusively on maximizing shareholders' profits (Friedman \& Ebenstein, 2012). Three causes might explain these findings: the millennial generation, the culture of the schools that participated in the study, and the effects of globalization and the Internet.

The millennial generation. Strauss and Howe (1998), scholars and recognized authorities in the study of generations, have argued and demonstrated that, in the last 500 years in every fourth generation (about 80 years), there is a major transition that has had a deep impact on people's attitudes and beliefs. Strauss and Howe point out that, in the United States, the first transition occurred during the 1770's Revolutionary War, followed by a second transition 85 years later with the Civil War, and then the Great Depression and WWII marked the third and final transition. If this trend is accurate and continues, we are at this moment entering a new transition that will mark a fundamental shift in values.

One symptom of this major transition may be that, as noted earlier, this new generation of MBA students is not content with businesses focusing exclusively on profitability (Mintzberg, 2004). For example, the 2008 Net Impact survey showed that $52 \%$ of MBA students agreed that businesses should play a role in addressing social and environmental issues. This percentage has nearly doubled since the 2001 survey (Aspen Institute, 2008). Millennials entering management positions today have a stronger social 
sensitivity than the previous generations, according to millennial generation scholars Notter and Grant (2015) and Caraher (2015). These authors cite research that showed that $56 \%$ of MBA students would be willing to take a $15 \%$ pay cut to be able to work in a company committed to CSR (Net Impact, 2012). CONE Communications, a leading firm in CSR research, found similar results. In their most recent study, they posit that, in the United States, $62 \%$ of millennials are willing to take a pay cut to work in a firm that engages in CSR activities, $87 \%$ are willing to pay more for a product with a social or environmental benefit, and $74 \%$ will volunteer for a cause supported by a company they trust (CONE Communications, 2015). More importantly, CONE Communications (2015) also found that 84\% of young millennials (aged 18-24) would consider CSR when deciding where to work versus only $75 \%$ of mature millennials (aged 24-35), which indicates that this trend will continue to increase.

This tension between purely altruistic and selfish motives toward CSR is reminiscent of what sociologist Raymond Aron (1962) calls a reasonable egoism in his masterpiece The Opium of the Intellectuals. Aron, who was a fervent opponent of both extreme Marxist and capitalist ideologies throughout the Cold War, argued that individuals should engage in neither saintly nor criminal behaviors but instead seek their own well-being within the limits of social responsibility. After half a century, Aron's warnings regarding ideological fanaticism of any kind seem to be permeating the mentality of this new generation of business students.

This form of pragmatism could very well be a social and cultural trend that will shape and define management practices in the future. Given Strauss and Howe's (1998) study on transitions, it is interesting to note that roughly four generations ago, Taylor's 
(1911/1967) mechanistic view of businesses planted the first seeds of what we know today as scientific management. Millennials might be advancing a transition toward more socially responsible and human-centered business practices, something which several scholars have called for (Datar et al., 2010; Maak \& Pless, 2006; Mintzberg, 2009; Moldoveanu \& Martin, 2008). In fact, Mayer (2014) provides evidence of this evolution in management practices, highlighting that younger business leaders are challenging many of what he calls corporation's defects, which have produced inequalities and social suffering.

Some could argue that the millennials' social orientation is just an expression of youthful idealism that will fade over time. However, extensive research has shown that this postmaterialistic orientation that values social justice, tolerance, and concern for the environment is rooted in deeply ingrained beliefs in this younger generation (Welzel, Inglehart, \& Kligemann, 2003). These researchers suggest that theories of human development such as Maslow's (1968) hierarchy of needs and others (Erikson, Paul, Heider, \& Gardner, 1959; Kegan, 2001; Plotkin, 2008) might explain this. The argument is that because this generation has grown up in an era of affluence and abundance in which well-being and security are taken for granted, there is less emphasis on the materialistic values previous generations developed as a result of the scarcity they encountered. As Bill Clinton (2007) once said, "I firmly believe that progress changes consciousness, and when you change people's consciousness, then their awareness of what is possible changes as well" (p. 38).

In summary, there is strong evidence suggesting that this new generation of MBA students is more focused on socially responsible business practices than previous 
generations were. Moreover, as Notter and Grant (2015) points out, scientific

management, as a discipline, might be at a point in time in which the four-generation cycle is completed and the world is about to enter a new era. However, it is important to recognize, as was mentioned earlier, that the students in this study attend business schools with an ethos that is particularly strong regarding social responsibility. The next section further addresses this point.

The culture of the business schools. Two issues are meaningful regarding the culture of the business schools surveyed in this study. The first is the strong emphasis that ESADE, INCAE, and USD provide on CSR teaching and practice, which could make these schools outliers in their social responsibility ethos in business education. The different manifestations of these strong cultural values, which Schein (2010) calls artifacts, espoused beliefs, and basic underlying assumptions, could act as embedding mechanisms that impose these same values on all the students attending these schools.

The second issue regarding these schools is that the students themselves might have chosen these institutions precisely because of this social orientation, and therefore they came into the program with a strong sensitivity toward social matters. Schein (2010) posits that individuals have a strong need for membership in a group that shares similar values, stressing that "this process of trying to be accepted by our membership and reference group is unconscious and, by virtue of that fact, very powerful" (p. 197). In short, the values at the organizational level (the schools) and the individual level (the students) may have coincided from the start, creating a nested and not separate system of beliefs and values. Scott (2001) describes this phenomena well, writing:

Cultural systems operate at multiple levels, from the shared definition of local situations, to the common frames and patterns of beliefs that comprise an 
organization's culture, to the organizing logics that structure organization fields, to shared assumptions and ideologies that define preferred political and economic systems at national and transnational levels. These levels are not sealed but nested, so that broad cultural frameworks penetrate and shape individual beliefs on the one hand, and individual constructs can work to reconfigure far flung belief systems on the other. (p. 68)

According to Joosten, Van Dijke, Van Hiel, and De Cremer (2014), consistent ethical behavior is the product of ethical identity and an environment that fosters its practice rather than simply being exposed to ethical values. This identity is what these business schools seem to be trying to develop. In the words of Luis Ugalde (1998), a Jesuit who is the rector of the Catholic University in Caracas, Venezuela, "If students learn a progressive ethic in school and find it irrelevant to their lives outside school, the impact may be scant” (Ugalde, Barros, \& McLean, 1998, p. 134). Following Ugalde's line of thought, Paine (2003) asserts that an increased number of business schools and corporations are trying to implement what she calls centre-driven decision making in which analyses of net present value (NVP) meet a moral point of view (MPV) in what she calls the zone of acceptability. Thus, the decision-making process links espoused values with the actual choices that business leaders have. In short, the zone of acceptability is a model that requires business students and practitioners to walk the talk.

The qualitative information gleaned from the focus groups provides evidence that there seem to be forces bolstering the development of this ethical identity in the millennial generation. This is what Schein (2010) calls the strengthening of underlying assumptions that unconsciously support consistent behaviors, which are in actuality based on espoused values. These factors are the Internet and globalization, which will be discussed next. 
Internet and globalization. "You know, in our parents' generation, people sent telegrams; now, communication across the world is instantaneous. That is why the social awareness that you mention is global; it does not matter where you are from." This quote by one of the students in the focus groups clearly reflects the impact that current communication technologies, especially the Internet, could have in raising global awareness in regard to social responsibility.

In a recent study of 48 countries, Ralston and Potocan (2014) concluded that social networking is the single most important factor for experiencing virtual travel and interacting with other cultures for those in their formative years, which should raise awareness regarding social, political, and economic problems anywhere in the world. More importantly, this social networking force has the capability to act as a group, even if the parties have never met, eliciting socially responsible practices from leaders across the world. Caraher (2015) describes this, writing, "This is a generation who has grown up one e-mail away from any CEO or political leader in the country and even the world" (p. 36). No other generation has had a tool as powerful as the Internet to influence world events. As one of the students commented in reference to TIME magazine's 2006 person of the year, "You, you, and me. All of us individually were the person of the year. We, as members of society, have the power to make a difference in ways our parents never dreamt of."

Globalization is another influence that could spread a more socially responsible way of making business decisions. Business schools are becoming more global, opening campuses in different parts of the world and establishing joint ventures with other universities in order to share best practices (Datar et al., 2010; Moldoveanu \& Martin, 
2008). The students graduating from these schools with a socially responsible orientation will be joining a work force that is more international and culturally diverse. For example, Colakoglu and Caligiuri (2008) report that there are over 65,000 multinational companies with over 850,000 subsidiaries operating worldwide, and this number should have grown since then. This trend will create a next generation of multicultural business leaders whose socially oriented values could reinforce this possible revision of business practices (Thomas, Brannen, \& Garcia, 2010). Of course, the effectiveness of the millennials in regard to social orientation will also depend on the meso-factors defined in the ICSRM: societal influence, government regulation, and socioeconomic system. The next section discusses the students' views regarding these factors.

Students' views regarding the meso-factors. The CSR literature described in Chapter Two identifies three factors related to the environment in which the organization is embedded that have an influence on its CSR activities. The first is the societal effect on company decisions (Donaldson \& Preston, 1995; Mitchell et al., 1997; Morsing \& Langer, 2007). The second is the socioeconomic system in which the firm operates (Fukukawa, 2010; Matten \& Moon, 2008; Richter, 2010). The third is the institutional strength and level of regulation in the region where the firm does business (Kostova et al., 2008; Schwartz \& Carroll, 2003). A discussion of the results regarding the students' views for each of these factors follows.

The role of society. The results revealed that students' attitudes across all three clusters strongly support the notion that society has a critical influence on business behavior. This result is not surprising given the students' attitudes toward CSR in which they seek to hold the tension between stakeholders' and stockholders' interests. In short, 
students feel that the role of society, represented primarily by the stakeholders of the firm, is integral to a more holistic view of the purpose of businesses, as Freeman (1984) suggested in his stakeholder's theory, presented in Chapter Two. In fact, there is ample research that shows a significant, positive effect of the pressure by stakeholders in an industry on the levels of CSR (Fernandez-Feijoo et al., 2014).

Not only does this group of students seem to accept the role of stakeholders, but they also act as one. For millennials, the power of social media as a tool of influence is part of their daily life. According to the Pew Research Center (2014b), 85\% of college students in the United States and Europe participate in digital networking on a daily basis. According to Notter and Grant (2015), this participation could be, for the most part, considered social and political activism since this is the millennials' preferred media for spreading their ideas and putting pressure where it is needed for the changes they believe in.

While Latin Americans scored slightly higher than the other two clusters, this may be more aspirational than real. As one of the INCAE student said, "I wish Latin America had the quality of government and institutions that Europe and the States have. In my country, civil society organizations have somehow made up for the lack in many of the government failures and, in the process, gained legitimacy." The World Values Survey (2012) results regarding the level of confidence in civil society organizations support this comment, with $71 \%$ of Latin Americans having a good deal of confidence in social organizations compared with around $60 \%$ in the United States and Latin Europe.

In short, the students from the three cultural clusters see civil society institutions as an integral part of their lives and as influencers of business behavior. This is probably 
because they have grown up in an environment that facilitates this role. This upbringing appears to span the globe, given that cultural factors only explain $5 \%$ of the variance.

Socioeconomic model. The results showed that all three groups shared a somewhat strong view towards free markets, with Latin Americans showing a slightly higher preference than the other two groups. These results are somewhat surprising. One would expect business students to show a marked preference for free market economies. To be sure, the results are skewed in favor of this system, showing a total mean of 4.50 , which indicates a favorable view of capitalism, but also recognizing that governments should assume certain economic responsibilities. These results are congruent with an extensive London Business School and Harvard Business School joint research of 42 countries spanning 7 years in which Ioannou and Serafeim (2012) demonstrated that countries characterized by a left political ideology tend to score lower on a CSR index and vice versa. Moreover, as countries move to more free market policies, there is a parallel increase in the acceptance of the role of business in solving societal problems.

This preference for free markets, given certain qualifications, means that these MBA students seem very aware of the economic inequalities that this system can produce, which several reputable scholars across the world have raised recently (Kotler, 2015; Merino, 2014; Piketty, 2015; Villalobos, 2013). As one of the students stated, "The States is considered the best example of a free market system, but inequality is also growing at unbearable levels. Free markets might produce GDP growth, but they do not assure a fair wealth distribution."

Interestingly, Latin Americans, whose countries have recently embraced free market policies, showed a slightly higher preference for this system than Anglos and 
Latin Europeans, which could also indicate an aspirational motive. In fact, the 2012 World Values Survey indicated that on a scale of 1 (left-leaning attitudes) to 10 (rightleaning attitudes) Latin Americans scored 6.10, whereas Latin Europeans scored 4.76 and Americans scored 5.76, which coincides with the results of this study. Moreover, a Pew Research Center (2014a) study regarding free market attitudes in Latin American countries showed that in Venezuela and Nicaragua, countries that have reversed the free market policies initiated in the 1990 s, almost $70 \%$ of the population affirmed the benefits of liberal economics, whereas in Chile and Colombia, countries that have deepened free market economic policies, only $50 \%$ of the population shared the same opinion.

In summary, all the MBA students showed somewhat of a preference for free market economic policies, provided that the inequalities that the system produces are properly addressed. The slight differences between the three groups seem to come from aspirational factors more than from cultural ones. In fact, the $\omega^{2}$ result indicates that the cultural dimensions only explain $5.5 \%$ of the differences.

Government regulation. The results about the students' perception of the role of government showed that all three groups affirmed its importance in implementing CSR. Of the three meso-factors analyzed in this study, the results regarding the students' views on government regulation are the most striking. Conventional wisdom would suggest that business people do not favor government's intervention on business matters. This does not seem to be the case with these MBA students, who seem to support a certain level of supervision and control.

This may be because the students recognize that corruption is a real and complex issue that must be addressed. As one of the students commented in the focus group, 
"Corruption is a multifaceted issue, not easy to solve ... precisely because of this complexity I have to accept that government regulation is inevitable."

The corporate scandals that led to the 2008 financial crisis probably strongly influenced not only this view towards government regulation but also the overall results, which might have produced a pendulum effect towards the desire for a more regulatory environment and a balanced motive towards CSR. However, this swing does not necessarily mean that eventually we will go back to deregulation and less control but perhaps instead to a more efficient system and a strengthening of the institutional framework. Joosten et al. (2014) argue that this evolution of the regulatory structure and the development of business leaders who are high in moral and ethical identity should reduce the need for regulatory resources and minimize unethical leadership. In the meantime, these students' views are consistent with the view of J. L. Campbell (2005), who decisively argues that "variations in socially responsible behavior is probably associated with variation in institutions and the stick and carrots they provide to constrain and enable such behavior" (p. 52).

In summary, cultural dimensions do not seem to have a significant effect on the students' views regarding the level of government regulation. Instead, the forces described above seem to drive a somewhat favorable view of government control over business activities.

Students' views regarding the ecto-factors. The ICSRM presented in Figure 1 suggests that the culture in which an organization operates might be a final and external level with the potential to influence the perception and practice of CSR. Understanding the extent to which this factor influences the endo-factor CSR and the other meso-factors 
was the primary objective of this study. To that end, the study examined four out of the nine cultural dimensions presented in project GLOBE: performance orientation, in-group collectivism, uncertainty avoidance, and power distance (House, 2011). A discussion of the results regarding the students' views for each of these cultural values follows.

Performance orientation. The results regarding performance orientation showed that there were significant differences between the three clusters in regard to this factor. While all three showed a high performance orientation, Latin Americans' attitudes were stronger than those of the other two clusters. These results are congruent with the findings of project GLOBE for each one of these cultural clusters, as can be seen in Table 20.

Table 20

Cultural Cluster and Performance Orientation

\begin{tabular}{lcccccc}
\hline & \multicolumn{3}{c}{ Societal Practices } & \multicolumn{3}{c}{ Societal Values } \\
\cline { 2 - 7 } Cultural Cluster & $M$ & $N$ & $S D$ & $M$ & $N$ & $S D$ \\
\hline Latin Europe & 3.94 & 6 & 0.28 & 5.94 & 6 & 0.27 \\
Latin America & 3.85 & 10 & 0.28 & 6.24 & 10 & 0.20 \\
Anglo & 4.37 & 7 & 0.22 & 6.03 & 7 & 0.14 \\
\hline
\end{tabular}

Note. Data from House et al. (2004), p. 262.

Latin Americans showed the highest score on values but the lowest on practices, a marked difference, which Argyris and Schön (2003) have called the difference between espoused values and reality. Once again, an aspirational motive might be driving this result, as was suggested regarding their scores on the meso-factors of society and economic model. In the words of a Latin American student, "In the old times, the 
majority of positions were not awarded for merit but rather for political connections or seniority. That practice is now changing, but we still have a long way to go."

The questionnaire used in this study did not measure the actual students' practices, but it would be reasonable to assume that they are closer to their values than the practices of those in the GLOBE study due to the influence of participants' close proximity and working relationships. For example, Schein (2010) states that every organization consists of a group of individuals that need to set common values and practices to work together as a community in order to succeed in dealing with the challenges they face. Business students are being trained to be leaders in the business world, and although performance orientation is not necessarily the opposite of being compassionate towards others, early leadership trait theories stressed performance orientation as one of the most important traits to be an effective leader (Mann, 1959; Stogdill, 1948). Therefore, it is only natural to expect business students to value performance. However, cultural dimensions did explain around $20 \%$ of the differences in these high performance orientation attitudes.

Collectivism. The results showed that there were differences among the cultural clusters on collectivism. While Anglos and Latin Europeans fell along the middle between individualism and collectivism, Latin Americans tended toward more collectivistic beliefs.

In terms of how each cluster ranked, the MBA students' scores matched the direction of the GLOBE study results and showed that Latin Americans displayed the highest collectivistic value, followed by Anglos and then Latin Europeans. However, the overall scores are lower compared to the scores in the GLOBE study (Table 21). This 
means that these business students' views tend to fall more toward the center of the continuum between individualism and collectivism than the general population's views Table 21

\section{Cultural Cluster and Collectivism}

\begin{tabular}{lcccccc}
\hline & \multicolumn{3}{c}{ Societal Practices } & \multicolumn{3}{c}{ Societal Values } \\
\cline { 2 - 7 } Cultural Cluster & $M$ & $N$ & $S D$ & $M$ & $N$ & $S D$ \\
\hline Latin Europe & 4.80 & 6 & 0.21 & 5.66 & 6 & 0.22 \\
Latin America & 5.52 & 10 & 0.24 & 6.06 & 10 & 0.20 \\
Anglo & 4.30 & 7 & 0.22 & 5.84 & 7 & 0.12 \\
\hline
\end{tabular}

Note. Data from House et al. (2004), p. 478.

do in their respective cultural clusters. This makes sense because the reward and promotion systems in the business world tend to be individually based. One of the students articulated this position well, saying, "I think that ultimately we all understand that it is impossible to do it all by ourselves and achieve the things we want. But, let's be clear; in a job interview, you are going to say that, yes, you worked in a group, but you will also say that you led the group. At the end, what is important is the individual achievement."

There are several studies that have contradictory results regarding the correlation between individualism-collectivism and CSR. For example, Kim and Kim (2010) found that individualism was negatively correlated with CSR practice. On the other hand, Ioannou and Serafeim (2012) demonstrated that, in individualistic societies, there is wider acceptance and support for the practice of CSR. This dissertation provides yet another finding, showing that a value that holds the tension between individualism and 
collectivism fosters the adoption of CSR practices. Although the majority of the students fell in this center of the spectrum, cultural differences did explain $23 \%$ of the differences.

Uncertainty avoidance. The results for this cultural factor showed that Anglos were lowest in attitudes toward uncertainty avoidance, Latin Americans were the highest, and Latin Europeans fell in the middle. The MBA students' scores regarding this cultural dimension are very similar to those found in project GLOBE. Specifically, in the GLOBE study, Latin Americans also displayed the highest uncertainty avoidance, followed by Latin Europeans and then Anglos (Table 22). However, the overall scores are lower in both values and practice compared to the GLOBE study, which means that these students show lower uncertainty avoidance than the general population in their respective cultural clusters.

Table 22

Cultural Cluster and Uncertainty Avoidance

\begin{tabular}{lcccccc}
\hline & \multicolumn{3}{c}{ Societal Practices } & \multicolumn{3}{c}{ Societal Values } \\
\cline { 2 - 7 } Cultural Cluster & $M$ & $N$ & $S D$ & $M$ & $N$ & $S D$ \\
\hline Latin Europe & 4.18 & 6 & 0.45 & 4.36 & 6 & 0.31 \\
Latin America & 3.62 & 10 & 0.25 & 4.98 & 10 & 0.27 \\
Anglo & 4.44 & 7 & 0.25 & 4.09 & 7 & 0.28 \\
\hline
\end{tabular}

Note. Data from House et al. (2004), p. 636.

Interestingly, project GLOBE also found a negative correlation $(r=-.80 p<.01)$ between economic prosperity and uncertainty avoidance. That is, the higher the level of economic development, the more comfortable the population feels in living with uncertainty and fewer rules and regulations. This may provide one possible explanation as to why Latin America, which has a less developed economy and a much lower GDP 
than the other two clusters, showed the highest level of uncertainty avoidance. A Latin American student concurred with this, saying, "You know, in Latin America, we have had so much political and economic instability that the last thing we need is more surprises; I like to plan, even if I have to change plans every year."

The correlation between uncertainty avoidance and CSR has not been researched prior to this study. However, the GLOBE study did find that in societies with less uncertainty avoidance, there are higher levels of humane-oriented leadership and participative leadership acceptance and practice. These styles of leadership should be more conducive to SRBL (Wheatley, 1999).

Power distance. The results showed that MBA students from all three cultural clusters displayed low scores on the power distance dimension. Despite this general attitude towards flatter social structures, Latin Americans' perspective was slightly more hierarchical than the perspectives of Latin Europeans and Anglos.

These results mirror those of the GLOBE study in regard to the cultural value of power distance (Table 23). However, the espoused values scores are almost twice the actual practice ones, which show a high aspirational attitude (Argyris \& Schön, 2003). Despite this gap in the general population, it is reasonable to infer from the research on millennials that in this group of students, the values and practice scores might be closer because they seem to very clearly reject power structures.

According to Caraher (2015) and Notter and Grant (2015), the Internet revolution seems to be influencing this generation's views regarding hierarchies and centralization of control. As information is shared, so is power. Also, the rapid expansion of and 
access to higher education across the world has led to the growth of the middle class, which is less tolerant of hierarchies and class differences.

Table 23

Cultural Cluster and Power Distance

\begin{tabular}{lcccccc}
\hline & \multicolumn{3}{c}{ Societal Practices } & \multicolumn{3}{c}{ Societal Values } \\
\cline { 2 - 7 } Cultural Cluster & $M$ & $N$ & $S D$ & $M$ & $N$ & $S D$ \\
\hline Latin Europe & 5.30 & 6 & 0.42 & 2.57 & 6 & 0.23 \\
Latin America & 5.70 & 10 & 0.27 & 2.52 & 10 & 0.39 \\
Anglo & 4.90 & 7 & 0.28 & 2.86 & 7 & 0.31 \\
\hline
\end{tabular}

Note. Data from House et al. (2004), p. 540.

Research regarding the correlation between power distance and CSR is also contradictory. Ioannou and Serafeim (2012) found that a positive score on power distance tends to create "a sense of noble obligation on the part of business executives to pay attention to the needs of their stakeholders, and of society more broadly" (p. 852). However, Ralston and Potocan (2014) found that in societies high in power distance, business executives' concern for others tends to be low because they do not consider it their responsibility.

In summary, the results regarding research questions one and two, how business students from three different cultural clusters differ, if at all in their motives and attitudes toward factors that support CSR, as well as how these students make meaning of these factors, indicate that, despite some differences, there are critical similarities regarding students' motives and views toward each of the ICSRM factors. This raises an important question, which is what, if any, might be the relationship be between these various factors? The discussion of the results regarding this question is addressed next. 


\section{Research Questions Three and Four: Relatedness Between the ICSRM Factors}

These questions addressed the gap in the CSR literature regarding the possible influence, if any, that the four project GLOBE cultural dimensions-performance orientation, collectivism, uncertainty avoidance, and power distance (ecto-factors) could have on MBA students' motives toward CSR (endo-factor) and their views regarding the role of society in monitoring businesses behavior, the ideal economic model, and the level of government regulation over business activity (meso-factors). Specifically, the research questions were:

1. To what degree, if at all, do cultural dimensions relate to business students' motives toward and views regarding the factors that support CSR, according to the ICSRM?

a. To what degree, if at all, do cultural dimensions relate to business students' motives toward CSR, as defined by the endo-factor (normative and utilitarian)?

b. To what degree, if at all, do cultural dimensions relate to business students' views regarding the meso-factors (societal, economic, and political)?

2. How do individuals from each of the three cultural clusters make meaning of the relationship between the cultural dimensions and the factors that support CSR, according to the ICSRM?

The overall result regarding this relatedness indicated that, despite all the models being statistically significant in predicting the dependent variables, only one independent variable in each of the models was significant. In other words, as will be explained next, 
the models tend to have a relatively low predictive capacity. In the four sections that follow, the results of each of the regressions used to analyze these relationships are discussed. In a fifth and final section, the results of the hierarchical regressions used to analyze the relatedness of both the meso- and ecto-factors to CSR, which showed the validity of the proposed ICSRM presented in Figure 1, are discussed.

Cultural dimensions to endo-factor. The goal of the study was to assess how MBA students' values regarding performance orientation, collectivism, uncertainty avoidance, and power distance (ecto-factors) influence whether their motives toward CSR are normative or utilitarian (endo-factor). The results showed that the model did have a slight predictive capacity regarding attitudes toward CSR, but only power distance was significant.

As was discussed in the previous section, the means of the motives toward CSR are basically identical for all the students, regardless of the cultural cluster to which they belong. Moreover, the standard deviation is relatively small, which indicates a narrow spread of the data. Consequently, the predictive capacity of the model, as was mentioned, has to be small. The effect of power distance over CSR is too small to reach any definitive conclusion.

In summary, for this group of students, it cannot be concluded that the cultural dimensions have any significant effect on their motives toward CSR. As was abundantly discussed in the previous section, the millenials' attitudes toward CSR seem to be a general generational perspective, which is strongly influenced by other factors such as globalization and the Internet. 
Cultural dimension to meso-factors. This study explored how the MBA students' values regarding performance orientation, collectivism, uncertainty avoidance, and power distance (ecto-factors) relate to their attitudes regarding each one of the three meso-factors: the influence of social players on business behavior, the preferred economic model to develop CSR activities, and the required level of government regulation on business operations. A discussion of the results for each of the mesofactors follows.

Cultural dimensions and society. The study attempted to predict the students' views regarding the ideal level of societal influence on business behavior based on the four cultural dimensions that constitute the ecto-factor. While the results showed that the model significantly predicted students' attitudes regarding societal influence, only performance orientation was significant.

These results seem to make sense because societies whose respondents report strong performance orientation tend to value innovation, learning, high targets, and results (House, 2011). Millennials distrust governments, but they have a new found confidence in the ability of civil society to address both market and state failures (Notter \& Grant, 2015). It is only natural then to expect that high performing individuals will embrace organizations they believe share their same values and beliefs (Schein, 2010).

Cultural dimensions and economic model. The goal was to predict the students' views regarding the best economic system to promote CSR activities based on the four cultural dimensions that constitute the ecto-factor. While the results showed that the model had a significant predictive capacity regarding students' attitudes toward the economic system, none of the factors except performance orientation was significant. 
This result makes sense for the same reasons as those for the meso-factor society. Additionally, high performing individuals tend to be risk takers who love competition and seek economic productivity and prosperity. It is no accident that countries whose inhabitants show high performance values are, at the same time, wealthier than those that are less wealthy and show low performance values. In fact, House (2011) found a significant correlation $(r=.61, p<.01)$ between the World Competitiveness Index and performance orientation practices. Thus, it seems cognizant to conclude that high performing individuals, such as these students, will prefer an economic system based on free market principles.

Cultural dimensions and government regulation. The objective was to predict students' views regarding the proper level of government regulation to promote CSR activities based on the four cultural dimensions that constitute the ecto-factor. While the results showed that the model had a significant capacity to predict students' views in regard to government regulation and CSR, none of the factors except power distance was statistically significant.

Mulder (1977) coined the term power distance to mean "the degree of inequality in power between a less powerful individual (I) and a more powerful other (O), in which I and O belong to the same social system" (p. 90). Throughout history, the rules of the dominant classes, enacted either by the state or religious institutions, have been a factor in maintaining the class and status power that this definition implies. It is no coincidence that countries with an absolute monarchical tradition, such as France, or countries in which the hierarchical structure of Roman Catholicism has influenced society's 
institutional model, such as in Latin America, tend to be high in power distance (House, 2011).

From these arguments, it can be inferred that the higher the power distance an individual favors, the more that person will seek government regulation to maintain order and the current status quo. In this case, the effect is relatively small, because, in general, these MBA students display a low power distance score.

All factors to the CSR motive. The objective was to predict the student's motives towards CSR, or the endo-factor (normative vs. utilitarian), based first on the student's views regarding the role of society, economy, and regulation, or the meso-factors, and then add the GLOBE cultural dimensions, or ecto-factors (power distance, uncertainty, collectivism, and performance).

The results indicated that the first regression model did significantly predict students' views toward the influence that the meso-factors have on their motives regarding CSR practices, and this significance was maintained in the second model, which added the ecto-factors. However, when the data were looked at independently, only government regulation was significant. And while adding the ecto-factors to the first model increased the predictability, it was not statistically significant, leading to the conclusion that the cultural dimensions do not seem to have a meaningful influence over the students' CSR motives.

These results are somewhat disappointing because, even though the model proved to be significant, the predictability values were relatively small. As has been mentioned repeatedly in this chapter, while there are similarities in the students' motives toward and views regarding the factors that support CSR, which the ICSRM posits, this theoretical 
schemata does not test the reasons behind possible differences either because these differences do not actually exist or are too small to produce meaningful relationships.

Despite these weaknesses in the regression models, both the quantitative and qualitative data suggest that students whose motives seem to hold a tension between a normative and utilitarian view of CSR also favor the role of civil society in monitoring businesses, prefer free market economies as long as inequalities are managed, and support government regulation to control corruption and fraud. Moreover, these students hold high performance orientation values, their views are slightly more collectivistic than individualistic, they are somewhat risk averse, and they disdain power distance practices. Epistemologically, these findings provide a contribution to the understanding of SRBL. After addressing the limitations of this study, this chapter will conclude by expanding on the study's significance and contribution to the field.

\section{Limitations}

The purpose of this study was to make an initial contribution to answering the important question as to whether certain cultural dimensions affect how business students, as future business leaders, understand the factors that seem to affect CSR, and/or their attitudes toward SRBL, and, if so, how. However, there were two significant considerations that limit any potential statistical generalization from the results. The first relates to the contested nature and complexity of the constructs that were analyzed. The second relates to the relatively small number of participants and the limited research sites in the study.

The first set of limitations refers to the ambiguity and continuing lack of consensus regarding the concept of CSR itself, as was previously pointed out in the 
literature review in Chapter Two. If a concept is not well defined, it can hardly be measured, much less used to make predictions that involve entire populations. Offering survey participants a very specific definition of CSR, and a continued restating of that definition in the focus groups as needed, served to mitigate but not eliminate this limitation.

How individual cultural dimensions are attributed to groups or populations is also complex and contested. Most definitions, including those used by project GLOBE (House, 2011), reflect averages in a population, and thus there are individuals who fall in the extremes of the normal curve. The assumption that statistical relationships at a group level also hold for the individual level is what Brewer and Venaik (2014) define as an ecological fallacy in cultural research. That is, the supposition that the relationships among the individual, organizational, and national levels of analysis is isomorphic. Moreover, some cross-cultural experts (Minkov, 2013) warn that despite the scientific rigor of project GLOBE, their taxonomy is not necessarily comparable to other cultural studies, which makes comparisons difficult and inexact.

Additionally, survey specialists (Heine, Lehman, Peng, \& Greenholtz, 2002) have expressed concern about the use of Likert scales in cross-cultural research because of what they call the reference group effect. Basically, this means that people tend to use a group they are familiar with as a point of comparison. Americans tend to compare themselves with Americans, Latin Americans with other Latin Americans, and Spaniards with other Spaniards or with Europeans. This might have had a confounding effect on comparisons between these three groups. For example, when discussing the quantitative results regarding the ideal economic model, for which all groups tended to favor free 
markets, it was evident that each group used the economic model of their own countries, with which they were familiar, as their point of reference. Economic policies, such as those having to do with price controls, which were considered somewhat left leaning in the Anglo cluster, were considered quite centered in Latin Europe and even somewhat right leaning in Latin America.

It is also important to highlight that business students might be culturally skewed in a particular direction. For example, it is possible that business schools attract individuals who tend to be more performance oriented than the overall population, as seems to be the case in this study. Finally, in addition to cultural influences, an individual's personal values and beliefs shape his or her perspective regarding political, economic, and social issues. These potential limitations and biases were taken into account in both the presentation and discussions of the results in this chapter and in previous chapters.

The second set of limitations is directly related to the sample size and unique characteristics of the study sites. This means that although the cross-case ANOVA regarding motives and views toward the factors that seem to affect CSR initiatives may provide an initial understanding of the phenomena, these results are not necessarily generalizable to all business school students in each of the cultural clusters, or even to other clusters with similar cultural dimensions. Moreover, the differences and similarities between the groups in this study and the relationship between motives and views toward CSR do not necessarily indicate a cause-effect relationship because other factors could be influencing the results. 
Regarding the uniqueness of the study sites, other factors are significant. For example, two of the schools, USD and ESADE, were founded under the umbrella of the Catholic faith, which tends to emphasize a social justice view of business. INCAE is a secular college but was founded with a vision of promoting social development in Central America. The genesis of these schools could make them outliers in their stand on the role of businesses in social betterment initiatives. Although this factor hinders the ability to generalize, it also provides useful information for promoting CSR. Donmoyer (2006) points out that outliers have significant inferential capacity and heuristic value because they tend to point to what is possible rather than what is typical. Thus, the possibility of expanding knowledge in this way could compensate for the lack of statistical generalizability.

The other limitation of the study is the relatively small number of sites and students that were sampled. As was pointed out in Chapter One of this study, there are more than 5,000 business schools in the world, from which 250,000 students graduate every year. Three schools with 290 participants is hardly a representative sample. However, the use of an explanatory mixed methods design provided the qualitative information necessary to build a more comprehensive cross-case analysis and a richer, thick description of the phenomena, which serves as important groundwork for future research that can expand the understanding of this issue.

Finally, the researcher's positionality should be highlighted. As noted previously, I am a business professional with more than 35 years of experience in running companies with varying degrees of CSR activity in different parts of the world, and I have also served as a board member of several nonprofit organizations. This experience has 
created a personal preference regarding the positive role that businesses should play in social betterment initiatives in a free market and democratic environment. Although this background might have created researcher bias, it also proved beneficial because knowledge of the subject enhanced my ability to interact with the participants.

To minimize potential bias, I followed Peshkin's (1988) recommendation to engage in reflective practices. For example, I was particularly aware of what Peshkin calls ethnic maintenance, which refers to the tendency to identify and value people who you feel belong to your own group. Additionally, Peshkin warns that in researching sensitive human issues (CSR could be considered one), there might be a tendency to fall in what he calls justice-seeking attitudes, in which your observations might be tinted by your own sense of right and wrong, or what he calls E-Pluribus-Unum, which is the propensity to see utopian solutions to complex problems.

While these are important limitations, the study offers a valuable contribution to the CSR literature and to the practice of SRBL. The next and final section outlines the significance and contributions of this research and suggests future avenues for research.

\section{Contributions and Future Research}

This study provided relevant information that could enhance the body of knowledge regarding the relationships between specific cultural dimensions and MBA students' attitudes toward factors that influence CSR as an expression of SRBL. As was shown in the literature review presented in Chapter Two, there are many studies that have tackled this issue from a particular country's perspective, but the role that culture plays in both the teaching and practice of CSR has not been researched in a holistic manner. 
Despite the inconclusive results described in Chapter Four and discussed in this chapter, this study provides a base for further research on this complex but important topic.

This is particularly important because as businesses globalize and more countries move to a free market, democratic system, the role of the private sector in social betterment initiatives will probably increase, as in fact has been seen with the proliferation of CSR courses in business schools and the increased adoption of its practice in several countries (Schlag \& Mercado, 2012). However, most of the CSR models and theories currently in use originated in countries of the Anglo cluster, particularly the United States. Therefore, the cultural dimensions of this cluster most probably affect how this subject is being taught in business schools, particularly as the U.S. business school model is replicated across the world.

This study suggests that MBA students are fairly similar in their values regarding social issues and have comparable cultural dimensions. However, cultural differences could have a significant impact on how theories and practices are implemented. Therefore, this study could be one more step, however small, in building the necessary knowledge to support CSR teaching and practice across the world. In fact, one key learning of this study suggests that perhaps Mintzberg (2009) is right in his assessment that there is a new MBA student who understands that business leaders' focus should go above and beyond short-term profitability. The study also indicates that perhaps Notter and Grant (2015) and Caraher (2015) are right in their claim that millenials are a unique generation that will bring more social sensitivity to the business community.

The results of this study, which mirror those of the latest Aspen Institute (2008) surveys on MBA students' social attitudes, seem to support that expectation. However, 
given the importance of this subject, there is a need of further research to expand on the rich but limited data that this study provided. For example, the inclusion of public universities and/or institutions with no religious influence might generate different results because the students might be less homogenous than the ones in this sample. Additionally, a longitudinal study that explores the changes that the students from this study go through once they graduate and face the real challenges of the business world could determine if this strong motive toward maintaining the tension between generating profits and the common good is in reality a deep and lasting transition in the business world or simply a fad that would fade over time. Hopefully, this study provided the basis for other scholars to better understand not only the possible relationship between cultural factors and SRBL but also new insights into the complex dynamics that drive the implementation of CSR activities across the world. 


\section{REFERENCES}

Akrivou, K., \& Bradbury-Huang, H. (2015). Educating integrated catalysts:

Transforming business schools toward ethics and sustainability. Academy of Management Learning \& Education, 14(2), 222-240.

Alas, R. (2006). Ethics in countries with different cultural dimensions. Journal of Business Ethics, 69(3), 237-247.

Ali, A. J., \& Al-Aali, A. (2012). Corporate social responsibility in Saudi Arabia. Middle East Policy, 19(4), 40-53.

Amann, W. (2011). Business schools under fire: Humanistic management education as the way forward. Houndmills, Basingstoke, Hampshire, United Kingdom: Palgrave Macmillan.

Aqueveque, C., \& Encina, C. (2010). Corporate behavior, social cynicism, and their effect on individuals' perceptions of the company. Journal of Business Ethics, 91(Suppl. 2), 311-324.

Argyris, C., \& Schön, D. A. (2003). Theory in practice: Increasing professional effectiveness. San Francisco, CA: Jossey-Bass.

Aron, R. (1962). The opium of the intellectuals. New York, NY: Norton.

Ashman, I., \& Winstanley, D. (2007). For or against corporate identity? Personification and the problem of moral agency. Journal of Business Ethics, 76(1), 83-95.

Ashton, T. S. (1948). The Industrial Revolution, 1760-1830. London, England: Oxford University Press.

Aspen Institute. (2008). The Aspen Institute guide to socially responsible MBA programs. Retrieved from http://public.eblib.com/choice/publicfullrecord.aspx?p=407890

Asslander, M. S. (2014). The corporation as citoyen? Towards a new understanding of corporate citizenship. Journal of Business Ethics, 120(4), 541-554.

Aupperle, K. E., Carroll, A. B., \& Hatfield, J. D. (1985). An empirical examination of the relationship between corporate social responsibility and profitability. The Academy of Management Journal, 28(2), 446-463.

Austin, J. E. (2000). The collaboration challenge: How nonprofits and businesses succeed through strategic alliances. San Francisco, CA: Jossey-Bass.

Axinn, C. N., Blair, M., Heorhiadi, A., \& Thach, S. V. (2004). Comparing ethical ideologies across cultures. Journal of Business Ethics, 54(2), 103-119. 
Banerjee, S. B. (2007). Corporate social responsibility: The good, the bad and the ugly. Cheltenham, United Kingdom: Edward Elgar.

Barnea, A., \& Rubin, A. (2010). Corporate social responsibility as a conflict between shareholders. Journal of Business Ethics, 97(1), 71-86.

Barnett, M. L. (2007). Stakeholder influence capacity and the variability of financial returns to corporate social responsibility. The Academy of Management Review, 32(3), 794-816.

Bartley, T., \& Child, C. (2014). Shaming the corporation: The social production of targets and the anti-sweatshop movement. American Sociological Review, 79(4), 653-679.

Bass, B. M., \& Bass, R. (2008). The Bass handbook of leadership : Theory, research, and application. New York, NY: Free Press.

Basu, K., \& Palazzo, G. (2008). Corporate social responsibility: A process model of sensemaking. The Academy of Management Review, 33(1), 122-136.

Bernabou, R., \& Tirole, J. (2010). Individual and corporate social responsibility. ECCA Economica, 77(305), 1-19.

Blake, R. R., \& Mouton, J. S. (1964). The managerial grid: Key orientations for achieving production through people. Houston, TX: Gulf.

Blanchard, K. H., Zigarmi, P., \& Zigarmi, D. (1985). Leadership and the one minute manager: Increasing effectiveness through situational leadership. New York, NY: Morrow.

Blasco, M. (2010). Corporate social responsibility in Mexico and France: Exploring the role of normative institutions. Business and Society, 49(2), 216-251.

Bowen, H. R. (1953). Social responsibilities of the businessman. New York, NY: Harper.

Bowie, N. E. (2013). Business ethics in the 21st century. New York, NY: Harper.

Brewer, P., \& Venaik, S. (2014). The ecological fallacy in national culture research. Organization Studies, 35(7), 1063-1086.

Brown, M. E., \& Mitchell, M. S. (2010). Ethical and unethical leadership. Business Ethics Quarterly, 20(4), 583-616.

Burns, J. M. (1978). Leadership. New York, NY: Harper \& Row. 
Campbell, D. T., \& Stanley, J. C. (1966). Experimental and quasi-experimental designs for research. Chicago, IL: McNally.

Campbell, J. L. (2005). Why would corporations behave in socially responsible ways? An institutional theory of corporate social responsibility. New York, NY: Harper.

Campbell, J. L. (2007). Special topic forum on corporations as social change agents: An institutional theory of corporate social responsibility. The Academy of Management Review, 32(3), 788-793.

Caraher, L. (2015). Millennials \& management: The essential guide to making it work at work. Cambridge, MA: Bibliomotion.

Carlyle, T. (1897). The works of Thomas Carlyle. New York, NY: P. F. Collier.

Carnegie, A., \& Nasaw, D. (2006). The gospel of wealth essays and other writings. New York, NY: Penguin Books.

Carroll, A. B. (2000). Corporate social responsibility: Evolution of a definitional construct. Human Resources Abstracts, 35(1), 112-124.

Carroll, A. B., Lipartito, K., Post, J. E., Werhane, P., \& Goodpaster, K. (2012). Corporate responsibility: The American experience. New York, NY: Harper.

Carson, K. A. (2001). The iron fist behind the invisible hand: Corporate capitalism as a system of state-guaranteed privilege. Montreal, Canada: Red Lion Press.

Chapple, W., \& Moon, J. (2005). Corporate social responsibility in Asia: A seven country study. Business and Society, 44(4), 415-441.

Churchill, G. A., Jr. (1979). A paradigm for developing better measures of marketing constructs. Journal of Marketing Research, 16(1), 64-73.

Ciulla, J. B. (1998). Ethics, the heart of leadership. Westport, CT: Quorum Books.

Ciulla, J. B. (2014). Ethics, the heart of leadership. Santa Barbara, CA: ABC-CLIO.

Clinton, B. (2007). Giving: How each of us can change the world. New York, NY: Knopf.

Colakoglu, S., \& Caligiuri, P. (2008). Cultural distance, expatriate staffing and subsidiary performance: The case of US subsidiaries of multinational corporations. International Journal of Human Resource Management, 19(2), 223-239. 
CONE Communications. (2015). 2015 Cone Communications Millennial CSR Study. Retrieved from http://www.conecomm.com/2015-cone-communicationsmillennial-csr-study-1

Creswell, J. W., \& Clark, V. L. P. (2011). Designing and conducting mixed methods research. Los Angeles, CA: Sage.

Crossan, M., Seijts, G., Gandzs, J., \& Mazutis, D. (2013). Developing leadership character in business programs. Academy of Management Learning and Education, 12(2), 285-305.

Dansereau, F., Graen, G., \& Haga, W. J. (1975). A vertical dyad linkage approach to leadership within formal organizations: A longitudinal investigation of the role making process. Organizational Behavior and Human Performance, 13(1), 4678.

das Neves, J. C. (2013). Managing ethically cultural diversity: Learning from Thomas Aquinas. Journal of Business Ethics, 116(4), 769-780.

Datar, S. M., Garvin, D. A., \& Cullen, P. G. (2010). Rethinking the MBA: Business education at a crossroads. Boston, MA: Harvard Business Press.

Davies, W. (2014). The limits of neoliberalism: Authority, sovereignty and the logic of competition. Thousand Oaks, CA: Sage.

de la Cuesta González, M., \& Martinez, C. (2004). Fostering corporate social responsibility through public initiative: From the EU to the Spanish case. Journal of Business Ethics, 55(3), 275-293.

de Oliveira, J. A. (2006). Corporate citizenship in Latin America: New challenges for business. Sheffield, United Kingdom: Greenleaf.

Dean, M. (2010). What is society? Social thought and the arts of government. The British Journal of Sociology, 61(4), 677-695.

Dewey, J., \& Boydston, J. A. (1983). The middle works of John Dewey, 1899-1924. Carbondale, IL: Southern Illinois University Press.

Dickson, M. W., Castaño, N., Magomaeva, A., \& Den Hartog, D. (2012). Conceptualizing leadership across cultures. Journal of World Business, 47(4), 483-492.

Dillman, D. A., Smyth, J. D., \& Christian, L. (2009). Internet, mail, and mixed-mode surveys: The tailored design method. Hoboken, NJ: Wiley \& Sons.

Donaldson, T. (1982). Corporations and morality. Englewood Cliffs, NJ: Prentice-Hall. 
Donaldson, T., \& Dunfee, T. W. (1999). Ties that bind: A social contracts approach to business ethics. Boston, MA: Harvard Business School Press.

Donaldson, T., \& Preston, L. E. (1995). The stakeholder theory of the corporation: Concepts, evidence, and implications. Academy of Management Review, 20(1), 65-91.

Donmoyer, R. (2006). Take my paradigm . . please. The legacy of Kuhn's construct in educational research. International Journal of Qualitative Studies in Education, 19(1), 11-34.

Dotlich, D. L., Cairo, P. C., \& Cowan, C. (2014). The unfinished leader: Balancing contradictory answers to unsolvable problems. San Francisco, CA: Josey-Bass.

Downton, J. V. (1973). Rebel leadership: Commitment and charisma in the revolutionary process. New York, NY: Free Press.

Drucker, P. F. (1998). Peter Drucker on the profession of management. Boston, MA: Harvard Business School Press.

Eesley, C., \& Lenox, M. J. (2006). Firm responses to secondary stakeholder action. Strategic Management Journal, 27(8), 765-781.

Eichholtz, P., Kok, N., \& Quigley, J. M. (2010). Doing well by doing good? Green office buildings. American Economic Review, 100(5), 2492-2509.

Eisenbeiß, S. A., \& Brodbeck, F. (2014). Ethical and unethical leadership: A crosscultural and cross-sectoral analysis. Journal of Business Ethics, 122(2), 343-359.

Elkington, J. (2000). Cannibals with forks: The triple bottom line of 21 st century business. Peace Research Abstracts, 37(5), 84-96.

Erikson, E. H., Paul, I. H., Heider, F., \& Gardner, R. W. (1959). Psychological issues: Identity and the life cycle; studies in remembering; on perception and event structure and the psychological environment; cognitive control. New York, NY: International Press.

Evans, M. G. (1996). House's “A path-goal theory of leader effectiveness.” The Leadership Quarterly, 7(3), 305-309.

Feldman, M. S., Sköldberg, K., Brown, R. N., \& Horner, D. (2004). Making sense of stories: A rhetorical approach to narrative analysis. Journal of Public Administration Research and Theory: J-PART, 14(2), 147-170.

Feldman, S. P. (2013). Trouble in the middle: American-Chinese business relations, culture, conflict, and ethics. New York, NY: Routledge. 
Fernandez-Feijoo, B., Romero, S., \& Ruiz, S. (2014). Effect of stakeholders' pressure on transparency of sustainability reports within the GRI framework. Journal of Business Ethics, 122(1), 53-63.

Fiedler, F. E. (1967). A theory of leadership effectiveness. New York, NY: McGraw-Hill.

Financial Times. (2015). Business education: Global MBA ranking 2015. Retrieved from http://rankings.ft.com/businessschoolrankings/global-mba-ranking-2015

Fleming, P. (2013). The end of corporate social responsibility: Crisis \& critique. Thousand Oaks, CA: Sage.

Follett, M. P. (1926). The giving of orders. In J. M. Shafritz, J. S. Ott, \& Y. S. Jang (Eds.), Classics of organizational theory (pp. 34-41). Belmont, CA: Cengage Learning.

Forman, J. P., \& Ross, L. A. (2013). Integral leadership: The next half-step. Albany, NY: State University of New York Press.

Fowler, F. J. (2014). Survey research methods. Los Angeles, CA: Sage.

Freeman, R. E. (1984). Strategic management: A stakeholder approach. Boston, MA: Pitman.

Freeman, R. E., \& Phillips, R. A. (2002). Stakeholder theory: A libertarian defense. Business Ethics Quarterly, 12(3), 331-349.

Freire, P. (2000). Pedagogy of the oppressed. New York, NY: Continuum.

Friedman, M. (1962). Capitalism and freedom. Chicago, IL: University of Chicago Press.

Friedman, M. (1970, September 13). The social responsibility of business is to increase its profits. The New York Times Magazine, 32-33, 122, 124, 126.

Friedman, M., \& Ebenstein, A. O. (2012). The indispensable Milton Friedman: Essays on politics and economics. Washington, DC: Regnery.

Fukukawa, K. (2010). Corporate social responsibility in Asia. New York, NY: Routledge.

Gardner, W. L., Avolio, B. J., \& Walumbwa, F. O. (2005). Authentic leadership theory and practice: Origins, effects and development. Bingley, United Kingdom: Emerald Group.

Geertz, C. (1973). The interpretation of cultures: Selected essays. New York, NY: Basic Books. 
Giacalone, R. A., \& Thompson, K. R. (2006). Business ethics and social responsibility education: Shifting the worldview. Academy of Management Learning and Education, 5(3), 266-277.

Gjølberg, M. (2010). Varieties of corporate social responsibility (CSR): CSR meets the "Nordic Model." Regulation \& Governance, 4(2), 203-229.

Glesne, C. (2011). Becoming qualitative researchers: An introduction. Boston, MA: Pearson.

Godfrey, P. C., Hatch, N. W., \& Hansen, J. M. (2010). Toward a general theory of CSRs: The roles of beneficence, profitability, insurance, and industry heterogeneity. Business and Society, 49(2), 316-344.

Greenleaf, R. K. (1977). Servant leadership: A journey into the nature of legitimate power and greatness. New York, NY: Paulist Press.

Greenspan, A. (2013). The map and the territory: Risk, human nature, and the future of forecasting. New York, NY: Penguin Press.

Guba, E. G., \& Lincoln, Y. S. (2005). Paradigmatic controversies, contradictions, and emerging confluences. In N. K. Denzin \& Y. S. Lincoln (Eds.), The Sage handbook of qualitative research (pp. 191-216). Thousand Oaks, CA: Sage.

Habermas, J. (1989). The structural transformation of the public sphere: An inquiry into a category of bourgeois society. Cambridge, MA: MIT Press.

Habermas, J., \& Fultner, B. (2005). Truth and justification. Cambridge, MA: MIT Press.

Hall, E. T. (2003). Beyond culture. New York, NY: Anchor Books.

Hamel, P. (2001). Globalization and social movements. New York, NY: Palgrave.

Hantrais, L., \& Mangen, S. P. (2007). Cross-national research methodology \& practice. New York, NY: Routledge.

Harrison, L. E., \& Huntington, S. P. (2006). Culture matters: How values shape human progress. New York, NY: Basic Books.

Hayek, F. A., \& Bartley, W. W. (1989). The fatal conceit : The errors of socialism. Chicago, IL: University of Chicago Press.

Heal, G. (2014). Corporate social responsibility: An economic and financial framework. International Library of Critical Writing in Economics, 30(3), 255-277. 
Heine, S. J., Lehman, D. R., Peng, K., \& Greenholtz, J. (2002). What's wrong with crosscultural comparisons of subjective Likert scales?: The reference-group effect. Journal of Personality and Social Psychology, 82(6), 903-918.

Hemingway, C. A. (2005). Personal values as a catalyst for corporate social entrepreneurship. Journal of Business Ethics, 60(3), 233-249.

Hobbes, T. (1652). De corpore politico, or, the elements of law moral \& politick: With discourses upon severall heads. London, England: Printed by Tho. Roycroft for John Martin.

Hofstede, G. H., Hofstede, G. J., \& Minkov, M. (2010). Cultures and organizations : software of the mind: Intercultural cooperation and its importance for survival. New York, NY: McGraw-Hill.

House, R. J. (1996). Path-goal theory of leadership: Lessons, legacy, and a reformulated theory. The Leadership Quarterly, 7(3), 323-352.

House, R. J. (2011). Culture, leadership, and organizations: The GLOBE study of 62 societies. Thousand Oaks, CA: Sage.

House, R. J., Hanges, P. J., Javidan, M., Dorfman, P. W., \& Gupta, V. (2004). Culture, leadership, and organizations: The GLOBE study of 62 societies. Thousand Oaks, CA: Sage.

House, R., Javidan, M., Hanges, P., \& Dorfman, P. (2002). Understanding cultures and implicit leadership theories across the globe: An introduction to project GLOBE. Journal of World Business, 37(1), 3-10.

Howell, J. M., House, R. J., \& Reginald, H. (1993). Socialized and personalized charisma: A theory of the bright and dark sides of leadership. Philadelphia, PA: Reginald H. Jones Center, Wharton School, University of Pennsylvania.

Husted, B. W., \& De Jesus Salazar, J. (2006). Taking Friedman seriously: Maximizing profits and social performance. Journal of Management Studies, 43(1), 75-91.

Innes, R., \& Sam, A. G. (2008). Voluntary pollution reductions and the enforcement of environmental law: An empirical study of the 33/50 program. Journal of Law and Economics, 51(2), 271-296.

Ioannou, I., \& Serafeim, G. (2012). What drives corporate social performance, the role of nation-level institutions. Journal of International Business Studies, 43(9), 834864. 
Jamali, D., \& Mirshak, R. (2007). Corporate social responsibility (CSR): Theory and practice in a developing country context. Journal of Business Ethics, 72(3), 243262.

Jones, L., Mackey, A., \& Whetten, D. (2014). Taking responsibility for corporate social responsibility: The role of leaders in creating, implementing, sustaining, or avoiding socially responsible behavior. Academy of Management Perspectives, 28(2), 164-178.

Joosten, A., Van Dijke, M., Van Hiel, A., \& De Cremer, D. (2014). Being in control may make you lose control: The role of self-regulation in unethical leadership behavior. Journal of Business Ethics, 121(1), 1-14.

Judge, T. A., Piccolo, R. F., \& Kosalka, T. (2009). The bright and dark sides of leader traits: A review and theoretical extension of the leader trait paradigm. The Leadership Quarterly, 20(6), 855-875.

Karam, C. M., \& Jamali, D. (2013). Gendering CSR in the Arab Middle East. Business Ethics Quarterly, 23(1), 31-68.

Katz, R. L. (1974). Skills of an effective administrator. Harvard Business Review, 52(5), 90-102.

Kegan, R. (2001). The evolving self: Problem and process in human development. Cambridge, MA: Harvard University Press.

Kemper, A., \& Martin, R. L. (2010). After the fall: The global financial crisis as a test of corporate social responsibility theories. European Management Review, 7(4), 229-239.

Khurana, R. (2010). From higher aims to hired hands: The social transformation of American business schools and the unfulfilled promise of management as a profession. Princeton, NJ: Princeton University Press.

Kim, Y., \& Kim, S. (2010). The influence of cultural values on perceptions of corporate social responsibility: Application of Hofstede's dimensions to Korean public relations practitioners. Journal of Business Ethics, 91(4), 485-500.

Kinderman, D. (2013). Corporate social responsibility in the EU, 1993-2013 institutional ambiguity, economic crises, business legitimacy and bureaucratic politics. Journal of Common Market Studies, 51(4), 701-720.

Kirkpatrick, L. (1991). Leadership: Do traits matter. Academy of Management Executive, $5(2), 48-80$. 
Kitzmueller, M., \& Shimshack, J. (2012). Economic perspectives on corporate social responsibility. Journal of Economic Literature, 50(1), 51-84.

Kluckhohn, F. R., \& Strodtbeck, F. (1961). Variations in value orientations. Evanston, IL: Row, Peterson.

Koehn, D. (2001). Local insights, global ethics for business. New York, NY: Rodopi.

Kostova, T., Roth, K., \& Dacin, M. T. (2008). Institutional theory in the study of multinational corporations: A critique and new directions. Academy of Management Review, 33(4), 994-1006.

Kotler, P. (2015). Confronting capitalism: Real solutions for a troubled economic system. New York, NY: Amacon.

Kraft, K. L., \& Singhapakdi, A. (1995). The relative importance of social responsibility in determining organizational effectiveness: Student responses. Journal of Business Ethics, 14(4), 315-328.

Krishnan, V. R. (2008). Impact of MBA education on students' values: Two longitudinal studies. Journal of Business Ethics, 83(2), 233-246.

Kuhn, T. S. (1970). The structure of scientific revolutions. Chicago, IL: University of Chicago Press.

Lawrence, J. T., \& Beamish, P. (2013). Globally responsible leadership: Managing according to the UN Global Compact. Thousand Oaks, CA: Sage.

Lewin, K., \& Gold, M. (1999). The complete social scientist: A Kurt Lewin reader. Washington, DC: American Psychological Association.

Maak, T., \& Pless, N. (2006). Responsible leadership. New York, NY: Routledge.

Mann, R. D. (1959). A review of the relationships between personality and performance in small groups. Psychological Bulletin, 56(4), 241-270.

Márquez, P. C., Reficco, E., \& Berger, G. (2010). Socially inclusive business: Engaging the poor through market initiatives in Iberoamerica. Cambridge, MA: Harvard University Press.

Martelle, S. (2007). Blood passion: The Ludlow Massacre and class war in the American West. New Brunswick, NJ: Rutgers University Press.

Martin, J. (2002). Organizational culture: Mapping the terrain. Thousand Oaks, CA: Sage. 
Maslow, A. H. (1968). Toward a psychology of being. New York, NY: Van Nostrand.

Matten, D., \& Moon, J. (2008). "Implicit" and "explicit" CSR: A conceptual framework for a comparative understanding of corporate social responsibility. Academy of Management Review, 33(2), 404-424.

Maxfield, S. (2008). Reconciling corporate citizenship and competitive strategy: Insights from economic theory. Journal of Business Ethics, 80(2), 367-377.

Mayer, C. P. (2014). Firm commitment: Why the corporation is failing us and how to restore trust in it. Oxford, United Kingdom: Oxford University Press.

McSweeney, B. (2002). Hofstede's model of national cultural differences and their consequences: A triumph of faith-A failure of analysis. Human Relations, 55(1), 89-118.

McWilliams, A., \& Siegel, D. S. (2011). Creating and capturing value: Strategic corporate social responsibility, resource-based theory, and sustainable competitive advantage. Journal of Management, 37(5), 1480-1495.

Merino, N. (2014). The wage gap. New York, NY: Greenheaven Press.

Meyers, L. S., Gamst, G., \& Guarino, A. J. (2013). Applied multivariate research: Design and interpretation. Los Angeles, CA: Sage.

Michalos, A. C., \& Poff, D. C. (2013). Citation classics from the Journal of Business Ethics. New York, NY: Springer.

Minkov, M. (2013). Cross-cultural analysis: The science and art of comparing the world's modern societies and their cultures. Thousand Oaks, CA: Sage.

Mintzberg, H. (2004). Managers, not MBAs: A hard look at the soft practice of managing and management development. San Francisco, CA: Berrett-Koehler.

Mintzberg, H. (2009). Managing. San Francisco, CA: Berrett-Koehler.

Mitchell, R. K., Agle, B. R., \& Wood, D. J. (1997). Toward a theory of stakeholder identification and salience: Defining the principle of who and what really counts. Academy of Management Review, 22(4), 853-886.

Mitra, R. (2012). "My country's future": A culture-centered interrogation of corporate social responsibility in India. Journal of Business Ethics, 106(2), 131-147.

Moldoveanu, M. C., \& Martin, R. L. (2008). The future of the MBA: Designing the thinker of the future. New York, NY: Oxford University Press. 
Morgan, D. L. (1998). The focus group guidebook. Thousand Oaks, CA: Sage.

Morsing, M., \& Langer, R. (2007). CSR-communication in the business press: Advantages of strategic ambiguity. Frederiksberg, Germany: CBS Center for Corporate Social Responsibility.

Morsing, M., \& Sauquet, A. (2011). Business schools and their contribution to society. London, England: Sage.

Mulder, M. (1977). The daily power game. New York, NY: Springer.

Mumford, M. D., \& Connelly, M. S. (1991). Leaders as creators: Leader performance and problem solving in ill-defined domains. The Leadership Quarterly, 2(4), 289-315.

Mumford, M. D., Zaccaro, S. J., Harding, F. D., Jacobs, T. O., \& Fleishman, E. A. (2000). Leadership skills for a changing world: Solving complex social problems. The Leadership Quarterly, 11(1), 11-35.

Myers, M. D. (2013). Qualitative research in business \& management. London, England: Sage.

Nahavandi, A. (2012). The art and science of leadership. Upper Saddle River, NJ: Prentice Hall.

Naím, M. (2013). The end of power: From boardrooms to battlefields and churches to states, why being in charge isn't what it used to be. New York, NY: Basic Books.

Nelling, E., \& Webb, E. (2009). Corporate social responsibility and financial performance: The virtuous circle revisited. Review of Quantitative Finance and Accounting, 32(2), 197-209.

Net Impact. (2012). Talent report: What workers want in 2012. Retrieved from https://netimpact.org/docs/publications-docs/NetImpact_WhatWorkers Want2012.pdf

Northouse, P. G. (2013). Leadership: Theory and practice. Thousand Oaks, CA: Sage.

Notter, J., \& Grant, M. (2015). When millenials take over: Preparing for the ridiculously optimistic future of business. Retrieved from http://proquest.safaribooksonline. $\mathrm{com} /$ ?pi $=1940858127$

Paine, L. S. (2003). Value shift: Why companies must merge social and financial imperatives to achieve superior performance. New York, NY: McGraw-Hill.

Patton, M. Q. (2002). Qualitative research and evaluation methods. Thousand Oaks, CA: Sage. 
Peshkin, A. (1988). In search of subjectivity-One's own. Educational Researcher, 17(7), 17-21.

Peterson, C., \& Seligman, M. (2004). Character strengths and virtues: A handbook and classification. Washington, DC: American Psychological Association; New York, NY: Oxford University Press.

Peterson, R. A., \& Ferrell, O. C. (2005). Business ethics: New challenges for business schools and corporate leaders. New York, NY: Routledge.

Pew Research Center. (2014a). Global attitudes and trends. Retrieved from http://www.pewglobal.org/question-search/

Pew Research Center. (2014b). Millennials in adulthood: Detached from institutions, networked with friends. Retrieved from http://www.pewsocialtrends.org/2014/ 03/07/millennials-in-adulthood/

Piketty, T. (2015). The economics of inequality. Paris, France: Belknap Press.

Plotkin, B. (2008). Nature and the human soul cultivating wholeness and community in a fragmented world. Novato, CA: New World Library.

Pojman, L. P. (2012). Ethics: Discovering right and wrong. Boston, MA: Wadsworth.

Polkinghorne, D. E. (1995). Narrative configuration in qualitative analysis. International Journal of Qualitative Studies in Education, 8(1), 5-12.

Porter, M. E. (1987). From competitive advantage to corporate strategy. Boston, MA: Harvard Business School.

Porter, M. E., \& Kramer, M. R. (2006). Strategy and society: The link between competitive advantage and corporate social responsibility. Harvard Business Review, 84(12), 78-92.

Porter, M. E., \& Kramer, M. R. (2008). The competitive advantage of corporate philanthropy. In A. Crane, D. Matten, \& L. Spence (Eds.), Corporate social responsibility: Readings and cases in a global context corporate social responsibility (pp. 286-305). New York, NY: Routledge.

Posner, R. A. (2009). A failure of capitalism: The crisis of '08 and the descent into depression. Cambridge, MA: Harvard University Press.

Prahalad, C. K. (2010). The fortune at the bottom of the pyramid: Eradicating poverty through profits. Upper Saddle River, NJ: Wharton School.

Quinn, R. E. (1988). Beyond rational management. San Francisco, CA: Jossey-Bass. 
Ralston, D. A., \& Potocan, V. (2014). Societal-level versus individual-level predictions of ethical behavior: A 48-society study of collectivism and individualism. Journal of Business Ethics, 122(2), 283-306.

Richter, U. H. (2010). Liberal thought in reasoning on CSR. Journal of Business Ethics, 97(4), 625-649.

Rishi, P., \& Moghe, S. (2013). Integrating corporate social responsibility and culture as a strategy for holistic corporate success in India. Journal of Corporate Citizenship, 51(4), 17-37.

Romero, S., \& Fernandez-Feijoo, B. (2013). Effect of Hofstede's cultural differences in corporate social responsibility disclosure. International Journal of Information Systems and Social Change, 4(1), 68-84.

Ronen, S., \& Shenkar, O. (1985). Clustering countries on attitudinal dimensions: A review and synthesis. Academy of Management Review, 10(3), 435-454.

Ruffín, C., \& Márquez, P. C. (2011). Private utilities and poverty alleviation: Market initiatives at the base of the pyramid. Cheltenham, United Kingdom: Edward Elgar.

Saldaña, J. (2013). The coding manual for qualitative researchers. London, England: Sage.

Sanborn, C., \& Portocarrero, S. F. (2005). Philanthropy and social change in Latin America. Cambridge, MA: Harvard University David Rockefeller Center for Latin American Studies.

Sanchez-Runde, C. J., Nardon, L., \& Steers, R. M. (2013). The cultural roots of ethical conflicts in global business. Journal of Business Ethics, 116(4), 689-701.

Schein, E. H. (2010). Organizational culture and leadership. San Francisco, CA: JosseyBass.

Scherer, A. G. (2008). Handbook of research on global corporate citizenship. Cheltenham, United Kingdom: Edward Elgar.

Scherer, A. G., \& Palazzo, G. (2007). Toward a political conception of corporate responsibility: Business and society seen from a Habermasian perspective. Academy of Management Review, 32(4), 1096-1120.

Schlag, M., \& Mercado, J. A. (2012). Free markets and the culture of common good. Dordrecht, The Netherlands: Springer. 
Schmidheiny, S. (1992). Changing course: A global business perspective on development and the environment. Cambridge, MA: MIT Press.

Schwartz, M. S., \& Carroll, A. B. (2003). Corporate social responsibility: A three-domain approach. Business Ethics Quarterly, 13(4), 503-530.

Scott, W. R. (2001). Institutions and organizations. Thousand Oaks, CA: Sage.

Secchi, D. (2009). The cognitive side of social responsibility. Journal of Business Ethics, $88(3), 565-581$.

Servaes, H., \& Tamayo, A. (2013). The impact of corporate social responsibility on firm value: The role of customer awareness. Management Science, 59(5), 1045-1061.

Shafer, W., Fukukawa, K., \& Lee, G. (2007). Values and the perceived importance of ethics and social responsibility: The U.S. versus China. Journal of Business Ethics, 70(3), 265-284.

Sigurjonsson, T. O., Vaiman, V., \& Arnardottir, A. (2014). The role of business schools in ethics education in Iceland: The managers' perspective. Journal of Business Ethics, 122(1), 25-38.

Singhapakdi, A., Vitell, S. J., Rallapalli, K. C., \& Kraft, K. (1996). The perceived role of ethics and social responsibility: A scale development. Journal of Business Ethics, $15(11), 1131$.

Smith, A. (1759/1976). The theory of moral sentiments. Oxford, United Kingdom: Oxford University Press.

Smith, A. (1776/1976). An inquiry into the nature and causes of the wealth of nations. Dublin, Ireland: Whitestone.

Stiglitz, J. E. (2003). The roaring nineties: A new history of the world's most prosperous decade. New York, NY: Norton.

Stogdill, R. M. (1948). Personal factors associated with leadership: A survey of the literature. The Journal of Psychology, 25, 35-71.

Strauss, W., \& Howe, N. (1998). The fourth turning: An American prophecy. New York, NY: Broadway Books.

Swanson, D. L., \& Fisher, D. G. (2008). Advancing business ethics education. Charlotte, NC: IAP.

Taylor, F. W. (1911/1967). The principles of scientific management. New York, NY: Norton. 
Teddlie, C., \& Tashakkori, A. (2009). Foundations of mixed methods research: Integrating quantitative and qualitative approaches in the social and behavioral sciences. Los Angeles, CA: Sage.

Thomas, D. C., Brannen, M. Y., \& Garcia, D. (2010). Bicultural individuals and intercultural effectiveness. European Journal of Cross-Cultural Competence and Management, 1(4), 315-333.

Thomas, D. C., \& Peterson, M. F. (2015). Cross-cultural management: Essential concepts. Thousand Oaks, CA: Sage.

Triandis, H. C. (1995). Individualism \& collectivism. Boulder, CO: Westview Press.

Trompenaars, F., \& Hampden-Turner, C. (2012). Riding the waves of culture: Understanding cultural diversity in business. London, England: Brealey.

Ugalde, L., Barros, N., \& McLean, G. F. (1998). Love: As the foundation of moral education and character development: A Latin American contribution for the 21st century. Washington, DC: Council for Research in Values and Philosophy; Caracas, Venezuela: Universidad Católica Andrés Bello.

Uhl-Bien, M., Graen, G. B., \& Scandura, T. A. (2000). Implications of leader-member exchange for strategic human resource management systems. Research in Personnel and Human Resources Management, 18, 137-149.

Velasquez, M. G. (2014). Business ethics: Concepts and cases. Boston, MA: Pearson Education.

Villalobos, C. (2013). Economic inequality in Latin America: Migration, education and structural change. Frankfurt, Germany: P. L. Academic Research.

Vitell, S. J., \& Nishihara, C. M. (2010). The role of ethics and social responsibility in organizational success: A Spanish perspective. Journal of Business Ethics, 91(4), 467-483.

Vitell, S. J., \& Paolillo, J. (2004). A cross-cultural study of the antecedents of the perceived role of ethics and social responsibility. Business Ethics: A European Review, 13(2-3), 185-199.

Voegtlin, C., \& Pless, N. M. (2014). Global governance: CSR and the role of the UN Global Compact. Journal of Business Ethics, 122(2), 179-191.

Waldman, D. A., \& Konrad, E. (2006). Cultural and leadership predictors of corporate social responsibility values of top management: A GLOBE study of 15 countries. Journal of International Business Studies, 37(6), 823-837. 
Wang, L., Malhotra, D., \& Murnighan, J. K. (2011). Economics education and greed. Academy of Management Learning and Education, 10(4), 643-660.

Welzel, C., Inglehart, R., \& Kligemann, H. D. (2003). The theory of human development: A cross-cultural analysis. European Journal of Political Research, 42(3), 341379.

Western, S. (2013). Leadership. Los Angeles, CA: Sage.

Wheatley, M. J. (1999). Leadership and the new science: Discovering order in a chaotic world. San Francisco, CA: Berrett-Koehler.

World Values Survey. (2012). Wave 2010-2012. Retrieved from http://www.world valuessurvey.org/WVSDocumentationWV6.jsp

Yukl, G. A. (1981). Leadership in organizations. Englewood Cliffs, NJ: Prentice-Hall.

Zaccaro, S. J. (2007). Trait-based perspectives of leadership. The American Psychologist, 62(1), 6-16. 
APPENDIX A

MBA Students' CSR Attitudes Survey 
(Name and logo of School) MBA Students' CSR Attitudes Survey

Your participation in this survey will greatly contribute towards understanding the relationship between culture and MBA students' attitudes toward socially responsible business leadership.

\section{Thank you for your time!}

Your contact information and survey responses will be confidential.

This Survey should not take more than 30 minutes.

Remember that there are no right or wrong answers. 


\section{Section One}

This first set of questions refers to your level of knowledge regarding the concept of Corporate Social Responsibility (CSR).

For the purpose of this survey the concept of CSR refers to: Business organizations that lawfully serve shareholders interests while also attending to those of the community.

1) How familiar are you regarding the concept of CSR that is stated above?

O Not at all

O Not very familiar

O Some familiarity

O Very familiar

2) What courses related to the CSR concept have you taken so far? Please select all that apply

口 Corporate Social Responsibility

$\square$ Business Ethics

- Social Entrepreneurship

B Business at the Bottom of the Pyramid

a Corporate Governance

C Cause marketing

$\square$ Other

ㅁone

3) How often are CSR issues discussed in your core business courses?

O Never

O Sometimes

O Frequently

O Not Sure

4) In which of the following socially oriented activities have you participated? Please select all that apply

Socially oriented business projects

Volunteering

Attending guest speakers' CSR lectures

Community service

$\square$ Other 


\section{Section Two}

In this section the questions refer to your attitudes and beliefs regarding the relationship between social responsibility issues and profits. Please rate the extent to which you DISAGREE or AGREE with each of the following statements by selecting the appropriate choice in the scale bellow.

\begin{tabular}{|c|c|c|c|c|c|c|c|}
\hline & $\begin{array}{l}\text { Strongly } \\
\text { Disagree }\end{array}$ & Disagree & $\begin{array}{l}\text { Somewhat } \\
\text { Disagree }\end{array}$ & $\begin{array}{c}\text { Neither } \\
\text { Agree nor } \\
\text { Disagree }\end{array}$ & $\begin{array}{l}\text { Somewhat } \\
\text { Agree }\end{array}$ & Agree & $\begin{array}{c}\text { Strongly } \\
\text { Agree }\end{array}$ \\
\hline $\begin{array}{l}\text { 5) Businesses } \\
\text { should participate } \\
\text { in socially } \\
\text { responsible } \\
\text { practices only if a } \\
\text { profit can be made } \\
\text { from it }\end{array}$ & O & O & O & O & O & O & O \\
\hline $\begin{array}{l}\text { 6) In business } \\
\text { decisions one } \\
\text { should look at all } \\
\text { stakeholders } \\
\text { interests, not only } \\
\text { at the investor's }\end{array}$ & O & O & O & O & O & O & 0 \\
\hline $\begin{array}{l}\text { 7) The only } \\
\text { responsibility of } \\
\text { business is to } \\
\text { make profits in a } \\
\text { legal manner, CSR } \\
\text { is just a moral } \\
\text { obligation }\end{array}$ & O & O & O & O & O & O & O \\
\hline $\begin{array}{l}\text { 8) To remain } \\
\text { globally } \\
\text { competitive, } \\
\text { businesses will } \\
\text { have to disregard } \\
\text { CSR issues }\end{array}$ & O & O & O & O & O & O & 0 \\
\hline $\begin{array}{l}\text { 9) Social } \\
\text { responsibility is a } \\
\text { fundamental task } \\
\text { for business } \\
\text { executives }\end{array}$ & O & O & O & O & O & O & 0 \\
\hline $\begin{array}{l}\text { 10) CSR and } \\
\text { profitability } \\
\text { should be } \\
\text { compatible. }\end{array}$ & O & O & O & O & O & O & O \\
\hline $\begin{array}{l}\text { 11) Corporations } \\
\text { have the same } \\
\text { obligations that } \\
\text { citizen do in } \\
\text { helping the } \\
\text { disadvantaged in } \\
\text { society }\end{array}$ & 0 & O & O & 0 & 0 & O & O \\
\hline $\begin{array}{l}\text { 12) CSR of a firm } \\
\text { is essential to its } \\
\text { long-term } \\
\text { profitability }\end{array}$ & O & 0 & 0 & O & O & O & O \\
\hline
\end{tabular}




\section{Section Three}

In this section the questions refer to your attitudes and beliefs regarding the role of stakeholders in business activities. Please rate the extent to which you DISAGREE or AGREE with each of the following statements by selecting the appropriate choice in the scale bellow.

\begin{tabular}{|c|c|c|c|c|c|c|c|}
\hline & $\begin{array}{l}\text { Strongly } \\
\text { Disagree }\end{array}$ & Disagree & $\begin{array}{l}\text { Somewhat } \\
\text { Disagree }\end{array}$ & $\begin{array}{l}\text { Neither } \\
\text { Agree nor } \\
\text { Disagree }\end{array}$ & $\begin{array}{l}\text { Somewhat } \\
\text { Agree }\end{array}$ & Agree & $\begin{array}{c}\text { Strongly } \\
\text { Agree }\end{array}$ \\
\hline $\begin{array}{l}\text { 13) Social } \\
\text { organizations } \\
\text { should encourage } \\
\text { businesses to look } \\
\text { after the } \\
\text { environment; to } \\
\text { care for nature and } \\
\text { save life resources }\end{array}$ & 0 & 0 & O & 0 & 0 & 0 & 0 \\
\hline $\begin{array}{l}\text { 14) Employees } \\
\text { should have a voice } \\
\text { in setting the social } \\
\text { agenda of a business }\end{array}$ & 0 & O & 0 & 0 & O & 0 & 0 \\
\hline $\begin{array}{l}\text { 15) Investing in } \\
\text { socially responsible } \\
\text { businesses is a good } \\
\text { way to keep } \\
\text { businesses ethical }\end{array}$ & O & 0 & O & 0 & O & 0 & 0 \\
\hline $\begin{array}{l}\text { 16) Corporations } \\
\text { should openly } \\
\text { report their CSR } \\
\text { activities to the } \\
\text { public }\end{array}$ & 0 & 0 & 0 & 0 & 0 & 0 & 0 \\
\hline $\begin{array}{l}\text { 17) Mass and social } \\
\text { media are good } \\
\text { ways to monitor } \\
\text { corporate behavior }\end{array}$ & 0 & 0 & 0 & 0 & 0 & 0 & 0 \\
\hline $\begin{array}{l}\text { 18) Non-profit } \\
\text { organizations and } \\
\text { businesses have } \\
\text { conflicting and } \\
\text { opposing agendas }\end{array}$ & O & O & O & O & 0 & O & O \\
\hline $\begin{array}{l}\text { 19) Corporate } \\
\text { behavior is pretty } \\
\text { much determined } \\
\text { by forces outside } \\
\text { societal control }\end{array}$ & O & 0 & O & O & 0 & O & 0 \\
\hline $\begin{array}{l}\text { 20) Consumer } \\
\text { groups should only } \\
\text { be concerned with } \\
\text { the quality of the } \\
\text { products, not the } \\
\text { way they were } \\
\text { produced }\end{array}$ & O & O & O & 0 & 0 & O & 0 \\
\hline
\end{tabular}




\section{Section Four}

In this section the questions refer to your attitudes and beliefs regarding your preferred socioeconomic model. Please rate the extent to which you DISAGREE or AGREE with each of the following statements by selecting the appropriate choice in the scale bellow.

\begin{tabular}{|c|c|c|c|c|c|c|c|}
\hline & $\begin{array}{l}\text { Strongly } \\
\text { Disagree }\end{array}$ & Disagree & $\begin{array}{c}\text { Somewhat } \\
\text { Disagree }\end{array}$ & $\begin{array}{l}\text { Neither Agree } \\
\text { nor Disagree }\end{array}$ & $\begin{array}{l}\text { Somewhat } \\
\text { Agree }\end{array}$ & Agree & $\begin{array}{c}\text { Strongly } \\
\text { Agree }\end{array}$ \\
\hline $\begin{array}{l}\text { 21) Government aid } \\
\text { to the poor does } \\
\text { more harm than } \\
\text { good, by making } \\
\text { people too dependent } \\
\text { on government } \\
\text { assistance }\end{array}$ & 0 & O & O & O & 0 & 0 & O \\
\hline $\begin{array}{l}\text { 22) Government is } \\
\text { almost always } \\
\text { wasteful and } \\
\text { inefficient }\end{array}$ & 0 & O & 0 & O & 0 & 0 & O \\
\hline $\begin{array}{l}\text { 23) I favor low taxes } \\
\text { on the wealthy and } \\
\text { corporations to } \\
\text { encourage } \\
\text { investment and } \\
\text { economic growth }\end{array}$ & O & O & O & O & O & O & O \\
\hline $\begin{array}{l}\text { 24) Price controls in } \\
\text { basic food items only } \\
\text { creates scarcity and } \\
\text { black markets }\end{array}$ & O & 0 & O & O & O & O & O \\
\hline $\begin{array}{l}\text { 25) Most people are } \\
\text { better off in a free } \\
\text { market economy, } \\
\text { even though some } \\
\text { people are rich and } \\
\text { some are poor }\end{array}$ & 0 & 0 & 0 & O & 0 & 0 & 0 \\
\hline $\begin{array}{l}\text { 26) The government } \\
\text { should take more } \\
\text { responsibility to } \\
\text { ensure that everyone } \\
\text { is provided for }\end{array}$ & 0 & O & 0 & 0 & 0 & 0 & O \\
\hline $\begin{array}{l}\text { 27) Competition is } \\
\text { harmful, it brings out } \\
\text { the worst in people }\end{array}$ & 0 & 0 & 0 & 0 & 0 & 0 & O \\
\hline $\begin{array}{l}\text { 28) Businesses can } \\
\text { only get rich at the } \\
\text { expense of others }\end{array}$ & 0 & O & O & 0 & O & O & O \\
\hline
\end{tabular}




\section{Section Five}

In this section the questions refer to your attitudes and beliefs regarding your preferred level of government regulation. Please rate the extent to which you DISAGREE or AGREE with each of the following statements by selecting the appropriate choice in the scale bellow.

\begin{tabular}{|c|c|c|c|c|c|c|c|}
\hline & $\begin{array}{l}\text { Strongly } \\
\text { Disagree }\end{array}$ & Disagree & $\begin{array}{l}\text { Somewhat } \\
\text { Disagree }\end{array}$ & $\begin{array}{c}\text { Neither } \\
\text { Agree nor } \\
\text { Disagree }\end{array}$ & $\begin{array}{c}\text { Somewhat } \\
\text { Agree }\end{array}$ & Agree & $\begin{array}{c}\text { Strongly } \\
\text { Agree }\end{array}$ \\
\hline $\begin{array}{l}\text { 29) This country has } \\
\text { gone to far in its } \\
\text { efforts to protect the } \\
\text { environment }\end{array}$ & O & 0 & O & O & 0 & O & O \\
\hline $\begin{array}{l}\text { 30) Stricter } \\
\text { environmental laws } \\
\text { and regulations cost } \\
\text { too many jobs and } \\
\text { hurt the economy }\end{array}$ & 0 & O & 0 & 0 & 0 & 0 & O \\
\hline $\begin{array}{l}\text { 31) Sometimes it } \\
\text { acceptable cheating } \\
\text { on taxes and } \\
\text { accepting bribes as a } \\
\text { business practice }\end{array}$ & O & 0 & O & O & O & O & O \\
\hline $\begin{array}{l}\text { 32) Having a strong } \\
\text { leader who does not } \\
\text { have to bother with } \\
\text { congress } \\
\text { (parliament) and } \\
\text { elections is } \\
\text { sometimes best for } \\
\text { the country }\end{array}$ & O & O & 0 & O & O & 0 & O \\
\hline $\begin{array}{l}\text { 33) We have too } \\
\text { many laws to } \\
\text { regulate businesses } \\
\text { and they are seldom } \\
\text { enforced }\end{array}$ & O & 0 & 0 & O & O & 0 & O \\
\hline $\begin{array}{l}\text { 34) Government } \\
\text { regulation of } \\
\text { businesses is } \\
\text { necessary to protect } \\
\text { the public interest }\end{array}$ & O & 0 & 0 & 0 & 0 & 0 & O \\
\hline $\begin{array}{l}\text { 35) Just the } \\
\text { possibility of } \\
\text { enactment of } \\
\text { regulatory laws } \\
\text { would be a strong } \\
\text { motivator for an } \\
\text { organization to } \\
\text { behave ethically }\end{array}$ & O & 0 & O & 0 & 0 & O & O \\
\hline $\begin{array}{l}\text { 36) Global regulation } \\
\text { and global } \\
\text { institutions are } \\
\text { necessary as } \\
\text { corporations } \\
\text { globalize }\end{array}$ & O & O & O & O & O & 0 & O \\
\hline
\end{tabular}




\section{Section Six}

In this section the questions refer to your attitudes and beliefs regarding certain cultural values. Please rate the extent to which you DISAGREE or AGREE with each of the following statements by selecting the appropriate choice in the scale bellow.

\begin{tabular}{|c|c|c|c|c|c|c|c|}
\hline & $\begin{array}{l}\text { Strongly } \\
\text { Disagree }\end{array}$ & Disagree & $\begin{array}{l}\text { Somewhat } \\
\text { Disagree }\end{array}$ & $\begin{array}{l}\text { Neither } \\
\text { Agree nor } \\
\text { Disagree }\end{array}$ & $\begin{array}{l}\text { Somewhat } \\
\text { Agree }\end{array}$ & Agree & $\begin{array}{c}\text { Strongly } \\
\text { Agree }\end{array}$ \\
\hline $\begin{array}{l}\text { 37) In this society, a person } \\
\text { influence is based on one's } \\
\text { ability and contribution to } \\
\text { society, rather than the } \\
\text { authority of one's position }\end{array}$ & 0 & 0 & $\mathrm{O}$ & 0 & 0 & 0 & 0 \\
\hline $\begin{array}{l}\text { 38) In this society, aging } \\
\text { parents generally live at } \\
\text { home with their children }\end{array}$ & 0 & 0 & 0 & 0 & 0 & 0 & 0 \\
\hline $\begin{array}{l}\text { 39) The way to be successful } \\
\text { in this society is to plan } \\
\text { ahead, not take life events as } \\
\text { they occur }\end{array}$ & 0 & 0 & 0 & 0 & 0 & 0 & 0 \\
\hline $\begin{array}{l}\text { 40) In this society, followers } \\
\text { are expected to obey their } \\
\text { leaders without questions }\end{array}$ & 0 & 0 & 0 & 0 & 0 & 0 & 0 \\
\hline $\begin{array}{l}\text { 41) In this society, major } \\
\text { rewards are based on } \\
\text { performance rather than } \\
\text { seniority or other political } \\
\text { connections }\end{array}$ & 0 & 0 & 0 & 0 & 0 & 0 & 0 \\
\hline $\begin{array}{l}\text { 42) In this society, children } \\
\text { take pride in the individual } \\
\text { accomplishment of their } \\
\text { parents }\end{array}$ & 0 & 0 & 0 & 0 & 0 & 0 & 0 \\
\hline $\begin{array}{l}\text { 43) In this society, } \\
\text { orderliness and consistency } \\
\text { are stressed, even at the } \\
\text { expense of experimentation } \\
\text { and innovation }\end{array}$ & 0 & 0 & 0 & 0 & 0 & 0 & 0 \\
\hline $\begin{array}{l}\text { 44) In this society, people in } \\
\text { position of power try to } \\
\text { increase their social distance } \\
\text { from less powerful } \\
\text { individuals }\end{array}$ & 0 & 0 & 0 & 0 & 0 & 0 & 0 \\
\hline $\begin{array}{l}\text { 45) In this society, being } \\
\text { innovative to improve } \\
\text { performance is generally } \\
\text { rewarded substantially }\end{array}$ & 0 & 0 & 0 & 0 & 0 & 0 & 0 \\
\hline $\begin{array}{l}\text { 46) In this society, children } \\
\text { generally live at home with } \\
\text { their parents until they get } \\
\text { married }\end{array}$ & 0 & 0 & 0 & 0 & 0 & 0 & 0 \\
\hline $\begin{array}{l}\text { 47) In this society, most } \\
\text { people live highly structured } \\
\text { lives with few unexpected } \\
\text { events }\end{array}$ & O & 0 & $\mathrm{O}$ & 0 & 0 & 0 & 0 \\
\hline $\begin{array}{l}\text { 48) In this society, } \\
\text { subordinates are generally } \\
\text { afraid to express } \\
\text { disagreement with their } \\
\text { bosses. }\end{array}$ & 0 & 0 & 0 & 0 & 0 & 0 & 0 \\
\hline
\end{tabular}




\section{Section Seven}

The remaining questions are for classification purposes only

49) Please indicate your gender

Male (1)

Female (2)

50) In what country were you born? And your mother? And your father?

Yourself

Your Mother

Your Father

51) In what country (countries) were you raised and socialized?

52) What is your age?

Y Younger than 21

21-28 years old

O 29-36 years old

Older than 36 years old 
APPENDIX B

Focus Group Interview Guide 


\section{Culture and Factors that Influence CSR Activities Focus Group Interview Guide}

\section{General Question}

What sort of meaning making do students articulate regarding the relationship between the endo-factors (normative and utilitarian) and the meso-factors (stakeholders, economic model and government regulation) in the practice of CSR?

\section{Specific Questions}

1) Do you see normative and utilitarian factors (Let the students explain what they understand by these two constructs) as having an effect on CSR activities?

2) What is the meaning making that you attribute to the survey results regarding the meso-factors? What do these numbers mean to you?

3) Do you feel societal factors (explain) influence CSR activities? If so how?

4) Do you feel that government regulations (explain) have an impact on the CSR activities of a business? If so how?

5) Do you think that the socio-economic (explain) system influences the level of CSR in a corporation? If so, how?

6) What is the meaning making that you attribute to the survey results regarding the meso-factors? What do these numbers mean to you?

7) Are there any other factors that, in your opinion, are important for businesses to engage in socially responsible leadership? 


\section{Mapping of Factors that Affect CSR Initiatives}

\begin{tabular}{|c|c|c|c|c|c|c|}
\hline \multicolumn{4}{|c|}{ Endo-Factors } & \multicolumn{2}{|c|}{ Meso-Factors } & \multirow[t]{2}{*}{ Other } \\
\hline \multirow{4}{*}{$\begin{array}{l}\frac{11}{2} \\
\frac{2}{0} \\
\frac{1}{2} \\
\frac{2}{2} \\
\frac{2}{0} \\
\text { के }\end{array}$} & & $\begin{array}{l}\text { Normative/ } \\
\text { Utilitarian }\end{array}$ & $\begin{array}{l}\text { Stakeholders } \\
\text { Influence }\end{array}$ & $\begin{array}{c}\text { Government } \\
\text { Regulation }\end{array}$ & $\begin{array}{c}\text { Economic } \\
\text { Model }\end{array}$ & \\
\hline & $\begin{array}{l}\text { Anglo Cluster: } \\
\text { High } \\
\text { Individualism } \\
\text { Low Power } \\
\text { Distance }\end{array}$ & & & & & \\
\hline & $\begin{array}{l}\text { Latin American } \\
\text { Cluster: } \\
\text { High } \\
\text { Collectivism } \\
\text { High Power } \\
\text { Distance }\end{array}$ & & & & & \\
\hline & $\begin{array}{l}\text { Latin Europe } \\
\text { Cluster: } \\
\text { Medium } \\
\text { Collectivism } \\
\text { and Power } \\
\text { Distance }\end{array}$ & & & & & \\
\hline
\end{tabular}


APPENDIX C

Students Demographics 
Table 24

Students' Demographics

\begin{tabular}{|c|c|c|c|}
\hline & Anglo & Latin European & Latin American \\
\hline Valid Surveys: 221 & 53 & 45 & 123 \\
\hline Countries & $\begin{array}{c}\text { USA: } 45 \\
\text { Canada: } 5 \\
\text { UK: } 3\end{array}$ & $\begin{array}{c}\text { Spain: } 37 \\
\text { Portugal: } 2 \\
\text { Italy: } 2 \\
\text { France: } 3 \\
\text { Greece: } 1\end{array}$ & $\begin{array}{c}\text { Costa Rica: } 40 \\
\text { Panama: } 15 \\
\text { Peru: } 12 \\
\text { Guatemala: } 10 \\
\text { Nicaragua: } 9 \\
\text { Venezuela: } 8 \\
\text { Colombia: } 7 \\
\text { Mexico: } 6 \\
\text { Argentina: } 4 \\
\text { Ecuador: } 4 \\
\text { Chile: } 3 \\
\text { Uruguay: } 2 \\
\text { Brazil: } 2 \\
\text { Bolivia: } 1\end{array}$ \\
\hline $\begin{array}{l}\text { Gender } \\
\text { Males: } 131 \\
\text { Females: } 90 \\
\end{array}$ & $\begin{array}{l}28 \\
25 \\
\end{array}$ & $\begin{array}{l}28 \\
17 \\
\end{array}$ & $\begin{array}{l}75 \\
48 \\
\end{array}$ \\
\hline $\begin{array}{l}\text { Specialization } \\
\text { Finance: } 71 \\
\text { Marketing: } 60 \\
\text { Supply Chain: } 44 \\
\text { Management: } 29 \\
\text { Others: } 12\end{array}$ & $\begin{array}{c}18 \\
15 \\
10 \\
4 \\
1\end{array}$ & $\begin{array}{c}15 \\
12 \\
8 \\
7 \\
3 \\
\end{array}$ & $\begin{array}{c}38 \\
33 \\
26 \\
18 \\
8 \\
\end{array}$ \\
\hline $\begin{array}{l}\text { Work Experience } \\
\text { 2-5 years: } 101 \\
>\text { Than } 5 \text { years: } 120\end{array}$ & $\begin{array}{l}23 \\
30\end{array}$ & $\begin{array}{l}20 \\
25\end{array}$ & $\begin{array}{l}58 \\
65\end{array}$ \\
\hline $\begin{array}{l}\text { Age } \\
<\text { Than 25: } 25 \\
\text { 25-30: } 143 \\
>\text { Than } 30: 53\end{array}$ & $\begin{array}{c}3 \\
33 \\
17\end{array}$ & $\begin{array}{c}4 \\
28 \\
13\end{array}$ & $\begin{array}{l}18 \\
82 \\
23\end{array}$ \\
\hline
\end{tabular}




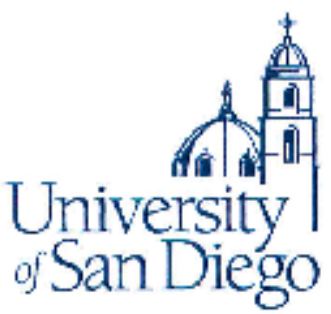

\section{Institutional Review Board Project Action Summary}

Action Datg: Februay 25, 2015 Noto: Approval expires one year afer n'tis date.

Type: _New Full Rorow _X_Nowi Exped tod Rovew _ Continuatior Reviey Exempt Revies sacirication

Action:

_x_Approved _Appresed Perding Mod ficat on

Nol Approved

Frojed Number: 2015-3ż-170

Researcherisi: Juan F. Ros a Dos SOLES

Dr. Afsanch Nahavendi Fac sol $=\mathrm{S}$

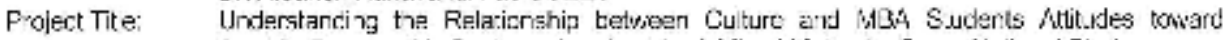
Secially Rosponsibic Business Lendersnip' A Mixer Matnocs; Cross-Vajicnal Study

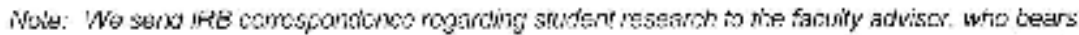

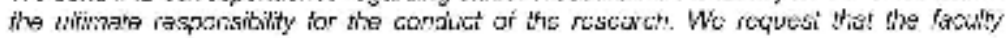

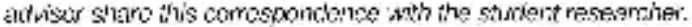

Modiflcations Required or Reasons for Non-Approval

Nono

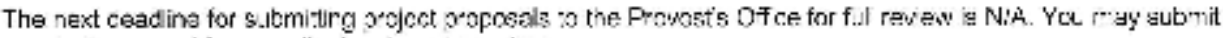
a proect proposal for expe-dited repietv at any time.

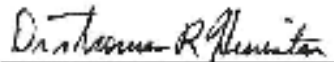

Di. Tromes R. Herinton

Administrator, Irstit.ticnal Reviau Buard

Uriversity of Sar Dieng

herrintan pisandieoo.codu

5rge Ajcalí Park

San Degn California 92110-2492

Offlee of the Executive Vice President and Provost

Hughes Administration Center, Room 214

5998 Alcala Park: San Diego: CA $92110-2492$

Phane (619) 260-4553 * Fax (619) 260-2210 * www.sandiegjo.edu 